\title{
Postcranial anatomy of Pissarrachampsa sera (Crocodyliformes, Baurusuchidae) from the Late Cretaceous of Brazil: insights on lifestyle and phylogenetic significance
}

Pedro L. Godoy, Mario Bronzati, Estevan Eltink, Júlio C. de A. Marsola, Giovanne M. Cidade, Max C. Langer, Felipe C. Montefeltro

The postcranial anatomy of Crocodyliformes has historically been neglected, as most descriptions are based solely on skulls. Yet, the significance of the postcranium in crocodyliforms evolution is reflected in the great lifestyle diversity exhibited by the group, with members ranging from terrestrial animals to semi-aquatic and fully marine forms. Recently, studies have emphasized the importance of the postcranium. Following this trend, here we present a detailed description of the postcranial elements of Pissarrachampsa sera (Mesoeucrocodylia, Baurusuchidae), from the Adamantina Formation (Bauru Group, Late Cretaceous of Brazil). The preserved elements include dorsal vertebrae, partial forelimb, pelvic girdle, and hindlimbs. Comparisons with the postcranial anatomy of baurusuchids and other crocodyliforms, together with body-size and mass estimates, lead to a better understanding of the paleobiology of Pissarrachampsa sera, including its terrestrial lifestyle and its role as a top predator. Furthermore, the complete absence of osteoderms in $P$. sera, a condition previously known only in marine crocodyliforms, suggests osteoderms very likely played a minor role in locomotion of baurusuchids, unlike other groups of terrestrial crocodyliforms. Finally, a phylogenetic analysis including the newly recognized postcranial features was carried out, and exploratory analyses were performed to investigate the influence of both cranial and postcranial characters in the phylogeny of Crocodyliformes. Our results suggest that crocodyliform relationships are mainly determined by cranial characters. However, this seems to be a consequence of the great number of missing entries in the data set with only postcranial characters and not of the lack of potential (or synapomorphies) for this kind of data to reflect the evolutionary history of Crocodyliformes. 
1 Postcranial anatomy of Pissarrachampsa sera (Crocodyliformes, Baurusuchidae) from the

2 Late Cretaceous of Brazil: insights on lifestyle and phylogenetic significance

3 Pedro L. Godoy ${ }^{1 *}$, Mario Bronzati ${ }^{2,3^{*}}$, Estevan Eltink ${ }^{4}$, Júlio C. de A. Marsola ${ }^{4}$, Giovanne M.

4 Cidade $^{4}$, Max C. Langer ${ }^{4}$, Felipe C. Montefeltro ${ }^{5}$

$5{ }^{1}$ School of Geography, Earth and Environmental Sciences, University of Birmingham,

6 Edgbaston, Birmingham, United Kingdom.

7 ㄹayerische Staatssammlung für Paläontologie und Geologie, Munich, Germany.

$8 \quad{ }^{3}$ Ludwig-Maximilians Universität, Munich, Germany

$9{ }^{4}$ Laboratório de Paleontologia de Ribeirão Preto, FFCLRP, Universidade de São Paulo, Ribeirão

10 Preto, SP, Brazil.

$11{ }^{5}$ Departamento de Biologia e Zootecnia, FEIS, Universidade Estadual Paulista, Ilha Solteira, 12 Brazil.

$1{ }^{*}$ These authors contributed equally to this work.

14 Corresponding author

15 Pedro L. Godoy

16 School of Geography, Earth and Environmental Sciences, University of Birmingham, Edgbaston,

17 Birmingham, United Kingdom

18 Email address: pedrolorenagodoy@gmail.com

\section{Abstract}


20 The postcranial anatomy of Crocodyliformes has historically been neglected, as most descriptions

21 are based solely on skulls. Yet, the significance of the postcranium in crocodyliforms evolution is

22 reflected in the great lifestyle diversity exhibited by the group, with members ranging from

23 terrestrial animals to semi-aquatic and fully marine forms. Recently, studies have emphasized the

24 importance of the postcranium. Following this trend, here we present a detailed description of the

25 postcranial elements of Pissarrachampsa sera (Mesoeucrocodylia, Baurusuchidae), from the

26 Adamantina Formation (Bauru Group, Late Cretaceous of Brazil). The preserved elements

27 include dorsal vertebrae, partial forelimb, pelvic girdle, and hindlimbs. Comparisons with the

28 postcranial anatomy of baurusuchids and other crocodyliforms, together with body-size and mass

29 estimates, lead to a better understanding of the paleobiology of Pissarrachampsa sera, including

30 its terrestrial lifestyle and its role as a top predator. Furthermore, the complete absence of

31 osteoderms in P. sera, a condition previously known only in marine crocodyliforms, suggests

32 osteoderms very likely played a minor role in locomotion of baurusuchids, unlike other groups of

33 terrestrial crocodyliforms. Finally, a phylogenetic analysis including the newly recognized

34 postcranial features was carried out, and exploratory analyses were performed to investigate the

35 influence of both cranial and postcranial characters in the phylogeny of Crocodyliformes. Our

36 results suggest that crocodyliform relationships are mainly determined by cranial characters.

37 However, this seems to be a consequence of the great number of missing entries in the data set

38 with only postcranial characters and not of the lack of potential (or synapomorphies) for this kind

39 of data to reflect the evolutionary history of Crocodyliformes.

\section{Introduction}

41 Baurusuchids are important components of the Late Cretaceous crocodyliform faunas

42 (Montefeltro et al., 2011; Godoy et al., 2014). Despite the uncertainties regarding its relation to

43 Sebecidae, the presence of a monophyletic Baurusuchidae within Notosuchia (Mesoeucrocodylia) 
44 is found in many recent analyses (e.g.: Sereno \& Larsson, 2009; Bronzati et al., 2012;

45 Montefeltro et al., 2013; Pol et al., 2014). The group is restricted to South America, with one

46 possible exception in Pakistan (Wilson et al., 2001; Montefeltro et al., 2011). The group exhibits

47 a peculiar morphology for crocodyliforms, including large size, a dog-like skull with

48 hypertrophied canines and cursorial limb morphology, illustrating their role as top predator in the

49 paleoenvironments they occurred (Montefeltro et al., 2011; Riff \& Kellner, 2011; Godoy et al., 50 2014).

51 Most of baurusuchid diversity (8 out of 10) comes from the Bauru Group, in southeast

52 Brazil, including Pissarrachampsa sera, from the Adamantina Formation (Montefeltro et al., 53 2011). As typical for descriptive works on crocodyliforms (e.g.: Wu et al., 1995; Buckley et al.,

54 2000; Gasparini et al., 2006; Novas et al., 2009; O’Connor et al., 2010; Iori \& Carvalho, 2011)

55 the original description of Pissarrachampsa sera was exclusively based on its skull morphology.

56 This practice does not seem to be related to the nature of the findings itself, as fossil

57 crocodyliforms are typically found with associated postcranium, as in the case of P. sera. Two

58 partially preserved skulls, including the holotype (Montefeltro et al., 2011), were collected in

59 2008. Later expeditions to the type locality, between 2008 and 2010, recovered additional

60 material referred to $P$. sera, including the postcranial elements described here.

\section{Material and methods}

62 Systematic paleontology

63 Crocodyliformes Benton \& Clark, 1988

64 Mesoeucrocodylia Whetstone \& Whybrow, 1983 sensu Benton \& Clark, 1988

65 Baurusuchidae Price, 1945

66 Pissarrachampsinae Montefeltro et al., 2011

67 Pissarrachampsa Montefeltro et al., 2011 
Pissarrachampsa sera Montefeltro et al., 2011

69 Holotype. LPRP/USP 0019, nearly complete skull and mandibles lacking the cranialmost portion

70 of the rostrum, seven dorsal vertebrae, partial forelimb, pelvic girdle, and hindlimbs.

71 Previously referred specimens. LPRP/USP 0018, partial rostrum with articulated mandibles.

72 Additional referred specimens. LPRP/USP 0739, an isolated left pes; LPRP/USP 0740, an

73 isolated right ulna; LPRP/USP 0741, an isolated right tibia; LPRP/USP 0742, an isolated left

74 ilium; LPRP/USP 0743, a partial isolated left femur; LPRP/USP 0744, articulated right femur,

75 tibia and fibula; LPRP/USP 0745, an isolated right manus; LPRP/USP 0746, an isolated right pes.

76 Type locality. Inhaúmas-Arantes Farm, Gurinhatã (Martinelli \& Teixeira, 2015), Minas Gerais

77 state, Brazil (19²0’41.8”S; 4955’12,9’W). The original description indicated the type locality

78 in the municipality of Campina Verde. However, new information using Global Positioning

79 System (GPS) data show it within the municipality of Gurinhatã.

80 Age and horizon. Adamantina Formation, Bauru Group, Bauru Basin; Late Cretaceous,

81 Campanian-Maastrichtian (Batezelli, 2015). Note, however, that the stratigraphic nomenclature

82 of the region, as well the ages of the units, is still under debate (see also Fernandes \& Coimbra,

83 1996; 2000; Fernandes, 2004; Batezelli, 2010, 2015; Fernandes \& Magalhães Ribeiro, 2014), and

84 the original description of Pissarrachampsa sera (Montefeltro et al., 2011) considered the type

85 locality as belonging to the Vale do Rio do Peixe Formation. 
86 Appended Diagnosis. Baurusuchid with four maxillary teeth; a longitudinal depression on the

87 rostral portion of frontal; frontal longitudinal ridge extending rostrally overcoming the frontal

88 midlength; supratemporal fenestra with equally developed medial and rostral rims; lacrimal duct

89 at the corner formed by the dorsal and lateral lacrimal surfaces; well developed rounded foramen

90 between the palpebrals; quadratojugal and jugal do not form a continuous ventral border (a notch

91 is present due to the ventral displacement of the quadratojugal); four quadrate fenestrae visible

92 laterally; quadrate lateral depression with rostrocaudally directed major axis; sigmoidal muscle

93 scar in the medial surface of the quadrate; ectopterygoid almost reaching the caudal margin of the

94 pterygoid wings; a single ventral parachoanal fenestra and one ventral parachoanal fossa (divided

95 into medial and lateral parachoanal subfossae); lateral Eustachian foramina larger than the medial

96 one; a deep depression on the caudodorsal surface of the pterygoid wings (Montefeltro et al.,

97 2011). The following postcranial features were identified as diagnostic for P. sera: ulnar shaft

98 subtriangular in cross-section and strongly bowed laterally; large lateral projection of the

99 supraacetabular crest of the ilium; femur with caudally pointed margin of the medial proximal

100 crest; well-developed femoral "femorotibialis ridge"; short and sharp crest at the craniolateral

101 margin of the distal tibia, ending caudal to the fibular contact of the distal hook; lateral

102 iliofibularis trochanter sharply raised and proximodistally elongated; fibular distal hook contact

103 with tibia placed more proximally relative to the distal articulation of the latter bone; absence of

104 astragalar fossa; restricted anterior hollow on the cranial surface of the astragalus; lateral tubercle

105 at the lateral ridge of calcaneal tuber; complete absence of postcranial osteoderms.

106 Field work permit

107 All necessary permits were obtained for the field work, which complied with all relevant

108 regulations. The field work and fossil collection was previously communicated to the 
110 from March 4th, 1942.

\section{Additional information}

112 Nine specimens are described here, including materials associated with the holotype (LPRP/USP

113 0019), all collected in expeditions to the type locality between 2008 and 2010. The postcranial

114 bones are referred to Pissarrachampsa sera, primarily due to the presence of features compatible 115 with the postcranial morphology of other baurusuchids, but also because the relatively restricted

116 locality "Inhaúmas-Arantes Farm" provided, so far, exclusively materials referred to P. sera. The 117 material assigned to the holotype was not collected at the same time as the skull (Montefeltro et 118 al., 2011). However, this association is assumed as the postcranial elements were spacially

119 identified during the first expedition placed only few centimeters from the back of the skull, in its 120 natural anatomical position in the same stratigraphic level in the outcrop. Also, it is unlikely that 121 the specimen assignations employed here is wrong, due to discrepant sizes, anatomical overlaps 122 and different locations in the quarry.

\section{Description}

124 The postcranial remains of Pissarrachampsa sera were compared within the context of 125 Crocodyliformes although special attention was given to the morphology of other baurusuchids 126 with postcranium. The comparisons focused on first-hand examination of specimens (Table 1), 127 however, published resources were also used.

129 Seven dorsal vertebrae are partially preserved in the holotype of Pissarrachampsa sera 130 (LPRP/USP 0019), all of which exhibit the typical amphicoelous morphology seen in Notosuchia 
131 (Pol, 2005; Nascimento \& Zaher, 2010). Five partial vertebrae are articulated in a series, one of

132 which lacks part of the neural arch, (Figure 1, A-C), and are recognized as mid- to caudal-dorsal

133 vertebrae, whereas the other two are isolated and very likely belong to a more cranial position in

134 the vertebral series (Figure 1, D). One of the features used to determine the axial position of the

135 preserved vertebrae was the relative position of the parapophysis and diapophysis. In

136 notosuchians, as in Baurusuchus albertoi (Nascimento \& Zaher, 2010), Sebecus icaeorhinus

137 (Simpson, 1937), and Notosuchus terrestris (Woodward, 1896), the diapophysis is located more

138 dorsally in cranial dorsal vertebrae, but migrate to a more ventral position caudally along the

139 series (Pol, 2005; Nascimento \& Zaher, 2010; Pol et al., 2012). On the other hand, the

140 parapophysis is located ventrally in cranial-dorsal vertebrae, and migrate to a more dorsal

141 position in more caudal elements, until it reaches the same dorsoventral level of the diapophysis

142 (Pol, 2005; Nascimento \& Zaher, 2010; Pol et al., 2012). The vertebrae in the articulated series

143 show no evidence of para- and diapophyses migration, with both structures located at the same

144 dorsoventral level at the distal portion of the transverse process. In addition, the preserved

145 prezygapophyses are fused with the transverse processes. In closely related taxa, such as

146 Baurusuchus albertoi and Notosuchus terrestris, this fusion is present in vertebrae caudal to the

147 seventh dorsal element (Pol, 2005; Nascimento \& Zaher, 2010), also suggesting that this

148 sequence does not belong to cranial-dorsal vertebrae.

149 The vertebrae of Pissarrachampsa sera have an elliptical centrum in cranial view and are

150 constricted at the middle, as typical for notosuchians (Pol, 2005). The centrum is slightly

151 craniocaudally longer than high (measured from the ventral margin to the level of the ventral

152 limit of the neural channel), and the dimensions are approximately the same in all preserved

153 centra (28 mm long, and $19 \mathrm{~mm}$ high). The preserved portion of the neural spine in the third

154 vertebra of the sequence suggests that this structure projects cranially, as in caudal dorsal

155 vertebrae of Baurusuchus albertoi. However, the neural spine of caudal-dorsal vertebrae of 
156 Baurusuchus bends caudally on its distal end (Nascimento \& Zaher, 2010); a condition not

157 accessible in $P$ sera. The transverse processes are caudally oriented, and project horizontally in 158 cranial and caudal views.

159 The base of the prezygapophyseal process is located ventral to the upper margin of the 160 neural canal, and projects dorsally and laterally. There is also a slight caudal projection and the 161 prezygapophyses do not extend beyond the cranial limit of the vertebral centrum. The articulation 162 area between the pre- and postzygapophyses is slightly oblique in relation to the horizontal plane 163 of the vertebral column. The postzygapophyses, in the second and third vertebrae of the 164 articulated series, are dorsally curved and project from the caudalmost part of the transverse 165 processes. There is a deep fossa cranial to the postzygapophysis, at the intersection of the neural 166 spine with the transverse process. Pol et al. (2012) suggest that this fossa is exclusively found in 167 notosuchians. The cranial limit of this fossa is marked by a ridge, which extends laterally from 168 the base of the neural spine to half of the lateral length of the transverse process.

169 One of the isolated vertebrae (Figure 1, D) provides additional information on the 170 vertebral morphology of Pissarrachmpsa sera. The dimensions of this vertebral centrum are 171 approximately the same as for those of the articulated series. However, the neural arch is slightly 172 craniocaudally longer. Also, its neural canal exhibits a rounded opening in cranial view. In caudal 173 view, the postzygapophyses are connected by the postspinal fossa (Pol et al., 2012). The U174 shaped ventral margin of this fossa forms a groove located ventral to the dorsal margin of the 175 neural canal (Figure 1, D), a feature that is also observed in cervical and dorsal vertebrae of 176 Baurusuchus albertoi (Nascimento, 2008; Nascimento \& Zaher, 2010). This groove becomes 177 progressively wider dorsally, until it merges with the zygapophyses. Also, in dorsal view, the 178 cranialmost part of the fossa is lateromedially narrower than the area between the 179 postzygapophyses. 
distinguishable in the best preserved isolated vertebra, and it is very likely that the neurocentral suture was also not completely closed in the dorsal vertebrae of the articulated series. Brochu (1996) proposed a cranial to caudal closure pattern of this suture for the crown-group Crocodylia,

so that juveniles retain the suture opened in caudal presacral vertebrae. Irmis (2007) observed a similar pattern in phytosaurs and tentatively suggested it is typical of members of the Pseudosuchia lineage, but not of the Avemetatarsalia lineage. However, after analyzing dorsal vertebrae of Notosuchus terrestris, Pol (2005) commented that this pattern described in Brochu (1996) might not be valid for Crocodyliformes outside the Crocodylia clade, such as

Pissarrachampsa sera. As the vertebrae described here belong to the holotype, which is likely a mature specimen based on comparisons to smaller specimens from the type locality, our results reinforce the inference of Pol (2005). Finally, Ikejiri (2012) showed that sutures of presacral vertebrae remain opened even in some very mature extant alligators, and Bailleaul et al. (2016) have demonstrated that addressing the stage of maturity of archosaurian specimens based on the

194 level of sutural closure in the skull can be misleading. In this context, vertebral sutural closure should not be used as the single factor when inferring the stage of maturity in crocodyliforms.

\section{Appendicular Skeleton}

\section{Forelimb}

$198 \underline{\text { Ulna }}$

199 The right ulna of the holotype of Pissarrachampsa sera is preserved (LPRP/USP 0019), as well 200 as a smaller referred right ulna (LPRP/USP 0740) that corresponds to a juvenile individual. The 201 holotypic ulna is damaged at both ends (Figure 2). Its maximum proximodistal length is $16.5 \mathrm{~cm}$, 202 and the midshaft mediolateral width is $1.8 \mathrm{~cm}$. The general shape is similar to that of other 
204 Sertich \& Groenke, 2010; Vasconcellos \& Carvalho, 2010; Riff \& Kellner, 2011; Godoy et al., 205 2014), but less lateromedially compressed than the gracile ulnae of Araripesuchus

206 tsangatsangana (Turner, 2006). The interosseous space between the articulated ulna and radius is

207 reduced, with nearly no space separating the distal and proximal thirds of both bones shafts. Only

208 in the midshaft region this space is noted, although relatively short if compared with the large

209 space seen in extant crocodylians (Brochu, 1992). This pattern is also seen in other terrestrial

210 fossil crocodyliforms, such as baurusuchids Stratiotosuchus maxhechti (Campos et al., 2001) and

211 Baurusuchus albertoi, as well as Araripesuchus tsangatsangana (Turner, 2006; Nascimento \&

212 Zaher, 2010; Riff \& Kellner, 2011).

213 The proximal end of the ulna is craniocaudally expanded compared to both the shaft and

214 distal end, as in other crocodyliforms. Since the proximal end is damaged, the structures of the

215 articular surface with the humerus are not preserved. The olecranon process is severely damaged, 216 hampering the assessment of its morphology. Nevertheless, two expansions are preserved in the

217 proximal end, a cranial process and a conspicuous lateral process. Prior to taphonomic damage, 218 the proximal surface of the lateral process corresponded to the ulnar radiohumeral surface, but the 219 radial facet is still preserved. In proximal view, the ulna-radius articulation forms a sinusoidal 220 contact (Figure 3, A). In caudal view, distal to the olecranon processes, scars are seen for the 221 insertion of the M. triceps brachii tendon (Meers, 2003).

222 The ulnar shaft is subtriangular in cross-section, similar to that of other baurusuchids and 223 Simosuchus clarki (Sertich \& Groenke, 2010) (Nascimento \& Zaher, 2010; Riff \& Kellner, 2011), 224 differing from the ovoid shaft of Araripesuchus tsangatsangana and Mahajangasuchus insignis 225 (Buckley \& Brochu, 1999) (Turner, 2006). The shaft is significantly bowed laterally, resembling 226 the flexure seen in Simosuchus clarki and Chimaerasuchus paradoxus (Wu et al., 1995), different 227 from the faint curvature seen in other baurusuchids and extant forms (Brochu, 1992; Wu \& Sues, 228 1996; Nascimento \& Zaher, 2010; Sertich \& Groenke, 2010; Vasconcellos \& Carvalho, 2010; 
229 Riff \& Kellner, 2011; Godoy et al., 2014). The cranial surface of the shaft bears a vascular

230 foramen proximal to the midheight, close to the medial margin. On the lateral surface (Figure 2,

231 C-D), distal to the lateral process of the proximal end, there is a groove for the insertion of $M$.

232 extensor carpi radialis brevis pars ulnaris (Meers, 2003), which is distally delimited by a ridge,

233 caudal to that groove. This ridge also marks the cranial limit of $M$. flexor ulnaris, which extends

234 distally to the distal condyle (Meers, 2003). As a whole, this lateral ridge extends proximodistally

235 in an almost straight line, and is similar to the marked ridge seen in other baurusuchids, as

236 Stratiotosuchus maxhechti and Baurusuchus albertoi, but more conspicuous than in

237 Araripesuchus tsangatsangana (Nascimento \& Zaher, 2010; Riff \& Kellner, 2011). On the caudal

238 surface (Figure 2, E-F), the limit between $M$. flexor digitorum longus and M. flexor ulnaris is

239 marked by a caudal ridge on the distal portion of the shaft. In Baurusuchus albertoi and

240 Simosuchus clarki this ridge is lesspronounced, giving a more rounded aspect to the caudal

241 surface of the shaft in these taxa (Nascimento, 2008; Sertich \& Groenke, 2010). On the medial

242 surface (Figure 2, G-H), just distal to the proximal end, there is an ovoid fossa for the insertion of

243 M. pronator quadratus (Meers, 2003). It is deeper than in Simosuchus clarki and Araripesuchus

244 tsangatsangana, but does not extend further distally as in Stratiotosuchus maxhechti (Turner,

245 2006; Sertich \& Groenke, 2010; Riff \& Kellner, 2011). Due to the fragmentary condition of the

246 region, the flexor ridge that would mark the limit between $M$. pronator quadratus and M. flexor

247 digitorum longus pars ulnaris (Meers, 2003) is not preserved. However, the latter muscle extends

248 distally until the cranial oblique process of the distal condyle, as seen by the well-marked scars

249 for its insertion proximal to the process, as seen in many fossil taxa (as Baurusuchus albertoi,

250 Stratiotosuchus maxhechti, Simosuchus clarki) and also in living forms (Brochu, 1992; Riff,

251 2007; Nascimento, 2008; Sertich \& Groenke, 2010).

252 The distal end of the ulna has a craniocaudal breadth $45 \%$ shorter than that of the

253 proximal end. The distal condyle has both cranial and caudal oblique processes turned medially. 
254 These processes are about the same size, giving the bone a heart-shaped outline in distal view.

255 The craniolateral process is not completely preserved, due to a damage that also affected the

256 distal surface of the condyle, preventing a precise assessment of the ulnare and radiale

257 articulations. Yet, preserved parts suggest the ulnar articulation with the carpal bones was similar

258 to that of other mesoeucrocodylians, such as Stratiotosuchus maxhechti, in which the cranial

259 oblique process articulates with the radiale and the caudal process articulates with the ulnare (Riff

260 \& Kellner, 2011).

$\underline{\text { Radius }}$

263 The right radius is preserved in the holotype of Pissarrachampsa sera (LPRP/USP 0019). The

264 straight proximodistal extension of its slender shaft gives the bone a rod-like shape; which seems

265 to be exaggerated due to the badly preserved proximal and distal ends (Figure 4). Its maximum

266 proximodistal length is $16 \mathrm{~cm}$, and the midshaft mediolateral width is $1.4 \mathrm{~cm}$. This general shape

267 resembles that of other baurusuchid radii (Nascimento \& Zaher, 2010; Vasconcellos \& Carvalho,

268 2010; Godoy et al., 2014), but it is less robust than in Stratiotosuchus maxhechti (Riff \& Kellner,

269 2011) and in extant crocodylians, such as Caiman and Alligator (Brochu, 1992).

270 The lateral and medial processes of the proximal condyle are not complete but the

271 lateromedial expansion of the proximal end is clear, as in most crocodyliforms (Pol, 2005). The

272 proximal end of the radius is bent cranially at an angle of approximately $25^{\circ}$. In cranial view

273 (Figure 4, A-B), the radiohumeral articular surface bears a concavity for the articulation of the

274 radial condyle of the humerus. In caudal view (Figure 4, E-F), part of a crest is seen, adjacent to

275 the lateral process of the proximal condyle. This crest is described by Pol (2005) for Notosuchus

276 terrestris as a thin proximodistal crest and is also present in Simosuchus clarki, as well as in the

277 baurusuchids Stratiotosuchus maxhechti and Baurusuchus albertoi (Nascimento \& Zaher, 2010;

278 Sertich \& Groenke, 2010; Riff \& Kellner, 2011). The ulnar facet is poorly preserved, but it is 
279 represented in caudal view by a concavity between the lateral and medial processes. The medial

280 process of the proximal condyle bears, on its medial surface, the scar for the tendon of $M$.

281 humeroantebrachialis inferior (Figure 4, E-H). This scar was described by Turner (2006) for

282 Araripesuchus tsangatsangana, and is also present in Simosuchus clarki and Baurusuchus

283 albertoi (Nascimento \& Zaher, 2010; Sertich \& Groenke, 2010). Caudodistal to this scar, the

284 tubercle for the insertion of M. biceps brachii is seen (Meers, 2003).

285 The radial shaft is elliptical in cross-section, and marked by scars and ridges for muscle

286 insertions. In cranial view (Figure 4, A-B), distal to the proximal condyle, the scar for the $M$.

287 abductor radialis insertion is present, lateral to the tuberosity for the insertion of $M$.

288 humeroradialis. This scar extends distally to the midlenght of the shaft, as in other notosuchians

289 and living crocodylians (Meers, 2003; Pol, 2005; Turner, 2006; Sertich \& Groenke, 2010). More

290 distally, in the midline of the cranial surface, a proximodistally elongated ridge separates the

291 insertions of $M$. supinator laterally and $M$. pronator teres, medially, along most of the shaft

292 (Meers, 2003). This ridge is also seen in Baurusuchus albertoi, but less marked than in

293 Stratiotosuchus maxhechti (Nascimento \& Zaher, 2010; Riff \& Kellner, 2011). The

294 proximodistally long insertions of $M$. extensor carpi radialis brevis and $M$. pronator quadratus

295 are better seen, respectively, on the lateral and caudal surfaces (Figure 4, C-F) (Meers, 2003). A

296 well-developed, proximodistal elongated ridge marks the caudal limit of M. extensor carpi

297 radialis brevis and the lateral limit of $M$. pronator quadratus (Meers, 2003) at the lateral surface

298 of the distal half of the shaft (Figure 4, C-D). This ridge extends from the first to the third

299 quarters of the shaft, resembling that of Simosuchus clarki, Baurusuchus albertoi and

300 Aplestosuchus sordidus (Godoy et al., 2014) (Sertich \& Groenke, 2010; Nascimento \& Zaher,

301 2010), but is smoother than that of Stratiotosuchus maxhechti (Riff \& Kellner, 2011). Also in

302 lateral view, another ridge, in the proximal half of the shaft, separates the insertion extensions of

303 M. extensor carpi radialis brevis and M. abductor radialis (Meers, 2003). This ridge almost 
304 reaches the cranial surface, as in other baurusuchids, differing from the pattern seen in

305 Simosuchus clarki, in which the ridge is restricted to the lateral surface (Sertich \& Groenke, 306 2010; Nascimento \& Zaher, 2010; Riff \& Kellner, 2011; Godoy et al., 2014).

307 The distal end of the radius is lateromedially expanded and strongly compressed

308 craniocaudally. In distal view, the caudal surface is concave for the articulation with the ulna

309 (Figure 3, B). On the caudal surface of the distal end (Figure 4, E-F) a small vascular foramen is

310 seen medial to the ulnar articulation concavity. The radiale articulates with the cranial convex

311 surface of the radius. This articulation gives the radial distal end two separate condyles, a more

312 distally extended medial condyle and a lateral one, as seen in Stratiotosuchus maxhechti and

313 Simosuchus clarki (Sertich \& Groenke; Riff \& Kellner, 2011).

\section{Carpus}

315 The holotype (LPRP/USP 0019) has both right radiale and ulnare preserved, along with an

316 incomplete right manus (Figure 5). Only the cranial surfaces of both bones are visible. The

317 pisiform and the distal carpal, which complete the carpus of Crocodylia, are not preserved in

318 Pissarrachampsa sera (Mook, 1921; Nascimento \& Zaher, 2010; Sertich \& Groenke, 2010). Both

319 radiale and ulnare are elongated bones, a synapomorphy of Crocodylomorpha (Walker, 1970;

320 Clark, 1986; Benton \& Clark, 1988). They are very constricted lateromedially and craniocaudally

321 compressed between enlarged proximal and distal ends, as in Simosuchus clarki, Stratiotosuchus

322 maxhechti and Baurusuchus albertoi (Riff, 2007; Nascimento \& Zaher, 2010; Sertich \& Groenke,

323 2010), differently from the highly elongated and slender carpals of Araripesuchus

324 tsangatsangana (Turner, 2006).

325 The proximal surface of the right radiale of Pissarrachampsa sera (holotype, LPRP/USP

326 0019) is not completely exposed. However, as the preserved medial two-thirds of the surface are

327 concave, this appears to be also the condition of the lacking portion, whereas the lateral third is 
328 occupied by a proximally directed convex lateral process. The same pattern is found in

329 Simosuchus clarki, Stratiotosuchus maxhechti, Notosuchus terrestris, Baurusuchus albertoi,

330 Sebecus icaeorhinus, and Yacarerani boliviensis (Novas et al., 2009) (Pol, 2005; Riff, 2007;

331 Nascimento \& Zaher, 2010; Sertich \& Groenke, 2010; Pol et al., 2012; Leardi et al., 2015b). The

332 exposed portion of the proximal surface represents the articulation for the distal end of the radius,

333 as described for Baurusuchus albertoi, Simosuchus clarki, Stratiotosuchus maxhechti and

334 Araripesuchus tsangatsangana (Turner, 2006; Riff, 2007; Nascimento \& Zaher, 2010; Sertich \&

335 Groenke, 2010). The presence of a marked longitudinal crest in the cranial surface of the radiale

336 has been described for several notosuchians, such as Notosuchus terrestris, Baurusuchus albertoi,

337 Sebecus icaeorhinus, Stratiotosuchus maxhechti, and Yacarerani boliviensis (Pol, 2005; Riff,

338 2007; Nascimento \& Zaher, 2010; Sertich \& Groenke, 2010; Pol et al., 2012; Leardi et al.,

339 2015b). On the other hand, Turner (2006) describes a "median ridge" in Araripesuchus

340 tsangatsangana, which may correspond to the longitudinal crest. There is no sign of such a crest

341 in the exposed surface of the radiale of Pissarrachampsa sera, but its absence cannot be

342 confirmed as most of the cranial surface of the radiale is embedded in the rock matrix.

Sertich \& Groenke (2010) described a prominent pit and a raised rugosity for Simosuchus

344 clarki, which topologically corresponds to the proximal portion of the cranial longitudinal crest in

345 Mahajangasuchus insignis, and represents the insertion of the M. extensor carpi radialis longus

346 (Meers, 2003). The presence of raised scars medial and lateral to this pit is has also been

347 described for Simosuchus clarki, consistent with the origin of the superficial extensor muscles for

348 digits I, II and III (Brochu, 1992; Meers, 2003; Sertich \& Groenke, 2010). In Pissarrachampsa

349 sera, despite the lack of the pit, it is possible that the exposed surface of the radiale includes the

350 insertion areas of those extensor muscles, or at least those lateral to the pit in Simosuchus clarki.

351 The ulnare of Pissarrachampsa sera (holotype, LPRP/USP 0019) seems to be

352 proximodistally shorter than the radiale (Figure 5), as in Araripesuchus tsangatsangana, 
353 Baurusuchus albertoi, Simosuchus clarki, Stratiotosuchus maxhechti, Notosuchus terrestris,

354 Yacarerani boliviensis, and Crocodylia (Mook, 1921; Pol, 2005; Turner, 2006, Turner, 2006;

355 Nascimento \& Zaher, 2010; Sertich \& Groenke, 2010; Leardi et al., 2015b). Its proximal articular

356 surface is covered by matrix, but its proximal outline seems to be subtriangular, with the apex

357 positioned cranially, as in Simosuchus clarki (Sertich \& Groenke, 2010).

358 The distal end of the ulnare is more expanded than the proximal, as in Notosuchus

359 terrestris, Sichuanosuchus shuhanensis (Wu et al., 1997), Baurusuchus albertoi, Araripesuchus

360 tsangatsangana, Stratiotosuchus maxhechti, Simosuchus clarki, Yacarerani boliviensis, and most

361 non-Crocodylia crocodyliforms (Pol, 2005; Turner, 2006; Riff, 2007; Nascimento \& Zaher, 2010;

362 Sertich \& Groenke, 2010; Leardi et al., 2015b). Yet, the bone is not exposed enough to see if this

363 expansion is symmetrical, as in Simosuchus clarki and Yacarerani boliviensis, or more marked

364 medially, as in Notosuchus terrestris, Stratiotosuchus maxhechti and Baurusuchus albertoi

365 (Leardi et al., 2015b)

$366 \underline{\text { Manus }}$

367 Two right manus are associated to Pissarrachampsa sera, one of the holotype (LPRP/USP 0019)

368 and an isolated one (LPRP/USP 0745). The holotypic right manus (Figure 5) is composed of five

369 digits: the first includes the metacarpal and the proximal phalanx; the second includes the

370 metacarpal, a poorly preserved proximal phalanx, and the distal phalanx; the third includes the

371 metacarpal and fragments of the medial portions of three phalanges; the last two digits include

372 only the metacarpals. The right manus of LPRP/USP 0745 preserves (albeit partially) all five

373 metacarpals, an incomplete proximal phalanx of the digit I, and a fragment that might represent

374 the proximal phalanx of the digit III. The holotypic manus is better seen in ventral view (Figure

375 5, B), whereas LPRP/USP 0745 has only its dorsal surface exposed. 
377 increase in length (Figure 5, B), as in Baurusuchus albertoi and Stratiotosuchus maxhetchi

378 (Nascimento \& Zaher, 2010; Riff \& Kellner, 2011). Metacarpal I is the most robust, as in

379 Notosuchus terrestris, Stratiotosuchus maxhechti, Simosuchus clarki, and Yacarerani boliviensis, 380 differing from Crocodylia, in which metacarpal I is similar in robustness to the others (Mook, 381 1921; Pol, 2005; Sertich \& Groenke, 2010; Riff \& Kellner, 2011; Leardi et al., 2015b). The 382 preserved proximal end of metacarpal $\mathrm{V}$ is dorsoventrally flat and lateromedially wide, as in 383 Baurusuchus albertoi, S. maxhetchi, and Yacarerani boliviensis (Nascimento \& Zaher, 2010; Riff 384 \& Kellner, 2011; Leardi et al., 2015b).

All phalanges preserved in the holotype are robust, with a blocky appearance in dorsal and ventral views, with a midlength constriction, also seen in Baurusuchus albertoi, Simosuchus clarki, Stratiotosuchus maxhetchi, Araripesuchus tsangatsangana, and Yacarerani boliviensis (Turner, 2006; Nascimento \& Zaher, 2010; Sertich \& Groenke, 2010; Riff \& Kellner, 2011; Leardi et al., 2015b). All manual phalanges of Pissarrachampsa sera that preserve their articular surfaces exhibit medial and lateral condyles, in both the distal and proximal surfaces.

\section{Pelvic Girdle}

$392 \underline{\text { Ilium }}$

393 One left ilium is partially preserved for Pissarrachampsa sera (Figure 6), from a referred 394 specimen (LPRP/USP 0742). It lacks the distal part of the postacetabular process, most of the 395 preacetabular process, and the ventral portion of the acetabular region. The acetabulum is deep, 396 as in Baurusuchus albertoi and Sebecus icaeorhinus, as a result from the strictly lateral 397 orientation of the supraacetabular crest (Nascimento \& Zaher, 2010; Pol et al., 2012). On the 398 other hand, the supraacetabular crest of Araripesuchus tsangatsangana projects not only laterally, 399 but also dorsally, which gives a shallower aspect to the acetabulum (Turner, 2006). In some 
400

401

402

403

404

405

406

407

408

409

410

411

412

413

414

415

416

417

418

419

420

421

422

423

424

neosuchians and living taxa, the crest is strongly inclined dorsally, giving an accentuated shallow aspect to the acetabulum in lateral view (Leardi et al., 2015a).

In Pissarrachampsa sera, the morphology of the dorsal surface of the acetabular roof resembles that of Baurusuchus albertoi (Figure 6, A-B) (Nascimento \& Zaher, 2010). In both taxa, the dorsal component of the supraacetabular crest is confluent with the remaining dorsal portion of the bone, extending as a flat horizontal surface, giving the ilium a broad aspect. On the other hand, in Sebecus icaeorhinus, Microsuchus schilleri (Dolgopol de Sáez, 1928), and living forms, such as Caiman latirostris (Daudin, 1802) (MZSP 2137), the supraacetabular crest is not confluent with the rest of the dorsal margin, but has a medial boundary (Pol et al., 2012; Leardi et al., 2015a). In Sebecus icaeorhinus and Caiman yacare (Daudin, 1802), the dorsal margin is sloped, with the portion corresponding to the supraacetabular crest lying dorsal to the medial portion of the iliac dorsal surface (Nascimento, 2008; Pol et al., 2012). Given the great lateral projection of the supraacetabular crest, the maximum width of the dorsal margin of the ilium of

Pissarrachampsa sera is located right above the caudal margin of the acetabular area. The rest of the dorsal surface becomes gradually narrower in the direction of both the pre- and postacetabular processes. Rugosities on the dorsal surface of the supraacetabular crest indicate the area for the attachment of M. iliotibialis 1 and 2 (Romer, 1923; Leardi et al., 2015a). In Pissarrachampsa sera, most of this surface is rugose, indicating a greater area for the attachment of those muscles. The proximal portion of the postacetabular process is at least four times dorsoventrally higher than lateromedially wide, and its dorsal margin is slightly caudoventrally. In medial view, it is possible to see the medial expansion of the dorsal portion of the postacetabular process, forming a ridge that extends craniocaudally (Figure 6, C-D). This ridge marks the dorsal limit of a concave surface on the medial portion of the ilium. Ventrally, this concavity is delimited by a curved ridge, which corresponds to the dorsal part of the articular surface for the second sacral rib (see Pol et al., 2012), and this same morphology is also seen in Baurusuchus albertoi and 
425 Sebecus icaeorhinus (Nascimento \& Zaher, 2010; Pol et al., 2012). On the other hand, in

426 Theriosuchus pusillus (Owen, 1879) and some extant taxa, such as Caiman yacare and

427 Melanosuchus niger (Spix, 1825), there is no evidence of a supraacetabular process medial crest,

428 which gives a more flattened aspect to the process above the articular surface for the second

429 sacral rib (Wu et al., 1996). Baurusuchus albertoi has a total of three sacral vertebrae, with the

430 articulation surface for the third element located in the distal portion of the postacetabular process

431 (Nascimento \& Zaher, 2010). Three sacral vertebrae are also found in other baurusuchids, such as

432 Baurusuchus salgadoensis (Carvalho et al., 2005) (Vasconcellos \& Carvalho, 2010) and

433 Aplestosuchus sordidus (Godoy et al., 2014), and there is no evidence of a different condition in

434 Pissarrachampsa sera, although this remains speculative due to the absence of more complete

435 remains.

436 Ischium

437 Both left and right ischia of the holotype of Pissarrachampsa sera (LPRP/USP 0019) are

438 partially preserved, lacking the distal portions of the ischial blade, and of the iliac and pubic

439 peduncles. Despite the incompleteness, the typical crocodyliform ischium is visible (Figure 7, A-

440 B), with a lateromedially constricted ischial blade, a caudal process which would probably

441 contact the ilium, and a cranial process which likely contacted both ilium and pubis (Sertich \&

442 Groenke, 2010). The notch between both processes formed the ventral margin of the perforate

443 acetabulum, similar to the condition seen in mesoeucrocodylians such as Chimaerasuchus

444 paradoxus, Mahajangasuchus insignis, Stratiotosuchus maxhechti, and Sebecus icaeorhinus (Wu

445 \& Sues, 1996; Buckley \& Brochu, 1999; Riff \& Kellner, 2011; Pol et al., 2012). The proximal

446 parts of both processes differ in thickness, with a more extended cranial process, as seen in

447 Stratiotosuchus maxhechti and Sebecus icaeorhinus (Riff \& Kellner, 2011; Pol et al., 2012). In 
448 these two taxa, however, the cranial process expands distally, becoming more robust, an unknown 449 condition for Pissarrachampsa sera.

450 On the lateral surface of the ischial blade (Figure 7, A-B), a ridge extends dorsoventrally

451 along its proximal third marking the limits of muscles attached to the ischium. The ischium is

452 very constricted lateromedially, cranial and caudal to this ridge, giving a sharp aspect to its 453 margins. Caudal to the ridge is the area for attachment of both $M$. flexor tibialis internus pars 3

454 laterally and M. ischiotrochantericus medially (Hutchinson, 2001a). In the distal portion of the 455 ischial blade, only the cranial margin is constricted, as the dorsoventral ridge becomes confluent

456 with the caudal margin, which becomes more rounded. The constricted cranial margin

457 corresponds to the attachment surface for M. puboischiofemoralis externus pars 3, on the medial 458 surface of the bone (Hutchinson, 2001a; Riff, 2007). In cranial and lateral views, it is possible to 459 see a tubercle on the dorsal portion of the ischial blade, ventral to the cranial process of the 460 ischium. Stratiotosuchus maxhechti bears a similar tubercle, which is interpreted as the 461 attachment point for M. pubioischiotibialis (Riff \& Kellner, 2011).

$462 \underline{\text { Pubis }}$

463 Both pubes are partially preserved (Figure 7, C) in the holotype of Pissarrachampsa sera 464 (LPRP/USP 0019). As is typical for Crocodyliformes, the proximal shaft of the pubis lacks the 465 obturator foramen present in some non-Crocodyliformes Crocodylomorpha, such as 466 Terrestrisuchus gracilis (Crush, 1984). In general, the pubis has a rod-like aspect, as also seen in 467 Baurusuchus albertoi, Stratiotosuchus maxhechti and the protosuchians Protosuchus richardsoni 468 (Brown, 1933) and Orthosuchus stormbergii (Nash, 1968) (Colbert \& Mook, 1951; Nash, 1975; 469 Nascimento \& Zaher, 2010; Pol et al., 2012). On the other hand, other crocodyliforms such as 470 Araripesuchus tsangatsangana, Notosuchus terrestris, Mahajangasuchus insignis, Theriosuchus 
471 pusillus, as well as the living forms, bear an expanded distal pubic end (Brochu, 1992; Wu et al.,

472 1996; Buckley \& Brochu, 1999; Turner, 2006; Pol, 2005).

473 Given the incompleteness of the pelvis of Pissarrachampsa sera, the isolation of the

474 pubis from the acetabulum cannot be asserted. Yet, in all Crocodyliformes, except protosuchians,

475 the pubis is excluded from the acetabulum by the cranial process of the ischium, which represents

476 the articulation point for the proximal end of the pubis (Colbert \& Mook, 1951). In

477 Pissarrachampsa sera, the partially preserved proximal articulation is lateromedially constricted,

478 and more constricted in its cranial third, giving it a pear-shaped aspect. This lateromedial

479 constriction extends distally along the shaft, as also seen in Stratiotosuchus maxhechti (Riff,

480 2007). Pissarrachampsa sera and Stratiotosuchus maxhechti also share the proximal pubic shaft

481 bent approximately 30 degrees in relation to the pubic blade. In other notosuchians, such as

482 Araripesuchus tsangatsangana and Simosuchus clarki, and also in the living Crocodylia, such

483 bending is unknown (Turner, 2006; Riff, 2007; Sertich \& Groenke, 2010). The pubic blade is

484 craniocaudally constricted in its medial third, which forms the pubic symphysis. Lateral to the

485 laminar symphyseal region, the ischial blade does not show any evidence of the craniocaudal

486 constriction. The attachment area for both $M$. puboischiofemoralis externus pars 1 and 2 is

487 probably located in the proximal two thirds of the transitional area between the constricted and

488 non-constricted regions of the pubic blade, in the caudal and cranial surfaces respectively

489 (Romer, 1923).

490 The pubis is a remarkably long element in Pissarrachampsa sera, when compared to that

491 of other crocodyliforms even lacking its distalmost portion. Indeed, even without the distal part,

492 the pubic length of Pissarrachampsa sera is $70 \%$ of the total length of the femur. This condition

493 is "more similar to that of Stratiotosuchus maxhechti (Riff, 2007), in which this ratio is $80 \%$, than

494 to the condition observed in other crocodyliforms: 25\% in Araripesuchus tsangatsangana; 42\%

495 in Edentosuchus tienshanensis (Young, 1973); 55\% in Sunosuchus junggarensis (Young, 1948); 
496 55\% in Mahajangasuchus insignis, and 57\% in Caiman yacare (Buckley \& Brochu, 1999; Pol et 497 al., 2004; Turner, 2006).

498 Hindlimb

499 Femur

500 There are four preserved femora known for Pissarrachampsa sera. The femoral pair of the 501 holotype (LPRP/USP 0019), as well as two smaller isolated and partially preserved left and right 502 elements (LPRP/USP 0743 and LPRP/USP 0744). The smaller right femur is still in articulation 503 with tibia and fibula, but the following description is based mostly on the holotypic material 504 (Figure 8), since these are better preserved. The femur is virtually straight in cranial and caudal 505 views, and its proximodistal length is about $24 \mathrm{~cm}$. It is longer than the tibia and or fibula, as seen 506 in most other Mesoeucrocodylia (Leardi et al., 2015a). In medial and lateral views, the shaft is 507 slightly bowed cranially, and the proximal and distal ends are cranially and caudally curved. The 508 proximal articulation surface is medially inturned, as seen in Baurusuchus albertoi and 509 Stratiotosuchus maxhechti, but not as displaced as in Araripesuchus tsangatsangana (Turner, 510 2006; Nascimento \& Zaher, 2010; Riff \& Kellner, 2011). In proximal view (Figure 8, I-J), the 511 robust articular surface is rounded and rugose at its distal portion, with scars for muscle insertion, 512 whereas the caudolateral extension of the head is slender, as in other baurusuchids and 513 Mariliasuchus amarali (Carvalho \& Bertini, 1999) (Nascimento \& Zaher, 2010; Riff \& Kellner, 514 2011; Nobre \& Carvalho, 2013). At this point, in caudal view (Figure 8, E-F), there is a 515 proximodistally extensive "greater trochanter" placed laterally, extending cranially and parallel to 516 the "medial proximal crest", at the caudal most extension of the head (Pol et al., 2012). The 517 "medial proximal crest" turns caudally in Pissarrachampsa sera, and not medially as in Sebecus 518 icaeorhinus (Pol et al., 2012). 
520 and scars for musculature insertion. The scars along the "greater trochanter" correspond to the 521 insertions of $M$. ischiotrochantericus and M. puboischiofemoralis internus 2, and are also

522 possibly related to the adductor fossa, placed cranially to these muscles insertions (Hutchinson, 523 2001b; Sertich \& Groenke, 2010; Nascimento \& Zaher, 2010). In caudal view (Figure 8, E-F), $M$. 524 puboischiofemoralis externus (Hutchinson, 2001b) attaches at the "medial proximal crest". In 525 cranial view (Figure 8, A-B), the "cranial flange" marks the transition between the proximal 526 femur and the shaft. There are many names for this structure in the literature: anteromedial 527 process (Fiorelli \& Calvo, 2007), anterior flange and caudofemoralis flange (Turner, 2006), and 528 cranium-medial crest (Riff, 2007; Nascimento \& Zaher, 2010). Although less sharp and 529 prominent than in Simosuchus clarki, this structure is well marked, and bears scars for 530 musculature insertions (Sertich \& Groenke, 2010). This condition is similar to that of other 531 baurusuchids and Araripesuchus tsangatsangana, but Microsuchus schilleri and other small 532 notosuchians, such as Mariliasuchus amarali, have a less marked "cranial flange", which is 533 absent in Sebecus icaeorhinus and Yacarerani boliviensis (Nobre \& Carvalho, 2006; Turner, 534 2006; Nascimento \& Zaher, 2010; Riff \& Kellner, 2011; Pol et al., 2012; Nobre \& Carvalho, 535 2013; Leardi et al., 2015b). In Pissarrachampsa sera, the "cranial flange" divides the femoral 536 shaft in medial and lateral parts. In cranial view (Figure 8, A-B), the insertion for $M$.

537 puboischiofemoralis internus 1 is flanked medially by a rugose convexity related to $M$. 538 caudofemoralis longus (Hutchinson, 2001b). Caudal to that, another smaller rough convexity, 539 also seen in Araripesuchus tsangatsangana, may correspond to the fourth trochanter (Turner, 540 2006). This corresponds to a shallow proximodistally oriented groove that extends distally as a 541 faint ridge and has scars for the insertion of M. caudofemoralis brevis (Hutchinson, 2001b). It 542 differs from the poorly developed fourth trochanter of Sebecus icaeorhinus, Microsuchus 
543 schilleri, and Yacarerani boliviensis and the very prominent structure seen in Simosuchus clarki

544 (Sertich \& Groenke, 2010; Pol et al., 2012; Leardi et al., 2015a; b).

545 Other muscle scars seen along the shaft, as well as a foramen mediodistal to the cranial

546 flange. Laterodistal to the flange lies the insertion area for the M. iliofemoralis (Hutchinson,

547 2001b) and distal to the flange, there is an extensive intermuscular line that almost reaches the

548 proximal limit of the intercondylar fossa (Romer, 1956). This corresponds to the $M$.

549 femorotibialis internus (Hutchinson, 2001b) and its distal most extension forms a longitudinal

550 ridge, named here "femorotibialis ridge". This intermuscular line does not form a ridge in the

551 juvenile specimen, and is interpreted as an ontogeny-related character. Caiman sp. (LPRP/USP N

552 0008) also has this intermuscular line, but it does not form a ridge. The presence of this ridge is

553 not clear in other notosuchians, except for Stratiotosuchus maxhecthi and Aplestosuchus

554 sordidus, in which it is smoother than in Pissarrachampsa sera (Riff \& Kellner, 2011; Godoy et

555 al., 2014). On the caudal face of the femoral shaft (Figure 8, E-F), the linea intermuscularis

556 caudalis extends obliquely, from the fourth trochanter to the proximal portion of the lateral

557 condyle, and forms the lateral border of the popliteal fossa. This scar corresponds to the boundary

558 between $M$. femorotibialis externus, craniomedially, and $M$. adductor femoris 1 \& 2,

559 caudolaterally (Hutchinson, 2001b).

560 The two distal condyles are well developed, forming the intercondylar fossa cranially and

561 a deep popliteal fossa caudally. The latter is rugose, as in Stratiotosuchus maxhechti, whereas the

562 intercondylar fossa has smoother scars for muscle insertions (Romer, 1956; Riff \& Kellner,

563 2011). The lateral or fibular condyle has a laterodistal concavity, possibly related to the fibular

564 articulation. It is about two times larger than the medial or tibial condyle, which is not as distally

565 expanded as the lateral condyle, a general crocodyliform condition (Sertich \& Groenke, 2010; Pol

566 et al., 2012). In lateral view (Figure 8, G-H), the rugose surface above the lateral condyle makes

567 the insertion of M. gastrocnemius (Brochu, 1992; Sertich \& Groenke, 2010). Cranially, the distal 
568 portion of the femur has a well developed medial supracondylar ridge, whereas the lateral

569 supracondylar ridge is smoother. This differs from the condition in Sebecus icaeorhinus, which

570 lacks a marked transition from the cranial to the lateral surfaces of the distal femur (Pol et al.,

571 2012). The caudal surface (Figure 8, E-F) of the distal femur bears both medial and lateral

572 supracondylar ridges (the latter would be the distal extension of the linea intermuscularis

573 caudalis), as well as a popliteal fossa between these (Hutchinson, 2001b; Pol et al., 2012). The

574 medial supracondylar ridge forms a proximodistally oriented crest, above the medial condyle,

575 separating the caudal and lateral surfaces of the distal portions of the femur. The medial facet of

576 the distal portion of the femur is almost flat, cranially bound by the medial supracondylar ridge,

577 whereas in Sebecus icaeorhinus this surface is slightly convex (Pol et al., 2012).

$578 \quad$ Tibia

579 Both tibiae of the holotype (LPRP/USP 0019) are nearly complete, and articulated with the 580 fibulae in their original position (Figure 9). Additionally, there is a smaller isolated right tibia

581 (LPRP/USP 0741), as well as the additional right tibia in articulation with femur and fibula

582 (LPRP/USP 0744). The shafts of the articulated tibia and fibula are very close to one another

583 (Figure 9, A-B), as are the radius and ulna. This condition is different from that of modern

584 crocodylians (e.g.: Caiman and Melanosuchus) in which this distance is larger. The tibia of

585 Pissarrachampsa sera is similiar in robustness to the tibiae of most crocodyliforms, differing

586 from the more gracile elements of Araripesuchus tsangatsangana and Microsuchus schilleri

587 (Brochu, 1992; Turner, 2006; Leardi et al., 2015a). The tibia is $18.6 \mathrm{~cm}$ long, i.e. 77\% the femur's

588 length, the same ratio of Sebecus icaeorhinus. This differs from other notosuchians, such as the

589 relatively short tibia of other baurusuchids, such as Baurusuchus albertoi and Stratiotosuchus

590 maxhechti, (about 72\%) and the elongated bone (82\%) of Araripesuchus tsangatsangana (Pol et

591 al., 2012). 
593 proximal surface is divided into medial and lateral facets (Figure 9, A-B), which respectively

594 correspond to the articulation areas for the tibial and fibular condyles of the femur. In proximal

595 view, the medial articulation (posteromedial proximal process of the tibia, according to Leardi et

596 al., 2015b) has a trapezoid-shape; a pattern also seen in other baurusuchids, such as

597 Stratiotosuchus maxhechti and Baurusuchus albertoi (Nascimento \& Zaher, 2010; Riff \&

598 Kellner, 2011). The medial articular facet is more protruded relative to the lateral one. The

599 proximal surface of the medial facet forms a gentle concavity, corresponding to the "proximal

600 pit" sensu Brochu (1992), and bears a pronounced deflection toward its caudomedial corner

601 (Figure 9). This condition is also observed in Sebecus icaeorhinus, which bears a gently

602 protruded medial facet, but differs from Mariliasuchus amarali, Yacarerani boliviensis, and

603 Stratiotosuchus maxhechti, in which that medial portion is weakly pronounced (Pol et al., 2012;

604 Leardi et al., 2015b). The latter condition is also present in modern crocodylians (e.g.: Caiman,

605 Melanosuchus and Alligator) resulting in equally projected facets. The lateral articular facet is

606 semi-lunar in shape and slightly concave in proximal view. The cranial border is rounded and the

607 caudal tip is somewhat deflected distally. It resembles the pattern of Sebecus icaeorhinus and

608 Yacarerani boliviensis, differing from the weakly projected tip of Mariliasuchus amarali,

609 Araripesuchus tsangatsangana and Stratiotosuchus maxhechti (Turner, 2006; Riff \& Kellner,

610 2011; Pol et al., 2012; Nobre \& Carvalho, 2013; Leardi et al., 2015b).

611 Cranially, the proximal expansion of the tibia bears a well-developed tuberosity for the

612 insertion of M. flexor tibialis internus (Figure 9, E-F). This insertion is proximodistally

613 elongated, as in Araripesuchus tsangatsangana, but it is more sharply raised and closer to the

614 proximal articular surface, a condition more marked than in extant taxa (e.g.: Alligator, Caiman

615 and Melanosuchus). Proximolaterally, there is a shallow depression related to the attachment of

616 the internal lateral ligament (Figure 9, E-F), as in Alligator mississippiensis (Daudin, 1802) 
617 (Brochu, 1992). Along with this depression, the lateral margin bears an anterolateral straight 618 ridge (anterolateral proximal ridge, according to Leardi et al., 2015b), corresponding to the 619 insertion of M. tibialis anterior. The ridge is proximodistally elongated, as in Araripesuchus 620 tsangatsangana, but not Simosuchus clarki, which bears a tuberosity in the corresponding area 621 (Turner, 2006; Sertich \& Groenke, 2010). Caudally (Figure 9, A-B), the lateral and medial 622 articular facets are separated by a small notch, the "fossa flexoria" sensu Hutchinson (2002) or 623 "posterior cleft" sensu Sertich \& Groenke (2010). In Pissarrachampsa sera this fossa is more 624 excavated, as in Araripesuchus tsangatsangana and Stratiotosuchus maxhechti, than in Sebecus 625 icaeorhinus, Yacarerani boliviensis, and Alligator mississippiensis (Brochu, 1992; Turner, 2006; 626 Riff \& Kellner, 2011; Pol et al., 2012; Leardi et al., 2015b). The tibial shaft is smooth and rounded in cross section, and craniolaterally bowed. This bowing (see character 336 of Leardi et al., 2015a) can be seen in different degrees within Mesoeucrocodylia. In Pissarrachampsa sera, Baurusuchus albertoi, Stratiotosuchus maxhechti, and Sebecus icaeorhinus the shaft is markedly bowed, differing from the slightly bowed tibia of Yacarerani boliviensis, Simosuchus clarki, and Araripesuchus tsangatsangana, or the straight one in Alligator (Pol et al., 2012; Leardi et al., 2015b). There is no distinguished torsion in the tibial shaft of Pissarrachampsa sera. In caudal view (Figure 9, A-B), it bears a faint ridge for the insertion of $M$. flexor digitorum longus. This structure is more prominent in other baurusuchids, such as Stratiotosuchus maxhechti and Baurusuchus albertoi, but absent in Araripesuchus tsangatsangana (Turner, 2006; Nascimento \& Zaher, 2010; Riff \& Kellner, 2011). In extant crocodylians, the longitudinal crest can be marked (e.g.: Alligator and Melanosuchus), or slightly prominent (Caiman).

The distal expansion of the tibia is divided inti lateral and medial portions, both contacting 640 the astragalus. The medial portion is distally projected, forming an oblique distal margin relative 641 to the transverse plane. A similar condition is seen in other mesoeucrocodylians, such as Sebecus 
642 icaeorhinus, Stratiotosuchus maxhechti, Notosuchus terrestris, Araripesuchus tsangatsangana, 643 and Yacarerani boliviensis (Turner, 2006; Fiorelli \& Calvo, 2008; Riff \& Kellner, 2011; Pol. et al, 644 2012; Leardi et al., 2015b), and it is different from the sub-equally expanded distal tibia of living 645 crocodylians (Alligator and Crocodylus), and also some notosuchians like Simosuchus clarki, 646 Mariliasuchus amarali, and Microsuchus schilleri (Brochu, 1992; Sertich \& Groenke, 2010; 647 Nobre \& Carvalho, 2013; Leardi et al., 2015a). In distal view, the tibial surface has a crescentic 648 shape, resembling more the pattern seen in Araripesuchus tsangatsangana and Yacarerani 649 boliviensis, than the "L-shaped” pattern of Sebecus icaeorhinus (Turner, 2006; Pol et al., 2012; 650 Leardi et al., 2015b). The craniolateral margin of the distal portion of the tibial expansion is 651 curved, followed by a short and sharp crest that ends caudally at the fibular contact (Figure 9, B, 652 indicated by an arrow). A triangular depression is seen at the caudal surface between the medial 653 and lateral edges of this expansion. First described for Araripesuchus tsangatsangana (Turner 654 2006), this structure is well excavated in other basal mesoeucrocodylians, such as Sebecus 655 icaeorhinus, Stratiotosuchus maxhechti, and Mariliasuchus amarali (Pol et al., 2012; Riff \& 656 Kellner, 2011; Nobre \& Carvalho, 2013), but relatively shallow in Baurusuchus albertoi and 657 Yacarerani boliviensis (Nascimento \& Zaher, 2010; Leardi et al., 2015b). Extant crocodylians, 658 such as Caiman, show a clear depression in the same area, but this structure is not triangular. 659 Cranially, close to the medial margin of the distal expansion, there is a protuberance for insertion 660 of $M$. interosseus cruris. This structure is placed more proximally in extant taxa, slightly 661 developed in Caiman and Melanosuchus, but marked in Alligator (Brochu, 1992). Among 662 Baurusuchidae, both Stratiotosuchus maxhechti and Baurusuchus albertoi bear the same 663 protuberance, although less prominent in the latter (Nascimento \& Zaher, 2010; Riff \& Kellner, 664 2011). Craniolaterally, the distal end of the tibia is devoid of the circular depression for the 665 attachment of the medial tibioastragalar ligament, which is clearly seen in Araripesuchus 666 tsangatsangana (Turner, 2006). 
667 Fibula

668 Both fibulae of the holotype of Pissarrachampsa sera (LPRP/USP 0019) are virtually complete 669 (Figure 9) and in articulation with the tibiae. This is also the case for the fibula of LPRP/USP 670 0744, preserved in articulation with femur and tibia. The fibula of the holotype is $17 \mathrm{~cm}$ long, 671 slender and slightly shorter than the tibia. The fibular width corresponds to half that of the tibia, 672 differing from Baurusuchus albertoi, the fibula of which is three times thinner than the tibia 673 (Nascimento \& Zaher, 2010). The proximal articular surface is gently concave, with the lateral 674 border more developed than the medial. In proximal view, the fibula is crescentic in shape and 675 the medial margin is slightly notched. In contrast, the proximal fibula of Stratiotosuchus 676 maxhechti is caudally wedged (Riff \& Kellner, 2011).

678 living forms Melanosuchus, Caiman, and Alligator, bear the same caudal expansion for the 679 attachment of the long external lateral ligament (Brochu, 1992), which is also present in 680 baurusuchids such as Stratiotosuchus maxhechti and Baurusuchus albertoi (Nascimento \& Zaher, 681 2010; Riff \& Kellner, 2011). Indeed, the shape of the proximal fibular end varies systematically 682 within Crocodyliformes (Turner, 2006). Whereas modern crocodylians, such as Alligator, bear a 683 straight caudal margin, Yacarerani boliviensis, Araripesuchus tsangatsangana, and 684 Araripesuchus gomesii have strongly inflected caudal margin (Turner, 2006; Leardi et al., 685 2015b), baurusuchids have an intermediate condition, with the caudal margin of the proximal 686 head is slightly curved. Proximocranially, there are attachment scars for M. flexor digitorius 687 longus. The lateral iliofibularis trochanter is sharply raised and proximodistally elongated (Figure 688 9, C-F), differing from that of Stratiotosuchus maxhechti, Baurusuchus albertoi, Araripesuchus 690 does not reach the proximal edge (Turner, 2006; Nascimento \& Zaher, 2010; Riff \& Kellner, 
691 2011; Leardi et al., 2015b). In extant forms, this trochanter is tubercle-shaped and distant from 692 the proximal edge (Brochu, 1992).

693 The fibular shaft is almost entirely compressed lateromedially, except in its middle 694 portion, which is elliptical in cross-section. Laterally, the fibular shaft bears faintly developed 695 ridges, as in Baurusuchus albertoi, corresponding to the origin of M. peroneus longus (sensu 696 Brochu, 1992) or M. fibularis longus (sensu Hutchinson, 2002). A different condition is seen in 697 Stratiotosuchus maxhechti, in which that ridge is well developed (Riff, 2007). Among extant 698 crocodylians, both Caiman and Melanosuchus show weakly developed ridges on the lateral 699 surface of the fibular shaft, whereas in Alligator the fibula bears well developed crests and a 700 slightly rugose shaft lateral surface (Brochu, 1992). In medial view, the shaft is mostly smooth 701 and lacks any distinctive muscle scar. However, the caudodistal surface is rugose, revealing scars 702 possibly related to the attachment for M. interosseus cruris, as also observed in Araripesuchus 703 tsangatsangana and Stratiotosuchus maxhechti (Turner, 2006; Riff, 2007). There is a small 704 vascular foramen on the caudal surface near the midshaft. The tibial distal end is enlarged with a 705 triangular distal outline, as in Araripesuchus tsangatsangana and Microsuchus schilleri (see 706 Leardi et al., 2015a: character 425). As in Alligator, Caiman, and Melanosu “hus, a "dis”al hook" 707 (sensu Brochu, 1992) contacts the tibia and tapers medially. This differs from the condition in 708 Stratiotosuchus maxhechti and Yacarerani boliviensis, in which the medial end of the distal 709 margin of the tibia is rounded (Riff \& Kellner, 2011; Leardi et al., 2015b). The contact of the 710 distal hook with the tibia is more proximal then the distal tibial articulation (Figure 9), and differs

711 from the pattern in Microsuchus schilleri, the distal hook of which contacts the tibia more

712 distally. This hook is absent in Araripesuchus tsangatsangana and Yacarerani boliviensis (Turner, 713 2006; Leardi et al., 2015b). 
715 Both complete astragali and calcanea are preserved in articulation (Figure 10) in the holotype of

716 Pissarrachampsa sera (LPRP/USP 0019), although the more distal tarsal bones are not preserved.

717 The best preserved left astragalus and calcaneum are slightly displaced from their original

718 positions. The tarsal morphology of Pissarrachampsa sera is similar to that of other

719 crocodylomorphs with the "crocodile normal" condition, in which the astragalar "peg" fits into

720 the calcaneal "socket" (Chatterjee, 1978; 1982). In this configuration, the astragalus is fixed in

721 articulation with tibia and the ankle rotation occurs between astragalus and calcaneum (Brochu, 722 1992).

723 Proximally, the astragalus bears a concave and laterally elongate surface for articulation

724 with the distal tibia (Figure 10, A-B). The division of this surface for the reception of medial and

725 lateral condyles of the tibia is weak and both facets are similar in lateromedial extension. These

726 are bounded caudally by a ridge, but this structure is more developed on the lateral region of the

727 medial tibial facet. As in the baurusuchids Baurusuchus albertoi and Stratiotosuchus maxhechti

728 and the sebecid Sebecus icaeorhinus (Riff \& Kellner, 2011; Pol et al., 2012), there is no sign of

729 an "astragalar fossa" (Hecht \& Tarsitano, 1984). This differs from the morphology of extant taxa,

730 Simosuchus clarki, and Yacarerani boliviensis, in which the fossa is present and well developed

731 (Hecht \& Tarsitano, 1984; Brochu, 1992; Sertich \& Groenke, 2010; Leardi et al., 2015b). The

732 lateral tibial facet is flat, equally developed lateromedially and ends just craniomedial to the

733 fibular facet (Figure 10, A-D). The lateromedial edge of the lateral tibial facet seems to lack the

734 notch observed in Yacarerani boliviensis, Stratiotosuchus maxhechti, Sebecus icaeorhinus, and

735 Lomasuchus palpebrosus (Gasparini et al., 1991), but this surface is damaged in both left and

736 right elements (Pol et al., 2012; Leardi et al., 2015b). The lateral tibial and fibular articular

737 surfaces are set almost perpendicular to each other, as in other fossil crocodyliforms, such as

738 Simosuchus clarki, Baurusuchus albertoi, Stratiotosuchus maxhechti, Yacarerani boliviensis, and

739 also in extant forms (Hecht \& Tarsitano, 1984; Brochu 1992, Nascimento \& Zaher, 2010; Sertich 
740 \& Groenke, 2010; Riff \& Kellner, 2011; Leardi et al., 2015b). The medial tibial articular facet is

741 reniform, as in Sebecus icaeorhinus, but more craniocaudally expanded, as in Simosuchus clarki

742 and Yacarerani boliviensis (Sertich \& Groenke, 2010; Leardi et al., 2015b). The fibular facet is

743 trapezoidal and slightly concave. Distally, the astragalus bears a medial distal roller (Hecht \&

744 Tarsitano, 1984) and the calcaneal articulation (Brochu, 1992). The distal roller is elliptical in

745 distal view and extends cranioproximally merging into the craniomedial edge of the tibial facet.

746 The metatarsals are not preserved in articulation with the astragali, but there is a slight depression

747 in the distal surface of the medial distal roller that is probably related to the articulation of both

748 first and second metatarsals, as in Baurusuchus albertoi, Simosuchus clarki, Stratiotosuchus

749 maxhechti, and extant forms (Hecht \& Tarsitano, 1984; Nascimento \& Zaher, 2010; Sertich \&

750 Groenke, 2010; Riff \& Kellner, 2011).

751 The calcaneal articulation is formed by a well developed distolaterally directed peg as in

752 other crocodyliforms. This is divided in two distinct areas, the distal area of articulation

753 ("astragalar trochlea" of Hecht \& Tarsitano, 1984) and the lateral articular surface. Yet, the

754 morphology of these facets cannot be accessed due the tight articulation with the calcaneum in

755 both sides. The cranial surface of the astragalus consists of a limited non-articular region (the

756 "anterior hollow" of Hecht \& Tarsitano, 1984). This area is more restricted when compared to

757 that of Sebecus icaeorhinus, Simosuchus clarki, and extant forms, but similar to the condition of

758 Baurusuchus albertoi and Stratiotosuchus maxhechti (Hecht \& Tarsitano, 1984; Brochu, 1992;

759 Nascimento \& Zaher, 2010; Sertich \& Groenke, 2010; Riff \& Kellner, 2011; Pol et al., 2012). As

760 in Sebecus icaeorhinus, Stratiotosuchus maxhechti, and Simosuchus clarki (Pol et al., 2012;

761 Leardi et al., 2015b), the "anterior hollow" does not seem bounded distally and laterally by crests,

762 but its lateralmost surface is somewhat damaged. Distally, the pit for the astragalar-tarsale

763 ligament is located at the anterior hollow, close to the medial distal roller (Brinkman, 1980). The

764 pit is well-developed, as in Yacarerani boliviensis, Simosuchus clarki, Stratiotosuchus maxhechti, 
765 and Sebecus icaeorhinus, differing from the reduced depression of Baurusuchus albertoi (Sertich

766 \& Groenke, 2010; Nascimento \& Zaher, 2010; Riff \& Kellner, 2011; Pol et al., 2012; Leardi et

767 al., 2015b). The vascular foramina observed in other taxa, such as Baurusuchus albertoi,

768 Stratiotosuchus maxhechti, and Simosuchus clarki (Nascimento \& Zaher, 2010; Sertich \&

769 Groenke, 2010; Riff \& Kellner, 2011), are not present in Pissarrachampsa sera, nor in Sebecus

770 icaeorhinus (Pol et al., 2012).

771 The calcaneum of Pissarrachampsa sera is robust and mediolaterally developed, as in

772 Yacarerani boliviensis, Baurusuchus albertoi, Stratiotosuchus maxhechti, and Sebecus

773 icaeorhinus, differs from the mediolaterally compressed calcaneum of Araripesuchus

774 tsangatsangana and Uruguaysuchus aznarezi (Rusconi, 1932) (Turner, 2006; Nascimento \&

775 Zaher, 2010; Sertich \& Groenke, 2010; Riff \& Kellner, 2011; Pol et al., 2012; Leardi et al.,

776 2015b). It is formed by a cranial body, a socket for the reception of the astragalar peg, and the

777 caudally directed tuber (Brochu, 1992). As in other crocodyliforms, the cranial body in P. sera

778 contacts the astragalus, fibula, and possibly the fourth distal tarsal (Brinkman, 1980; Hecht \&

779 Tarsitano, 1984; Brochu. 1992; Sertich \& Groenke, 2010; Pol et al., 2012).

780 The cranial and proximal portions of the cranial body form a well-developed rounded

781 articular surface (a roller) that articulates medially with the astragalus and proximally with the

782 fibula. This morphology is widespread, also seen in living forms and other fossil crocodylians, as

783 Baurusuchus albertoi, Stratiotosuchus maxhechti, Sebecus icaeorhinus, Simosuchus clarki, and

784 Araripesuchus tsangatsangana (Brinkman, 1980; Turner, 2006; Sertich \& Groenke, 2010;

785 Nascimento \& Zaher, 2010; Riff \& Kellner, 2011; Pol et al., 2012). No ridge is present at the

786 articular surface of the roller, which in Simosuchus clarki separates the medial articulation area

787 for the astragalus and the lateral articulation area for the fibula (Sertich \& Groenke, 2010). This

788 rounded surface slopes abruptly cranioventrally, forming a distally directed surface, which

789 probably contacted the fourth distal tarsal. In Pissarrachampsa sera, this surface is flat and 
790 elliptical in distal view, resembling the condition in Stratiotosuchus maxhechti (Riff \& Kellner,

791 2011). The lateral portion of the cranial body forms a well-developed flat surface that lacks any

792 articular facet. This surface is proximodistally restricted and does not overcome the proximodistal

793 extension of the distal tuber. The medial face of the cranial body forms the calcaneal socket. Most

794 of the morphology of this area is not accessible due the articulation with the astragalus, but a faint

795 medial flange overhangs the calcaneal socket as in Simosuchus clarki (Sertich \& Groenke 2010).

796 The calcaneal tuber is caudally directed and sub-elliptical in caudal view, as in

797 Baurusuchus albertoi and Stratiotosuchus maxhechti (Nascimento \& Zaher, 2010; Riff \&

798 Kellner, 2011). The caudal surface of the tuber is orthogonal to the distal facet of the calcaneal

799 condyle, and is deeply concave, forming a slot for attachment of M. gastrocnemius (Brochu,

800 1992; Leardi et al., 2015b). The concavity divides the tuber into well-marked lateral and medial

801 ridges, as in Baurusuchus albertoi, Stratiotosuchus maxhechti, Sebecus icaeorhinus,

802 Araripesuchus tsangatsangana, and Simosuchus clarki (Turner, 2006; Riff \& Kellner, 2011;

803 Sertich \& Groenke, 2010; Pol et al., 2012). Unlike in Stratiotosuchus maxhechti, there is no

804 transversal ridge separating the caudal surface in proximal and distal areas (Riff \& Kellner,

805 2011). The lateral ridge is shorter than the medial one, as in Simosuchus clarki and

806 Uruguaysuchus aznarezi, whereas in other taxa (Baurusuchus albertoi, Stratiotosuchus

807 maxhechti, Sebecus icaeorhinus) both ridges are equally developed (Sertich \& Groenke, 2010;

808 Nascimento \& Zaher, 2010; Riff \& Kellner, 2011; Pol et al., 2012). The lateral ridge bears a

809 lateral tubercle, as in Yacarerani boliviensis, Sebecus icaeorhinus and Stratiotosuchus maxhechti

810 (Riff \& Kellner 2011; Pol et al., 2012; Leardi et al., 2015b). The tubercle extends laterodistally

811 and invades the lateral surface of the calcaneal tuber (Figure 10, E-F). A well-defined groove

812 flanks the medial side of the calcaneal tuber. This corresponds to the "medial channel" of Hecht

813 \& Tarsitano (1984). It expands proximolaterally in a shallow and wide surface that terminates

814 abruptly at the lateral edge of the calcaneum. A lateral groove also separates the distal articular 
815 surface of the cranial body from the calcaneum tuber, just medial to the lateral tubercle, as seen in

816 Simosuchus clarki (Sertich \& Groenke, 2010).

$817 \underline{\text { Pes }}$

818 Pissarrachampsa sera has three preserved pedes, the left pes of the holotype (LPRP/USP 0019)

819 and two referred (a left and a right) pedes (LPRP/USP 0739 and LPRP/USP 0746). The holotype

820 pes is represented by four articulated metatarsals (Figure 11, B), whereas LPRP/USP 0739

821 includes four isolated metatarsals, and LPRP/USP 0746 comprises four partially preserved

822 articulated digits (Figure 11, A). Metatarsal V is not preserved in any of the specimens of

823 Pissarrachampsa sera, following the trend of reduction of that metatarsal towards

824 Crocodylomorpha (Parrish, 1987). Therefore, the four metatarsals preserved in Pissarrachampsa

825 sera constitute the entire number of fully functional pedal digits, as in all living crocodylians and

826 most fossil crocodyliforms (Riff, 2007).

827 The metatarsals of Pissarrachampsa sera are longer than the metacarpals, as in

828 Baurusuchus albertoi, Araripesuchus tsangatsangana, Stratiotosuchus maxhetchi, Simosuchus

829 clarki and Yacarerani boliviensis (Turner, 2006; Nascimento \& Zaher, 2010; Sertich \& Groenke,

830 2010; Riff \& Kellner, 2011; Leardi et al., 2015b). Moreover, metatarsals II and III are slightly

831 longer than metatarsals I and IV, as in Baurusuchus albertoi and possibly in Yacarerani

832 boliviensis and S. maxhetchi (Nascimento \& Zaher, 2010; Riff \& Kellner 2011; Leardi et al.,

833 2015b). The proximal articular surfaces of the metatarsals are lateromedially expanded,

834 especially in their lateral margin. As a result, the proximal surface of each metatarsal overlaps the

835 medial portion of the proximal surface of the immediate lateral metatarsal (Figure 11 -

836 LPRP/USP 0746) as in Baurusuchus albertoi, Simosuchus clarki, and Stratiotosuchus maxhetchi

837 (Nascimento \& Zaher, 2010; Sertich \& Groenke, 2010; Riff \& Kellner, 2011). This morphology

838 is different from that of Araripesuchus tsangatsangana, in which a medial expansion of these 
839 surfaces underlies the proximal surface of the immediate medial metatarsal, and from Yacarerani

840 boliviensis, in which there is a medial expansion of the surface in each metatarsal that overlaps

841 the immediate medial metatarsal (Turner, 2006; Leardi et al., 2015b). The distal articular surfaces

842 are divided by a groove in the medial and lateral condyles, as in Simosuchus clarki, Baurusuchus

843 albertoi and Stratiotosuchus maxhechti (Nascimento \& Zaher, 2010; Sertich \& Groenke, 2010;

844 Riff \& Kellner, 2011).

845 Only LPRP/USP 0746 preserves articulated phalanges (Figure 11, A), but the phalangeal

846 formula cannot be assessed. The phalanges have a blocky appearance and a constriction between

847 the expanded proximal and distal ends, as in Simosuchus clarki, Baurusuchus albertoi,

848 Stratiotosuchus maxhechti, and Araripesuchus tsangatsangana (Turner, 2006; Nascimento \&

849 Zaher, 2010; Sertich \& Groenke, 2010; Riff \& Kellner, 2011). The proximal phalanges preserved

850 in LPRP/USP 0746 are relatively longer than those preserved in the right manus of the holotype

851 (both hands are similar in size), a pattern described for both Baurusuchus albertoi and

852 Stratiotosuchus maxhechti (Nascimento \& Zaher, 2010; Riff \& Kellner, 2011). Also, the proximal

853 phalanges preserved in LPRP/USP 0746 are longer than the preserved more distal phalanges, as

854 in Baurusuchus albertoi, Araripesuchus tsangatsangana, and S. maxhetchi (Turner, 2006;

855 Nascimento \& Zaher, 2010; Riff \& Kellner, 2011).

856 Aside from the articulated phalanges of LPRP/USP 0746, three disarticulated pedal

857 ungual phalanges were found associated with the holotype skeleton (Figure 11, C). They decrease

858 in size from the first to the third digit, as in Baurusuchus albertoi, Stratiotosuchus maxhechti,

859 Uberabasuchus terrificus and living crocodylians (Müller \& Alberch, 1990; Vasconcellos, 2006;

860 Riff, 2007; Nascimento \& Zaher, 2010). They form curved claws, with a robust base, and bear

861 foramina in both lateral and medial surfaces, as also present in Baurusuchus albertoi and,

862 possibly, in Araripesuchus tsangatsangana (Turner, 2006; Nascimento, 2008; Nascimento \&

863 Zaher, 2010). 


\section{Results and discussion}

865 Body size and mass estimates of Pissarrachampsa sera

866 The preserved elements of the holotype (LPRP/USP 0019), particularly the femora, allow

867 estimating the body size and mass of Pissarrachampsa sera. Based on the protocol presented by

868 Farlow et al. (2005), we estimated that Pissarrachampsa sera had a total length varying between

8692.7 and 3.5 meters, and a body mass between 81 and 163 kilograms (for detailed results see

870 Supplemental Information). This significant variation is also observed in estimates for other

871 terrestrial crocodyliforms, such as Protosuchus and Sebecus (Farlow et al., 2005; Pol et al.,

872 2012). The regressions of Farlow et al. (2005) were built with data from Alligator

873 mississippiensis, and might not be as accurate as desired for fossil taxa with different habits and

874 body proportions, as already pointed out by other works (e.g: Young et al., 2011; Pol et al., 875 2012).

876 Indeed, the comparison with nearly complete baurusuchid specimens permits assessing 877 the accuracy of these regressions for the group. Comparisons to more complete baurusuchids 878 such as the $1.9 \mathrm{~m}$ long specimen referred to Baurusuchus salgadoensis (lacking only the skull 879 and pectoral girdle), the $1.3 \mathrm{~m}$ long holotype of Baurusuchus albertoi (lacking the tip of tail and 880 snout), and the $1.1 \mathrm{~m}$ long holotype of Aplestosuchus sordidus (lacking the tail) (Nascimento, 881 2008; Vasconcellos \& Carvalho, 2010; Godoy et al., 2014) suggest that it is unlikely that any of 882 these specimens reached the maximum length estimated for Pissarrachampsa sera (3.49 m) using 883 the regressions. Further, after applying the formulas from Farlow et al. (2005) for Baurusuchus 884 albertoi and B. salgadoensis (both with femora well preserved), we obtained a total length of 885 approximately 3.8 meters for both taxa (see Supplemental Information). Even though not 886 completely preserved, this is evidence that, at least for baurusuchids, these regressions are 887 overestimating the size of the specimens. Additionally, in order to test the validity of the mass 
888 estimates obtained with the formulas from Farlow et al. (2005), we also applied the equations

889 presented by Campione \& Evans (2012), which uses proximal (stylopodial) limb bone

890 circumference to obtain total body mass, and seems to work well for many fossil taxa (e.g:

891 Castanhinha et al., 2013; Benson et al., 2014; Reisz \& Fröbisch, 2014). After applying the femur-

892 based equation, the mass estimate obtained for Pissarrachampsa sera was approximately 71

893 kilograms, lower than the lowest value obtained using Farlow et al. (2005) formulas.

894 Regardless of the incompleteness of specimens and inaccuracy of size estimates, it is very

895 likely that an adult individual of Pissarrachampsa sera reached at least 2 meters (Figure 12),

896 placing the taxon amongst the largest terrestrial predators of Late Cretaceous environments in

897 southeast Brazil, together with other baurusuchids and theropods (Riff \& Kellner, 2011; Godoy et

898 al, 2014). The Bauru Group rocks have provided numerous carnivorous crocodyliforms (e.g.:

899 Campos et al., 2001; Carvalho et al., 2005; Godoy et al., 2014), particularly baurusuchids, and 900 many titanosaur sauropods (e.g.: Kellner \& Azevedo, 1999; Salgado \& Carvalho, 2008; Santucci

901 \& Arruda-Campos, 2011), but very few theropods (Novas et al., 2008; Bittencourt \& Langer, 902 2011; Méndez et al., 2012; Azevedo et al., 2013). This has been used as evidence for the

903 rearrangement of roles in this paleoecosystem, with baurusuchids occupying the typical

904 ecological niche of theropods or at least competing for the same niche (Gasparini et al., 1993;

905 Candeiro \& Martinelli, 2006; Riff \& Kellner, 2011). However, although the morphology of

906 baurusuchids indicates a highly specialized predatory habit, similar to that of theropods, it seems

907 unlikely that even larger baurusuchids could have preyed on adult sauropods (>8-meter length for

908 some titanosaurs; Salgado \& Carvalho, 2008), if assumed as solitary predators. Although young

909 theropods could have had similar diets to baurusuchids, the morphological differences are also

910 indicative of distinct feeding (Martinelli et al., 2013). Indeed, this hypothesis is supported by the

911 single reliable and identifiable direct evidence of predation among baurusuchids, in which a small

912 sphagesaurid (Mesoeucrocodylia, Notosuchia) was found in the abdominal cavity of the 
913 holotypic skeleton of Aplestosuchus sordidus (Godoy et al., 2014). As such, if adult sauropods

914 had any predator in this Cretaceous ecosystem, theropods remain as the most likely ones, and the

915 scarcity of theropods might reflect incomplete or biased sampling. Accordingly, some niche

916 partitioning may have occurred, with baurusuchids preying on smaller animals, as well as young

917 or hatchling sauropods, and adult theropods being able to prey on larger individuals.

918 Terrestriality in Pissarrachampsa sera

919 A series of anatomical features have been recognized as related to the terrestrial habits of

920 Crocodyliformes, many of which are observed in the postcranial skeleton of Pissarrachampsa

921 sera. Most of these concern an upright posture and gait, with the limbs held under the body rather

922 than to the side as in extant crocodylians. A characteristic presumably linked to terrestriality is the

923 reduced space between articulated ulna and radius in Pissarrachampsa sera. Although

924 contrasting with the relatively large space in extant crocodylians, this pattern is also observed in

925 other baurusuchids, such as Stratiotosuchus maxhechti and Baurusuchus albertoi, as well as in

926 the terrestrial notosuchian Araripesuchus tsangatsangana (Brochu, 1992; Turner, 2006;

927 Nascimento \& Zaher, 2010; Riff \& Kellner, 2011). Similarly, the space between tibia and fibula

928 of Pissarrachampsa sera is also reduced. Further, the proximal portion of its tibia bears a well-

929 protruded medial facet that corresponds to the articulation with the tibial condyle of the femur.

930 The uneven proximal facets rotate the distal tibia laterally when in articulation with the femur.

931 Accordingly, both propodium and epipodium were arranged on the same long axis (in caudal or

932 cranial views), allowing a parasagittal movement of the leg during locomotion. This condition is

933 also seen in the terrestrial notosuchians Sebecus icaeorhinus and Simosuchus clarki (Sertich \&

934 Groenke, 2010; Pol et al., 2012). The proximal articulation facets of the tibia are caudally

935 separated by an excavated fossa flexoria, and cranially, by a large tuberosity for the insertion of

936 M. flexor tibialis internus. This is evidence of a tight/stable knee joint in agreement with an erect 
937 posture. Also, the distal tibial articulation of Pissarrachampsa sera is obliquely disposed, with a

938 more enlarged medial facet, as in Stratiotosuchus (Riff \& Kellner, 2011). Extant crocodylians, on

939 the other hand, bear equally developed distal ends (medial and lateral) of the tibia, allowing a

940 range of sprawling to semi-erect high walk (Brinkman, 1980; Parrish 1986; 1987; Gatesy, 1991).

941 This oblique articulation and the sharp distal end of the tibia fits tightly with the astragalus, and

942 can reduce the range of movements. But it also indicates a stable articulation with the foot,

943 allowing some lateral displacement, matching the medial displacement of the distal tibia,

944 denoting an upright posture. This is similar to the ankle articulation morphology seen in the

945 terrestrial sphenosuchians and protosuchians (Parrish, 1987), but it is also observed in more

946 closely-related taxa, as Araripesuchus tsangatsangana and Sebecus icaeorhinus.

947 Additionally, the less curved femur of P. sera, in comparison to that of living

948 crocodylians, is in accordance with a more erect posture. The faint curvature in this bone is

949 similiar to that seen in Stratiotosuchus maxhechti, for which a parasagittal posture was also

950 claimed (Riff \& Kellner, 2011). Hutchinson (2001b) argues that limb bones, such as the femur,

951 with a less accentuate curvature are subjected to bending stresses rather than torsional stresses.

952 That anatomical acquisition would then be related to a more erect posture and terrestrial habits in

953 the archosaurian lineage, whereas bones under torsional stresses, such as sigmoid femora, are

954 associated with forms with a sprawling posture. Still, some of features pointed out by Parrish

955 (1987) as linked to a parasagittal posture in archosaurians are also observed in Pissarrachampsa

956 sera, such as a well-developed and medially inturned femoral head, prominent caudally oriented

957 femoral condyles, and a conspicuous fibular condyle (or lateral condyle). Further, the femur

958 orientation is compatible with the morphology of the ilium of $P$. sera. The laterally projected and

959 enlarged supraacetabular crest would make it impossible for the femur to be strictly laterally

960 oriented (Riff \& Kellner, 2011), but would be compatible with a vertical orientation of a

961 parasagital posture. Still in the pelvic girdle, Pissarrachampsa sera possess a tubercle on the 
962 lateral surface of the ischium, located in the attachment area of M. pubioischiotibialis. Riff \&

963 Kellner (2011) pointed out that this tubercle is absent in extant forms, and its big size in

964 Stratiotosuchus, similar to the morphology observed in P. sera, can indicate that this muscle was

965 more developed in the baurusuchids. Indeed, Reilly \& Blob (2003) show that, in Alligator, this

966 muscle is activated during the "high-walk" locomotion mode, which is compatible with the

967 interpretation of Riff \& Kellner (2011) suggesting that a greater development of the $M$.

968 pubioischiotibialis is compatible with a permanent parasagital posture, more related to a 969 terrestrial lifestyle.

The lack of osteoderms in Pissarrachampsa sera

971 Pissarrachampsa sera is represented by a series of specimens all from the same locality. The

972 specimens range from the relatively complete and fairly articulated holotype to isolated

973 fragmentary cranial and postcranial elements. So far, no osteoderm was found associated with

974 these specimens, neither elsewhere in the type locality. This raises the question whether the lack

975 of osteoderms represents a taphonomic signature or a genuine anatomical feature of the taxon. In

976 the latter case, Pissarrachampsa sera would be the first terrestrial crocodyliform to completely

977 lack any body armor, with biomechanical implications to be explored.

978 The specimens of Pissarrachampsa sera were collected without rigorous taphonomic

979 control, but there is geological and paleontological evidence that supports the absence of

980 osteoderms as unrelated to taphonomy. The type locality of $P$. sera is assigned to the Adamantina

981 Formation and the deposition of this geological unity is associated with arid to semi-arid

982 conditions (Fernandes \& Coimbra, 1996; 2000; Batezelli, 2015). In the same way, the local

983 geology suggests a developed paleosol profile that is also indicative of arid to semi-arid

984 conditions (Marsola et al., in prep). In this scenario, the prolonged periods without sedimentation

985 lead to erosion and pedogenesis. Furthermore, well-preserved and complete crocodyliform egg 
986 clutches are found in the same levels of the body fossils of Pissarrachampsa sera (Marsola et al.,

987 2011). Crocodyliform eggs are particularly fragile to long-range transport (Grellet-Tinner et al.,

988 2006; Hayward et al., 2000), whereas the skeletal elements of $P$. sera do not show significant

989 signs of abrasion caused by transport (Montefeltro et al., 2011). Therefore, the decay and burial

990 of the P. sera remains most likely occurred in a low-energy, probably sub-aerial environment.

991 Araújo-Junior \& Marinho (2013) analyzed the taphonomy of one specimen of

992 Baurusuchus pachecoi from the same formation, collected in Jales (São Paulo, Brazil), which

993 matches the putative pre-burial conditions experienced by Pissarrachampsa sera. In that study,

994 osteoderms were found close to their in vivo position, even after being exposed to some degree of

995 scavenging and sub-aerial decay. A similar pattern of osteoderm disarticulation was found by

996 Beardmore et al. (2012) for the marine crocodyliform Steneosaurus (Geoffroy Saint-Hilaire,

997 1825), from the Posidonienschiefer Formation (Lower Jurassic, Germany), which decayed and

998 were buried in a quiet-water, marine basin. In that case, osteoderms are placed close to the

999 carcass even in specimens with greater degree of disarticulation. The same pattern is seen in

1000 actualistic taphonomic experiments in juvenile Crocodylus porosus (Schneider, 1801), in which

1001 the osteoderms remain at the vicinity of the carcass even with relatively prolonged subaerial and

1002 subaqueous decay (Syme \& Salisbury, 2014, Figure 6). In fact, a series of fossil crocodyliforms,

1003 both close and distantly related to Pissarrachampsa sera, are recovered with associated

1004 osteoderms, even showing a relatively advanced degree of disarticulation, as. Susisuchus

1005 anatoceps (Salisbury et al., 2003), Candidodon itapecuruense (Carvalho \& Campos, 1988)

1006 (Nobre, 2004), Simosuchus clarki (Krause et al., 2010), Alligatorellus (Gervais, 1871) (Schwarz-

1007 Wings et al., 2011), Wannchampsus kirpachi (Adams, 2014), Diplocynodon (Pomel, 1847)

1008 (Hastings \& Hellmund, 2015), and Caipirasuchus montealtensis (Andrade \& Bertini, 2008) (Iori

1009 et al., 2016). We took into consideration the possibility that Pissarrachampsa sera had its

1010 osteoderms disarticulated earlier in the decay process. This is possible and is supported by 
1011 specimens of closely-related notosuchians with fairly articulated postcrania but lacking 1012 osteoderms, such as Mariliasuchus amarali (UFRJ-DG-50-R), Notosuchus terrestris (MUCPv1013 137), Sebecus icaeorhinus (Pol et al., 2012). However, in the particular case of P. sera we regard 1014 this as unlikely, given the complete absence of these elements in the entire outcrop and the 1015 number of specimens recovered. Therefore, in light of all evidence we suggest the lack of 1016 osteoderms is an inherent and diagnostic feature of Pissarrachampsa sera. Desojo, 2011), as these structures are found in most pseudosuchians (Brown, 1933; Wu \& Chatterjje, 1993; Clark \& Sues, 2002; Sues et al., 2003; Pol \& Norell, 2004; Clark, 2011; Nesbitt, 2011; Scheyer \& Desojo, 2011). Likewise, this ancestral condition is inferred for most internal nodes of Crocodyliformes, which bear at least one pair of parasagittal rows forming the body armor (Salisbury \& Frey, 2001; Frey \& Salisbury, 2001; Hill, 2005; Pierce \& Benton, 2006; Jouve et al., 2006; Marinho \& Carvalho 2009; Pol et al., 2009; Hill, 2010; Andrade et al., 2011; Pol et al., 2012; Nobre \& Carvalho, 2013; Tennant \& Mannion, 2014). The only exception known so far is the complete absence of osteoderms in the marine metriorhynchids, a feature probably associated with their aquatic lifestyle (Young et al., 2010; 2013; Molnar et al., 2015). Similarly, metriorhynchids do not have palpebral bones roofing the orbits (Nesbitt et al., 2012), and previous analyses of the crocodylian skeletogenesis show that postcranial osteoderms match the palpebral development (Vickaryous \& Hall, 2008). In this case, it might have been a common cause underlying the successive loss of the palpebrals and postcranial osteoderms in Thalattosuchia and Metriorhynchidae. is related to an increasing aquatic adaptation in this group, whereas the rigid series of osteoderms 1034 of early crocodylomorphs would be related to terrestrial habits. In this scenario, the presence of 1035 non-imbricate osteoderms in basal thalattosuchians (Teleosauridae) and the more flexible 
1036 arrangement of these structures in the extant semi-aquatic forms would represent intermediate 1037 stages (Salisbury \& Frey, 2001; Molnar et al., 2015). The presence of one pair of parasagittal 1038 rows of oval osteoderms is considered a plesiomorphic state for Baurusuchidae, as all specimens 1039 previously described with postcranial remains exhibit this pattern (Nascimento \& Zaher, 2010; 1040 Vasconcellos \& Carvalho, 2010; Araújo-Júnior \& Marinho, 2013; Godoy et al., 2014). The 1041 osteoderms of these forms (e.g.: Aplestosuchus sordidus) barely imbricate and are not sutured to 1042 their counterparts, which might represent an intermediate condition towards the total lack of 1043 osteoderms seen in $P$. sera. The phylogenetic position of $P$. sera among Pissarrachampsinae, as 1044 well as its smaller size when compared to Baurusuchinae, lead to two possible underlying factors 1045 for the absence of body armor in this taxon. It could be assigned as a synapomorphy of 1046 Pissarrachampsinae and interpreted as a historical factor, also implying the absence in other 1047 members of the clade, for which we still do not have information (Campinasuchus dinizi and 1048 Wargosuchus australis). Alternatively, if the absence of osteoderms is confirmed in the other 1049 smaller and early-diverging taxa, Cynodontosuchus rothi (Woodward, 1896) and 1050 Gondwanasuchus scabrosus (Marinho et al., 2013), this condition could be linked to the reduced 1051 size of the taxa.

1052 Yet, in both scenarios, the complete absence absence of osteoderms in $P$. sera and the 1053 reduction of the body armor in other baurusuchids had biomechanical implications, with the 1054 osteoderms in other baurusuchids possibly playing a diminutive role in the bracing system and in 1055 the sustained terrestrial locomotion of these animals. This is different from what is inferred for 1056 other terrestrial Crocodylomorpha such as "sphenosuchians" and the peirosaurids, in which the 1057 osteoderms played an important role in the bracing system and sustained erect locomotion 1058 (Salisbury \& Frey, 2001; Molnar et al., 2015; Tavares et al., 2015). One exception to the general 1059 pattern is the absence of osteoderms in the "sphenosuchian" Junggarsuchus sloani (Clark et al., 1060 2004). This assertion is supported by the reduced transverse process and the verticalized 
1061 zygapophyses which imply a bracing system not compatible to the extant forms (Salisbury \& 1062 Frey, 2001). The preserved vertebrae in $P$. sera belong to caudal-dorsal postion therefore not 1063 overlapping the more cranial vertebrae preserved in Junggarsuchus sloani (Clark et al., 2004).

1064 However, the vertebrae of $P$. sera also have more verticalized zygapophyses suggesting reduced 1065 undulating lateral movements in both taxa. On the other hand, the transverse process preserved in 1066 P. sera is expanded and more similar to the extant forms than to Junggarsuchus sloani (Salisbury 1067 \& Frey, 2001; Clark et al., 2004, Molnar et al., 2015). An expanded transverse process is also 1068 present in caudal-dorsal vertebrae of metriorhynchids (Young et al., 2013, Molnar et al., 2015). 1069 Accordingly, there is no perfect correlation between the occurrence of expanded transverse 1070 process and presence of osteoderms in crocodyliforms. In light of the evidence, we suggest that 1071 Baurusuchidae in general, and P. sera in particular, acquired a unique bracing system with little 1072 or no participation of the osteoderms in the sustained erect locomotion.

1073 Phylogenetic analysis and the significance of postcranial characters in Crocodyliformes 1074 phylogeny

1075 Here, for the first time, the postcranial data for Pissarrachampsa sera was included in a 1076 phylogenetic analysis. This resulted in scoring a total of 34 additional characters (see the 1077 Supplemental Information) for the taxon in the data matrix presented by Leardi et al. (2015a), 1078 which is the most recent work including a substantial amount of postcranial characters. The 1079 resulting data matrix (439 characters and 111 taxa) was analysed in TNT (Goloboff et al., 2008a; 1080 2008b) via heuristic searches under the following parameters: 10000 replicates of Wagner Trees, 1081 hold 10, TBR (tree bi-section and reconnection) for branch swapping, and collapse of zero length 1082 branches according to "rule 1" of TNT (min.length= 0). The result of our analysis (Supplemental 1083 Information) was exactly that presented by Leardi et al. (2015a), and all the clades are supported 1084 by the same set of synapomorphies as in the original study. 
1086 anatomy for the phylogenetic relationships of crocodyliforms based on the data matrix used in 1087 this study. We created two subsets of the original matrix, one using only cranial characters (315 1088 characters), and another solely with postcranial characters (124 characters). As some of the taxa 1089 in this dataset do not have either cranial or post-cranial data, we performed an extra "control 1090 analysis" including only taxa for which elements of both subsets of the skeleton are scored. This 1091 "control analysis" was performed to test whether simply removing taxa caused an impact on the 1092 overall relationships between taxa. A total of 39 taxa (all from the ingroup) were excluded 1093 following this criteria (Supplemental Information), and the 72 remaining taxa were used in the 1094 two exploratory analyses.

1096 (Figure 13) is consistent with that of the original dataset. A single difference in the branching 1097 pattern is that the "protosuchians" are less resolved than in the original dataset, but a fully 1098 compatible structure is recovered for Mesoeucrocodylia. In the basal dichotomy of this clade, one 1099 of the branches leads to Notosuchia, including Uruguaysuchidae, Peirosauridae, and Ziphosuchia, 1100 with the latter containing Baurusuchidae and Sebecidae. The other branch leads to Neosuchia, 1101 including a clade containing the longirostrine forms (Tethysuchia + Thalattosuchia) and another clade including Atoposauridae, Goniopholididae and Eusuchia. Thus, this result indicates that the deletion of the 39 taxa did not have a significant impact on the inferred relationships.

1105 great number of polytomies and is similar to the original complete analysis (Leardi et al., 2015a), even the arrangement of "protosuchians" (Figure 14), but there are important discrepancies. One is related to the paraphyletic arrangement of taxa retrieved as members of the Notosuchia clade in 1108 the original and control analyses. Some clades within Notosuchia (sensu Pol et al., 2012; 2014; 1109 Leardi et al., 2015a; b), such as Sphagesauridae, Uruguaysuchidae, and Baurusuchidae, are still 
1110 grouping in a more inclusive clade, but sebecids and peirosaurids are more closely related to

1111 neosuchians than to other notosuchians. Still, a monophyletic Sebecia (Peirosauridae +

1112 Sebecidae) is recovered in this exploratory analysis, recovering a pattern proposed by previous

1113 works (Larsson \& Sues, 2007; Montefeltro et al., 2013). The clade Sebecia was supported by

1114 anatomical similarities of the palate of both peirosaurids and sebecids, which in the absence of

1115 postcranial characters, favour the recovery of this relationship.

1116 Additional differences are in the internal relationships of Neosuchia. Despite the presence

1117 of monophyletic Goniopholididae, Tethysuchia, Thalattosuchia, and Atoposauridae, substantial

1118 changes are noted, as Eusuchia is paraphyletically arranged in relation to Tethysuchia +

1119 Thalattosuchia. The recovery of the clade encompassing Tethysuchia and Thalattosuchia probably

1120 reflects the major modifications on the skull of longirostrine forms belonging to these groups.

1121 The results were very different when the analysis was conducted only with postcranial

1122 characters. The strict consensus is poorly resolved (Supplemental Information). A strict consensus

1123 tree with low resolution can occur for distinct reasons, such as conflicts related to the numerous

1124 taxa with a reduced number of scored characters (missing data) and/or to the scarcity of

1125 overlapping elements among taxa (e.g.: various specimens have few elements preserved), or still

1126 to a high ratio of conflicting information. To evaluate the causes of conflict in the postcranial

1127 dataset we ran an analysis using the TNT script IterPCR (Pol \& Escapa, 2009). The results

1128 (Supplemental Information) indicate that the main cause of conflict in this dataset is missing data.

1129 Results show that for 25 unstable taxa (out of 35) the instability is caused by missing data. Thus,

1130 for only 10 of these 35 the instability is related to both missing data and conflicting information

1131 among different characters (i.e. character states of distinct characters indicating alternative and

1132 controversial positons). Accordingly, in order to better explore the data, we pruned the most

1133 unstable taxa of the MPT's of this analysis by using the command pcrprune in TNT (Goloboff \&

1134 Szumik, 2015). 

taxonomic content as in the original analysis (i.e. including peirosaurids, uruguaysuchids and ziphosuchians). However, the relationship between peirosaurids and uruguaysuchids, as well as among some other notosuchians, differ from the original results (Leardi et al., 2015a). Yet, the importance of postcranial morphology to support the affinities of peirosaurids to notosuchians is strengthened, following previous evidences presented by Pol et al. (2012; 2014). Also, the

1141 presence of a monophyletic Notosuchia illustrates the peculiarity of the notosuchian postcranial anatomy, which could be related to the emergence of a new terrestrial lifestyle, different from 1143 other terrestrial crocodyliforms, such as the "protosuchians". Further, the results of the analyses 1144 using only the postcranial information show that some "protosuchians" are found together with 1145 the notosuchians, in a clade with only terrestrial forms (the only exception being Leidyosuchus 1146 and the affinity of this taxa to the terrestrial forms is derived from characters based on osteoderm anatomy). The Thalattosuchia clade is also recovered in this analysis, illustrating the peculiar 1148 postcranial anatomy of these taxa linked to a fully aquatic lifestyle. Another clade recovered 1149 includes semi-aquatic crocodyliforms (the only exception being Shamosuchus), including goniopholidids and eusuchians, but their relations largely deviate from the "control analysis". relationships (i.e. those that appear in the control and original analyses but not in the analysis with cranial characters only), such as the affinity of peirosaurids and uruguaysuchids to 1155 Notosuchia, the monophyly of sebecosuchia (in the context of the original dataset used here). However, the general arrangement is still determined by characters related to the skull. Finally, we do not consider that the results presented here reflect the inability of 1158 postcranial data to illustrate the evolutionary history of the group. Indeed, we consider this is 1159 influenced by historical factors associated with the study of fossil crocodyliforms. Descriptions 
1160 are usually based on skulls; postcranial elements are neglected, sometimes never described or

1161 mentioned in the descriptive works. However, the postcranium may play a bigger role in

1162 phylogenetic studies, as Crocodyliformes range from fully terrestrial animals to semi-aquatic and

1163 fully marine forms, and this diversity in lifestyle leads to different postcranial morphologies (e.g.:

1164 Riff \& Kellner, 2011; Molnar et al., 2015). Indeed, our exploratory analysis performed only with

1165 postcranial characters recovered three clades mainly representative of three different lifestyles (a

1166 "terrestrial" clade, a "semi-aquatic" clade, and a "marine" clade). However, the different

1167 homoplasy indexes show that this grouping is probably not a result of convergent events. The

1168 Rescaled Consistency Index (RCI - Farris, 1989) for the analysis with postcranial characters is

11690.37 , higher than those for the analyses with cranial characters (0.28), the control analysis $(0.28)$,

1170 or the original analysis (0.22). A direct comparison of these values might be misleading, as

1171 different datasets exhibit particularities that could influence the results. For example, the higher

1172 RCI value for the postcranial dataset could result from the high percentage of missing data, as

1173 data of this nature cannot be homoplasious (71\% in the postcranial dataset, against 37\% in the

1174 cranial dataset, 47\% in the control dataset, and 55\% in the original dataset). On the other hand,

1175 this great number of missing data in the postcranial data set also suggests that there is still much

1176 to explore on the postcranial anatomy of Crocodyliformes, as the amount of missing data is not

1177 only related to the absence of preserved materials but also because studies describing

1178 postcranium are scarce. In this way, future work, describing more postcranial elements and

1179 proposing more characters based on this type of data will show if the phylogeny of

1180 Crocodyliformes is truly "skull-based" or merely "skull-biased".

\section{Conclusions}

1182 The study of the postcranial skeleton of Pissarrachampsa sera allowed the recognition of some

1183 exclusive features of this taxon in the context of Baurusuchidae, such as the short and sharp crest 
1184 at the craniolateral margin of the distal tibial expansion, the raised and proximodistally elongated

1185 iliofibularis trochanter of the fibula, and the more proximally placed contact between the fibular 1186 distal hook and the tibia. Also, some features related to a terrestrial lifestyle were identified, as

1187 the reduced interosseous space between both radio-ulna and tibia-fibula, the tubercle in the lateral 1188 surface of the ischium, as well as a well-protruded medial facet and a well-excavated fossa 1189 flexoria in the tibia.

1190 An important feature is the complete absence of osteoderms in Pissarrachampsa sera, the 1191 first suggested for a terrestrial crocodyliform. This complete loss of body armor was previously 1192 known only for metriorhynchids, which have extreme adaptations for a fully marine habit. In this 1193 scenario, osteoderms probably played a minor role in locomotion of terrestrial baurusuchids, with 1194 their complete absence in Pissarrachampsa sera representing the endpoint of this trend in the 1195 group. Further, the body size and mass estimations indicate that $P$. sera was a large predator in 1196 the terrestrial ecosystems of the Bauru Group, but it is unlikely that it fed on adult sauropods also 1197 present at this stratigraphic unit.

1198 Finally, our exploratory phylogenetic analyses indicate that, at least for the matrix used in 1199 this study, crocodyliform relationships are determined primarily by skull characters. However, 1200 this is more likely a consequence of the high percentage of missing data in the postcranial data set 1201 and not of the inability of this data to reflect the evolutionary history of Crocodyliformes.

1202 Supplemental Information

1203 Supplemental Information

1204 Body size and mass estimations and details of the phylogenetic analyses.

1205 Phylogenetic matrices 
1206 Matrices used for the phylogenetic analyses in this study, including the exploratory analyses 1207 (nexus format) and the results from the IterPCR script.

\section{Institutional Abbreviations}

1209 AMNH, American Museum of Natural History, New York, USA.

1210 CPPLIP, Centro de Pesquisas Paleontológicas Llewellyn Ivor Price, Peirópolis, Uberaba, Brazil.

1211 FMNH, Field Museum of Natural History, Chicago, Illinois, USA.

1212 DGM, Museu de Ciências da Terra, Departamento Nacional de Produção Mineral (DNPM), Rio

1213 de Janeiro, Brazil.

1214 IVPP, Institute of Vertebrate Paleontology and Paleoanthropology, Chinese Academy of

1215 Sciences, Beijing, China.

1216 LPRP/USP, Laboratório de Paleontologia de Ribeirão Preto, Universidade de São Paulo;

1217 Ribeirão Preto, Brazil.

1218 MACN, Museo Argentino de Ciencias Naturales, Buenos Aires, Argentina.

1219 MUCP, Museo de Geología y Paleontología, Universidad Nacional del Comahue, Neuquén,

1220 Argentina.

1221 MZSP, Museu de Zoologia da Universidade de São Paulo, São Paulo, Brazil.

1222 NHMUK, Natural History Museum, London, UK.

1223 SAM, Iziko-South African Museum, Cape Town, South Africa.

1224 UA, University of Antananarivo, Antananarivo, Madagascar.

1225 UCMP, University of California Museum of Paleontology, Berkeley, USA.

1226 UFRJ, Museu de Paleontologia e Estratigrafia, Universidade Federal de Rio de Janeiro, Rio de

1227 Janeiro, Brazil.

1228 UFU, Universidade Federal de Uberlândia, Uberlândia, Brazil. 


\section{Acknowledgements}

1230 We thank the staff of the Laboratório de Paleontologia de Ribeirão Preto (Universidade de São

1231 Paulo), specially Elisabete Gimenes Dassie, for the help with screening of specimens. We also

1232 thank Maíra Massarani that made part of the excavation crew. Access to comparative fossil

1233 specimens was possible thanks to Carl Mehling and Mark Norell (AMNH), Thiago Marinho

1234 (CPPLIP), Douglas Riff (UFU), William Simpson (FMNH), Rodrigo da Rocha Machado (DGM),

1235 Stella Alvarez and Alejandro Kramarz (MACN), Lorna Steel (NHMUK), Sheena Kaal (SAM),

1236 Patricia Holroyd and Kevin Padian (UCMP), and Liu Jun, Corwin Sullivan, and Zheng Fang

1237 (IVPP). Thorough reviews by Agustin Martinelli, James Clark, and Diego Pol greatly improved

1238 the final manuscript. This contribution used TNT v.1.1, a program made freely available thanks to 1239 a subsidy by the Willi Hennig Society.

\section{References}

Adams T. 2014. Small crocodyliform from the Lower Cretaceous (Late Aptian) of Central Texas and its systematic relationship to the evolution of Eusuchia. Journal of Paleontology 88:1031-1049. 10.1666/12-089

Andrade MB, Bertini RJ. 2008. A new Sphagesaurus (Mesoeucrocodylia: Notosuchia) from the Upper Cretaceous of Monte Alto City (Bauru Group, Brazil), and a revision of the Sphagesauridae. Historical Biology, 20: 101-136.

Andrade MB, Edmonds R, Benton MJ, Schouten R. 2011. A new Berriasian species of Goniopholis (Mesoeucrocodylia, Neosuchia) from England, and a review of the genus Zoological Journal of the Linnean Society 163:S66-S108. 10.1111/j.10963642.2011.00709.x

Araújo-Júnior H, Marinho T. 2013. Taphonomy of a Baurusuchus (Crocodyliformes, Baurusuchidae) from the Adamantina Formation (Upper Cretaceous, Bauru Basin), Brazil: 
1253

1254

1255

1256

1257

1258

1259

1260

1261

1262

1263

1264

1265

1266

1267

1268

1269

1270

1271

1272

1273

1274

1275

1276

1277

Implications for preservational modes, time resolution and paleoecology. Journal of South American Earth Sciences 47:90-99. 10.1016/j.jsames.2013.07.006

Azevedo RPF, Simbras FM, Furtado MR, Candeiro CRA, Bergqvist LP. 2013. First brazilian carcharodontosaurid and other new theropod dinosaur fossils from the CampanianMaastrichtian Presidente Prudente Formation, São Paulo State, southeastern Brazil. Cretaceous Research 40:131-142. 10.1016/j.cretres.2012.06.004

Bailleul AM, Scannella JB, Horner JR, Evans DC. 2016. Fusion patterns in the skulls of modern archosaurs reveal that sutures are ambiguous maturity indicators for the Dinosauria. PLoS ONE 11 e0147687. 10.1371/journal.pone.0147687

Batezelli A. 2010. Arcabouço tectono-estratigráfico e evolução das bacias Caiuá e Bauru no Sudeste brasileiro. Brazilian Journal Geology 40:265-285.

Batezelli A. 2015. Continental systems tracts of the Brazilian Cretaceous Bauru Basin and their relationship with the tectonic and climatic evolution of South America. Basin Research:1-25. 10.1111/bre. 12128

Beardmore SR, Orr PJ, Manzocchi T, Furrer H. 2012. Float or sink: modelling the taphonomic pathway of marine crocodiles (Mesoeucrocodylia, Thalattosuchia) during the death-burial interval. Palaeobiodiversity and Palaeoenvironments 92:83-98. 10.1007/s12549-011-0066-0

Benson RB, Campione NE, Carrano MT, Mannion PD, Sullivan C, Upchurch P, Evans DC. 2014. Rates of dinosaur body mass evolution indicate 170 million years of sustained ecological innovation on the avian stem lineage. PLoS Biology 12 e1001853. 10.1371/journal.pbio.1001853

Benton M, Clark JM. 1988. Archosaur phylogeny and the relationships of the Crocodylia. In: Benton M, ed. The Phylogeny and Classification of the Tetrapods, Oxford: Clarendon Press, 295-338. 
1278 Bittencourt JS, Langer MC. 2011. Mesozoic dinosaurs from Brazil and their biogeographic 1279 implications. Anais da Academia Brasileira de Ciências, 83: 23-60. 10.1590/S000137652011000100003

Brinkman D. 1980. The hind limb step cycle of Caiman sclerops and the mechanics of the crocodile tarsus and metatarsus. Canadian Journal of Zoology 464:1-23. 10.1139/z80-301

Brochu CA. 1992. Ontogeny of the postcranium in crocodylomorph archosaurs. MSc Thesis, The University of Texas.

Brochu CA. 1996. Closure of neurocentral sutures during crocodilian ontogeny; implications for maturity assessment in fossil archosaurs. Journal of Vertebrate Paleontology 16:49-62. 10.1080/02724634.1996.10011283

Bronzati M, Montefeltro FC, Langer MC. 2012. A species-level supertree of Crocodyliformes. Historical Biology 24:598-606. 10.1080/08912963.2012.662680

Bronzati M, Montefeltro FC, Langer MC. 2015. Diversification events and the effects of mass extinctions on Crocodyliformes evolutionary history. Royal Society Open Science, 2: 140385. 10.1098/rsos.140385

Brown B. 1933. An ancestral crocodile. American Museum Novitates 638:1-4.

Buckley GA, Brochu CA. 1999. An enigmatic new crocodile from the Upper Cretaceous of Madagascar. Cretaceous Fossil Vertebrates: Special Papers in Paleontology 60:149-175.

Buckley GA, Brochu CA, Krause DW, Pol D. 2000. A pug-nosed crocodyliform from the Late Cretaceous of Madagascar. Nature 405:941-944. 10.1038/35016061

Campione NE, Evans DC. 2012. A universal scaling relationship between body mass and proximal limb bone dimensions in quadrupedal terrestrial tetrapods. BMC Biology, 10: 1-21 $10.1186 / 1741-7007-10-60$ 
1301 Campos DA, Suarez JM, Riff D, Kellner AWA. 2001. Short note on a new Baurusuchidae

1302 (Crocodyliformes, Metasuchia) from the Upper Cretaceous of Brazil. Boletim do Museu $1303 \quad$ Nacional 57:1-8.

1304 Candeiro CRA, Martinelli AG. 2006. A review of paleogeographical and chronostratigraphical 1305 distribution of mesoeucrocodylian species from the upper Cretaceous beds from the Bauru 1306 (Brazil) and Neuquén (Argentina) groups, Southern South America. Journal of South American Earth Sciences, 22: 116-129. 10.1016/j.jsames.2006.08.001

Carvalho IS, Bertini RJ. 1999. Mariliasuchus, um novo Crocodylomorpha (Notosuchia) do Cretáceo da Bacia Bauru, Brasil. Revista Geologia Colombiana, 24:83-105.

Carvalho IS, Campos DA. 1988. Um mamífero triconodonte do Cretáceo Inferior do Maranhão, Brasil. Anais de Academia Brasileira de Ciências, 60:437-446.

Carvalho IS, Campos ACA, Nobre PH. 2005. Baurusuchus salgadoensis, a new crocodylomorpha from the Bauru Basin (Cretaceous), Brazil. Gondwana Research, 8:11-30.

Castanhinha R, Araújo R, Júnior LC, Angielczyk KD, Martins GG, Martins RM, Chaouiya anatomy of a new emydopoid genus from the Upper Permian of Mozambique. PLoS ONE 8 e80974. 10.1371/journal.pone.0080974

Chatterjee S. 1978. A primitive parasuchid (phytosaur) from the Upper Triassic Maleri Formation of India. Palaeontology 21:83-127.

Chatterjee S. 1982. Phylogeny and classification of thecodontian reptiles. Nature 295:317-320. doi:10.1038/295317a0

Clark J. 2011. A new shartegosuchid crocodyliform from the Upper Jurassic Morrison Formation of western Colorado. Zoological Journal of the Linnean Society 163:S152-S172. 10.1111/j.1096-3642.2011.00719.x 
1325 Clark JM, Xu X, Forster CA, Wang Y. 2004. A Middle Jurassic ‘sphenosuchian’ from China 1326 and the origin of the crocodylian skull. Nature: 430: 1021-1024.

1327

1328

1329

1330

1331

1332

1333

1334

1335

1336

1337

1338

1339

1340

1341

1342

1343

1344

1345

1346

1347

1348

1349

Clark J, and Sues H. 2002. Two new basal crocodylomorph archosaurs from the Lower Jurassic and the monophyly of the Sphenosuchia. Zoological Journal of the Linnean Society 136:7795. 10.1046/j.1096-3642.2002.00026.X

Colbert EH, Mook CC. 1951. The ancestral crocodilian Protosuchus. Bulletin of the American Museum of Natural History 97:149-182.

Crush PJ. 1984. A late Upper Triassic sphenosuchid crocodilian from Wales. Palaeontology 27:131-157.

Daudin FM. 1802. Histoire naturelle, générale et particulière des reptiles. Tome Second. Paris: Dufart, pp. 432.

Dolgopol de Sáez MD. 1928. Un nuevo goniofolido Argentino. Anales de la Sociedad Científica Argentina, 105:287-290

Farlow JO, Hurlburt GR, Elsey RM, Britton AR, Langston Jr, W. 2005. Femoral dimensions and body size of Alligator mississippiensis: estimating the size of extinct mesoeucrocodylians. Journal of Vertebrate Paleontology 25:354-369. 10.1671/02724634(2005)025[0354:FDABSO]2.0.CO;2

Farris JS. 1989. The retention index and the rescaled consistency index. Cladistics 5:417-419. 10.1111/j.1096-0031.1989.tb00573.x

Fernandes LA. 2004. Mapa litoestratigráfico da parte oriental da Bacia Bauru (PR, SP, MG), escala 1:1.000.000. Boletim Paranaense de Geociências 55.

Fernandes LA, Coimbra AM. 1996. A Bacia Bauru (Cretáceo Superior, Brasil). Anais da Academia Brasileira de Ciências 68:105-195.

Fernandes LA, Coimbra AM. 2000. Revisão estratigráfica da parte oriental da Bacia Bauru (Neocretáceo). Revista Brasileira de Geociências 30:717-728. 
1350 Fernandes LA, Magalhães Ribeiro CM. 2014. Evolution and palaeoenvironment of the Bauru

1351

1352

1353

1354

1355

1356

1357

1358

1359

1360

1361

1362

1363

1364

1365

1366

1367

1368

1369

1370

1371

1372

1373

1374

Basin (Upper Cretaceous, Brazil). Journal of South American Earth Sciences 61:715-90. 10.1016/j.jsames.2014.11.007

Fiorelli LE, Calvo JO. 2007. The first "protosuchian" (Archosauria: Crocodyliformes) from the Cretaceous (Santonian) of Gondwana. Arquivos do Museu Nacional 65:417-459.

Fiorelli LE, Calvo JO. 2008. New remains of Notosuchus terrestris Woodward, 1896 (Crocodyliformes: Mesoeucrocodylia) from Late Cretaceous of Neuquen, Patagonia, Argentina. Arquivos do Museu Nacional 66:83-124.

Frey E, Salisbury SW. 2001. The kinematics of aquatic locomotion in Osteolaemus tetrapis Cope. In: Grig GC, Seebacher F, Franklin CE, eds. Crocodilian Biology and Evolution. Sydney, Australia: Surrey Beatty \& Sons, 85-134.

Gasparini Z, Chiappe LM, Fernandez M. 1991. A new Senonian peirosaurid (Crocodylomorpha) from Argentina and a synopsis of the South American Cretaceous crocodilians. Journal of Vertebrate Paleontology, 11: 316-333.

Gasparini Z, Fernandez M, Powell J. 1993. New tertiary sebecosuchians (Crocodylomorpha) from South America: phylogenetic implications. Historical Biology, 7: 1-19.

Gasparini Z, Pol D, Spalletti LA. 2006. An unusual marine crocodyliform from the JurassicCretaceous boundary of Patagonia. Science 311:70-73. 10.1126/science.1120803

Gatesy SM. 1991. Hind limb movements of the American alligator (Alligator mississippiensis) and postural grades. Journal of Zoology 224:577-588. 10.1111/j.1469-7998.1991.tb03786.x

Geoffroy Saint-Hilaire, E. 1825. Recherches sur l'organisation des Gavials, sur leurs affinités naturelles desquelles résulte la nécessité d'une autre distribution générique: Gavialis, Teleosaurus, Steneosaurus. Memoires du Museum National d'Histoire Naturelle, 12: 97-155.

Georgi JA, Krause DW. 2010. Postcranial axial skeleton of Simosuchus clarki (Crocodyliformes: Notosuchia) from the Late Cretaceous of Madagascar. Society of 
1375

1376

1377

1378

1379

1380

1381

1382

1383

1384

1385

1386

1387

1388

1389

1390

1391

1392

1393

1394

1395

1396

1397

Vertebrate Paleontology Memoir 10, Journal of Vertebrate Paleontology 30:99-121.

$10.1080 / 02724634.2010 .519172$

Gervais P. 1871. Remarques au sujet des Reptiles provenant des calcaires lithographiques de Cerin, dans le Bugey, qui sont conservés au Musée de Lyon. Comptes Rendus des Séances de l'Academie de Sciences, 79-83.

Godoy PL, Montefeltro FC, Norell MA, Langer MC. 2014. An additional baurusuchid from the Cretaceous of Brazil with evidence of interspecific predation among Crocodyliformes. PLoS ONE 9 e97138. 10.1371/journal.pone.0097138

Goloboff PA, Farris JS, Nixon KC. 2008a. TNT, a free program for phylogenetic analysis. Cladistics 24:774-786. 10.1111/j.1096-0031.2008.00217.x

Goloboff PA, Farris JS, Nixon KC. 2008b. TNT: Tree analysis using new technologies. Program and documentation available from the authors and at http://www.zmuc.dk/public/phylogeny.

Goloboff PA, Szumik CA. 2015. Identifying unstable taxa: Efficient implementation of tripletbased measures of stability, and comparison with Phyutility and RogueNaRok. Molecular phylogenetics and evolution 88:93-104. 10.1016/j.ympev.2015.04.003

Grellet-Tinner G, Chiappe LM, Norell M, Bottjer D. 2006. Dinosaur eggs and nesting behaviors: A paleobiological investigation. Palaeogeography, Palaeoclimatology, Palaeoecology 232:294-321. 10.1016/j.palaeo.2005.10.029

Hastings A, Hellmund M. 2015. Rare in situ preservation of adult crocodylian with eggs from the Middle Eocene of Geiseltal, Germany. Palaios 30:446-461. 10.2110/palo.2014.062

Hayward J, Zelenitsky D, Smith D, Zaft D, Clayburn J. 2000. Eggshell taphonomy at modern gull colonies and a dinosaur clutch site. Palaios 15:343-355. 10.2307/3515541 
1398 Hecht MK, Tarsitano SF. 1984. The tarsus and metatarsus of Protosuchus and its phyletic 1399 implications. In: Rhodin AG, Miyata K, eds. Advances in herpetology and evolutionary 1400 biology, Museum of Comparative Zoology: Harvard University Press, 332-349.

1401

1402

1403

1404

1405

1406

1407

1408

1409

1410

1411

1412

1413

1414

1415

1416

1417

1418

1419

1420

1421

Hill RV. 2005. Integration of morphological data sets for phylogenetic analysis of amniota: The importance of integumentary characters and increased taxonomic sampling. Systematic Biology 54:530-547. 10.1080/10635150590950326

Hill RV. 2010. Osteoderms of Simosuchus clarki (Crocodyliformes: Notosuchia) from the Late Cretaceous of Madagascar. Society of Vertebrate Paleontology Memoir 10, Journal of Vertebrate Paleontology 30:154-176. http://dx.doi.org/10.1080/02724634.2010.518110

Hutchinson JR. 2001a. The evolution of pelvic osteology and soft tissues on the line to extant birds (Neornithes). Zoological Journal of the Linnean Society 131:123-168. 10.1111/j.10963642.2001.tb01313.x

Hutchinson JR. 2001b. The evolution of femoral osteology and soft tissues on the line to extant birds (Neornithes). Zoological Journal of the Linnean Society 131:169-197.

Hutchinson JR. 2002. The evolution of hindlimb tendons and muscles on the line to crowngroup birds. Comparative Biochemistry and Physiology Part A 133:1051-1086. 10.1016/S1095-6433(02)00158-7

Ikejiri T. 2012. Histology-based morphology of the neurocentral synchondrosis in Alligator mississippiensis (Archosauria, Crocodylia). The Anatomical Record 295:18-31. 10.1002/ar.21495.

Iori FV, Carvalho IS. 2011. Caipirasuchus paulistanus, a new sphagesaurid (Crocodylomorpha, Mesoeucrocodylia) from the Adamantina Formation (Upper Cretaceous, TuronianSantonian), Bauru Basin, Brazil. Journal of Vertebrate Paleontology 31:1255-1264. http://dx.doi.org/10.1080/039.031.0601 
1422

1423

1424

1425

1426

1427

1428

1429

1430

1431

1432

1433

1434

1435

1436

1437

1438

1439

1440

1441

1442

1443

1444

Iori FV, Carvalho IS, Marinho TS. 2016. Postcranial skeletons of Caipirasuchus

(Crocodyliformes, Notosuchia, Sphagesauridae) from the Upper Cretaceous (TuronianSantonian) of the Bauru Basin, Brazil. Cretaceous Research, 60: 109-120.

10.1016/j.cretres.2015.11.017

Irmis RB. 2007. Axial Skeleton Ontogeny in the Parasuchia (Archosauria: Pseudosuchia) and Its Implications for Ontogenetic Determination in Archosaurs. Journal of Vertebrate Paleontology. 27:350-361.

Jouve S, Iarochene M, Bouya B, Amaghzaz M. 2006. A new species of Dyrosaurus (Crocodylomorpha, Dyrosauridae) from the early Eocene of Morocco: phylogenetic implications. Zoological Journal of the Linnean Society 148:603-656. 10.1111/j.10963642.2006.00241.x

Kellner AWA, Azevedo SAK. 1999. A new sauropod dinosaur (Titanosauria) from the Late Cretaceous of Brazil. Proceedings of the Second Gondwana Dinosaur Symposium 15:111142.

Krause DW, Sertich JJ, Rogers RR, Kast SC, Rasoamiaramanana AH, Buckley GA. 2010. Overview of the discovery, distribution, and geological context of Simosuchus clarki (Crocodyliformes: Notosuchia) from the Late Cretaceous of Madagascar. Society of Vertebrate Paleontology Memoir 10, Journal of Vertebrate Paleontology 30: 4-12. $10.1080 / 02724634.2010 .516784$

Larsson HCE, Sues HD. 2007. Cranial osteology and phylogenetic relationships of Hamadasuchus rebouli (Crocodyliformes: Mesoeucrocodylia) from the Cretaceous of Morocco. Zoological Journal of the Linnean Society 149:533-567. doi:10.1111/j.10963642.2007.00271.x 
1445 Leardi JM, Fiorelli LE, Gasparini Z. 2015a. Redescription and reevaluation of the taxonomical 1446 status of Microsuchus schilleri (Crocodyliformes: Mesoeucrocodylia) from the Upper 1447 Cretaceous of Neuquén, Argentina. Cretaceous Research 52:153-166.

1448 Leardi JM, Pol D, Novas FE, Suarez Riglos M. 2015b. The postcranial anatomy of Yacarerani 1449 boliviensis and the phylogenetic significance of the notosuchian postcranial skeleton. $1450 \quad$ Journal of Vertebrate Paleontology e995187. 10.1016/j.cretres.2014.09.007

1451 Marinho T, Carvalho I. 2009. An armadillo-like sphagesaurid crocodyliform from the Late 1452 Cretaceous of Brazil. Journal of South American Earth Sciences 27:36-41.

$1453 \quad$ 10.1016/j.jsames.2008.11.005

1454

1455 1456 1457 1458 1459 1460 1461 1462 1463 1464 1465 1466 1467

Marinho TS, Iori FV, Carvalho IS, Vasconcellos FM. 2013. Gondwanasuchus scabrosus gen. et sp. nov., a new terrestrial predatory crocodyliform (Mesoeucrocodylia: Baurusuchidae) from the Late Cretaceous Bauru Basin of Brazil. Cretaceous Research, 44:104-111.

Marsola JCA, Montefeltro FC, Langer MC. 2011. New Baurusuchidae eggs from the Bauru Group (Vale do Rio do Peixe Formation, Late Cretaceous, Minas Gerais, Brazil). In: IV Congresso Latinoamericano de Paleontologia de Vertebrados. p R88.

Marsola JCA, Batezelli A, Montefeltro FC, Grellet-Tinner G, Langer MC. in prep.Palaeoenvironmental characterization of a crocodilian nesting site from the Late Cretaceous of Brazil and the evolution of crocodyliform nesting strategies . Palaeogeography, Palaeoclimatology, Palaeoecology.

Martinelli AG, Ribeiro LCB, Mendez AH, Neto FM, Cavellani CL, Felix E, Ferraz MLF, Teixeira VDPA. 2013. Insight on the theropod fauna from the Uberaba Formation (Bauru Group), Minas Gerais State: new megaraptoran specimen from the Late Cretaceous of Brazil. Rivista Italiana di Paleontologia e Stratigrafia, 119: 205-214. 10.13130/2039-4942/6035 
1468 Martinelli AG, Teixeira VPA. 2015. The Late Cretaceous vertebrate record from the Bauru

1469 Group in the Triângulo Mineiro, southeastern Brazil. Boletín Geológico y Minero 126:129$1470 \quad 158$.

1471 Meers MB. 2003. Crocodylian forelimb musculature and its relevance to Archosauria. The $1472 \quad$ Anatomical Record Part A 274:891-916.

1473 Méndez AH, Novas FE, Iori FV. 2012. First record of Megaraptora (Theropoda, 1474 Neovenatoridae) from Brazil. Comptes Rendus Palevol 11:251-256. 10.1016/j.crpv.2011.12.007

Molnar JL, Pierce SE, Bhullar BAS, Turner AH, Hutchinson JR. 2015. Morphological and 1477 functional changes in the vertebral column with increasing aquatic adaptation in crocodylomorphs. Royal Society Open Science 2:150439. 10.1098/rsos.150439

Montefeltro FC, Larsson HC, França MA, Langer MC. 2013. A new neosuchian with Asian affinities from the Jurassic of northeastern Brazil. Naturwissenschaften 100:835-841. 10.1007/s00114-013-1083-9

Montefeltro FC, Larsson HCE, Langer MC. 2011. A new baurusuchid (Crocodyliformes, Mesoeucrocodylia) from the Late Cretaceous of Brazil and the phylogeny of Baurusuchidae. PLoS ONE 6 e21916. 10.1371/journal.pone.0021916

Mook CC. 1921. Notes on the postcranial skeleton in the Crocodilia. Bulletin of the American Museum of Natural History 44:67-100.

Müller GB, Alberch P. 1990. Ontogeny of the limb skeleton in Alligator mississippiensis:

1488 Developmental invariance and change in the evolution of archosaur limbs. Journal of Morphology 203:151-164. 10.1002/jmor.1052030204

Nascimento PM. 2008. Descrição morfológica e posicionamento filogenético de um região de General Salgado (SP). MSc Thesis, Universidade de São Paulo. 
1493 Nascimento PM, Zaher H. 2010. A new species of Baurusuchus (Crocodyliformes,

1494 Mesoeucrocodylia) from the Upper Cretaceous of Brazil, with the first complete postcranial

1495 skeleton described for the family Baurusuchidae. Papéis Avulsos de Zoologia 50:323-361.

$1496 \quad 10.1590 /$ S0031-10492010002100001

1497 Nash DS. 1968. A crocodile from the Upper Triassic of Lesotho. Jounal of Zoology, London, $1498 \quad 156: 163-179$.

1499 Nash DS. 1975. The morphology and relationships of a crocodilian, Orthosuchus stormbergi, 1500 from the Upper Triassic of Lesotho. Annals of South African Museum 67:227-329.

1501 Nesbitt S. 2011. The early evolution of archosaurs: relationships and the origin of major clades. 1502 Bulletin of the American Museum of Natural History:1-288.

1503 Nesbitt S, Turner A, Weinbaum J. 2012. A survey of skeletal elements in the orbit of 1504 Pseudosuchia and the origin of the crocodylian palpebral. Earth and Environmental Science 1505 Transactions of the Royal Society of Edinburgh 103:365-381. 10.1017/S1755691013000224

1506 1507 1508 1509 1510 1511 1512 1513 1514 1515 1516 1517

Nobre PH. 2004. Morfologia pós-craniana de Candidodon itapecuruense (Crocodylomorpha, Mesoeucrocodylia), do Cretáceo do Brasil. Revista Brasileira de Paleontologia, 7: 87-92.

Nobre PH, Carvalho IS. 2013. Postcranial skeleton of Mariliasuchus amarali Carvalho and Bertini, 1999 (Mesoeucrocodylia) from the Bauru Basin, Upper Cretaceous of Brazil. Ameghiniana 40:98-113. 10.5710/AMGH.15.8.2012.500

Novas FE, Carvalho IS, Ribeiro LCB, Méndez AH. 2008. First abelisaurid bone remains from the Maastrichtian Marília Formation, Bauru Basin, Brazil. Cretaceous Research, 29: 625635. 10.1016/j.cretres.2008.01.010

Novas FE, Pais DF, Pol D, Carvalho IS, Scanferla A, Mones A, Suarez Riglos M. 2009. Bizarre notosuchian crocodyliform with associated eggs from the Upper Cretaceous of Bolivia. Journal of Vertebrate Paleontology 29:1316-1320.

http://dx.doi.org/10.1671/039.029.0409

PeerJ reviewing PDF | (2016:02:8992:2:0:NEW 3 May 2016) 
1518

1519

1520

1521

1522

1523

1524

1525

1526

1527

1528

1529

1530

1531

1532

1533

1534

1535

1536

1537

1538

1539

1540

O’Connor PM, Sertich JJ, Stevens NJ, Roberts EM, Gottfried MD, Hieronymu TL, Jinnah

ZA, Ridgely R, Ngasala SE, Temba J. 2010. The evolution of mammal-like crocodyliforms

in the Cretaceous Period of Gondwana. Nature 466:748-751. 10.1038/nature09061

Owen R. 1879. Monograph on the fossil Reptilia of the Wealden and Purbeck Formations.

Supplement IX, Crocodilia (Goniopholis, Brachydectes, Nannosuchus, Theriosuchus, and Nuthetes). Monograph of the Palaeontographical Society, 33: 1-19.

Parrish JM. 1986. Locomotor adaptations in the hindlimb and pelvis of the Thecodontia. Hunteria 1:1-36.

Parrish JM. 1987. The origin of crocodilian locomotion. Paleobiology 13:396-414.

Pierce S, Benton M. 2006. Pelagosaurus typus Bronn, 1841 (Mesoeucrocodylia: Thalattosuchia) from the Upper Lias (Toarcian, Lower Jurassic) of Somerset, England. Journal of Vertebrate Paleontology 26:621-635. 10.1671/0272-4634

Pol D. 2005. Postcranial remains of Notosuchus terrestris (Archosauria: Crocodyliformes) from the upper Cretaceous of Patagonia, Argentina. Ameghiniana 42:1-17. http://dx.doi.org/10.1080/02724634.2012.646833

Pol D, Escapa IH. 2005. Unstable taxa in cladistics analysis: identification and the assessment of relevant characters. Cladistics. 25: 515-527. 10.1111/j.1096-0031.2009.00258.x

Pol D, Ji SA, Clark JM, Chiappe LM. 2004. Basal crocodyliforms from the Lower Cretaceous Tugulu Group (Xinjiang, China), and the phylogenetic position of Edentosuchus. Cretaceous Research 25:603-622. 10.1016/j.cretres.2004.05.002

Pol D, Leardi JM, Lecuona A, Krause M. 2012. Postcranial anatomy of Sebecus icaeorhinus (Crocodyliformes, Sebecidae) from the Eocene of Patagonia. Journal of Vertebrate Paleontology 32:328-354. 10.1080/02724634.2012.646833 
1541

1542

1543

1544

1545

1546

1547

1548

1549

1550

1551

1552

1553

1554

1555

1556

1557

1558

1559

1560

1561

1562

1563

1564

1565

Pol D, Nascimento PM, Carvalho AB, Riccomini C, Pires-Domingues RA, Zaher H. 2014. A new notosuchian from the Late Cretaceous of Brazil and the phylogeny of advanced notosuchians. PLoS ONE 9 e93105. 10.1371/journal.pone.0093105

Pol D, Norell M. 2004. A new gobiosuchid crocodyliform taxon from the Cretaceous of Mongolia. American Museum Novitates 1-31. http://dx.doi.org/10.1206/00030082(2004)458<0001:ANGCTF>2.0.CO;2

Pol D, Turner A, Norell M. 2009. Morphology of the Late Cretaceous crocodylomorph Shamosuchus djadochtaensis and a discussion of neosuchian phylogeny as related to the origin of Eusuchia. Bulletin of the American Museum of Natural History 1-103.

Pomel A. 1847. Note sur les animaux fossiles découverts dans le département de l’Allier. Bulletin de la Société Géologique de France, 4: 378-385.

Price LI. 1945. A new reptil from the Cretaceous of Brazil. Notas Preliminares e Estudos Divisão de Geologia e Mineralogia 25:1-8.

Reilly SM, Blob RW. 2003. Motor control of locomotor hind-limb posture in the American alligator (Alligator mississippiensis). Journal of Experimental Biology. 206: 4327-4340.

Reisz RR, Fröbisch J. 2014. The oldest caseid synapsid from the Late Pennsylvanian of Kansas, and the evolution of herbivory in terrestrial vertebrates. PLoS ONE 9 e94518. 10.1371/journal.pone.0094518

Riff D. 2007. Anatomia apendicular de Stratiotosuchus maxhechti (Baurusuchidae, Cretáceo Superior do Brasil) e análise filogenética dos Mesoeucrocodylia. PhD Thesis, Universidade Federal do Rio de Janeiro.

Riff D, Kellner AWA. 2011. Baurusuchid crocodyliforms as theropod mimics: clues from the skull and appendicular morphology of Stratiotosuchus maxhechti (Upper Cretaceous of Brazil). Zoological Journal of the Linnean Society 163:S37-S56. 10.1111/j.10963642.2011.00713.x 
1566 Romer AS. 1923. Crocodilian pelvic muscles and their avian and reptilian homologues. Bulletin 1567 of the American Museum of Natural History 48:533-552.

1568 Romer AS. 1956. Osteology of the reptiles. Chicago: The University of Chicago Press.

1569 Rusconi C. 1933. Sobre reptiles cretáceos del Uruguay (Uruguaysuchus aznarezi, ngn sp.) y sus 1570 relaciones con los notosúquidos de Patagonia. Boletín del Instituto de Geología y

Salgado L, \& Carvalho IS. 2008. Uberabatitan ribeiroi, a new titanosaur from the Marília Formation (Bauru Group, Upper Cretaceous), Minas Gerais, Brazil. Palaeontology 51: 881901. 10.1111/j.1475-4983.2008.00781.x

1575

1576 Perforaciones, 19: 1-64.

Salisbury SW, Frey E. 2001. A biomechanical transformation model for the evolution of semispheroidal articulations between adjoining vertebral bodies in crocodilians. In: Grig GC, Seebacher F, Franklin CE, eds. Crocodilian Biology and Evolution. Sydney, Australia: Surrey Beatty \& Sons, 85-134.

Salisbury S, Frey E, Martill D, Buchy M. 2003. A new crocodilian from the Lower Cretaceous Crato Formation of north-eastern Brazil. Palaeontographica Abteilung a-PalaozoologieStratigraphie 270:3-47.

Santucci RM, Arruda-Campos AC. 2011. A new sauropod (Macronaria, Titanosauria) from the Adamantina Formation, Bauru Group, Upper Cretaceous of Brazil and the phylogenetic relationships of Aeolosaurini. Zootaxa 3085:1-33.

Scheyer TM, Desojo JB. 2011. Paleohistology and external microanatomy of rauisuchian osteoderms (Archosauria: Pseudosuchia). Palaeontology 54:1289-1302. 10.1111/j.14754983.2011.01098.x

Schneider JG. 1801. Historiae Amphibiorum naturalis et literariae. Fasciculus secundus continens Crocodilos, Scincos, Chamaesauras, Boas. Pseudoboas, Elapes, Angues. Amphisbaenas et Caecilias. Frommanni, Jena. pp. 374 
1591 Schwarz-Wings D, Klein N, Neumann C, Resch U. 2011. A new partial skeleton of

$1592 \quad$ Alligatorellus (Crocodyliformes) associated with echinoids from the Late Jurassic

1593 (Tithonian) lithographic limestone of Kelheim, S-Germany. Fossil Record 14:195-205.

$1594 \quad$ 10.1002/mmng.201100007

1595 Sereno P, Larsson H. 2009. Cretaceous crocodyliforms from the Sahara. ZooKeys 28:1-143.

$1596 \quad$ 10.3897/zookeys.28.325

1597 Sertich JJW, Groenke JR. 2010. Appendicular Skeleton of Simosuchus clarki

1598 (Crocodyliformes: Notosuchia) from the Late Cretaceous of Madagascar. Society of

1599 Vertebrate Paleontology Memoir 10, Journal of Vertebrate Paleontology 30:122-153.

$1600 \quad 10.1080 / 02724634.2010 .516902$

1601 Simpson GG. 1937. An ancient eusuchian crocodile from Patagonia. American Museum

$1602 \quad$ Novitates, 927:1-3.

1603 Soares PC, Landim PMB, Fulfaro VJ, Sobreiro Neto AF. 1980. Ensaio de caracterização do

1604 Cretáceo no Estado de São Paulo: Grupo Bauru. Revista Brasileira de Geociências 10:177$1605 \quad 185$.

1606

1607

1608

1609

1610

1611

1612

1613

1614

Spix JB. 1825. Animalia nova sive Species novae lacertarum quas in itinere per Brasiliam annis MDCCCXVII-MDCCCXX jussu et auspicious Maximiliani Josephi I Bavariae Regis. F.S. Munich, pp. 26.

Sues HD, Olsen P, Carter J, Scott D. 2003. A new crocodylomorph archosaur from the Upper Triassic of North Carolina. Journal of Vertebrate Paleontology 23:329-343.

Syme C, Salisbury S. 2014. Patterns of aquatic decay and disarticulation in juvenile Indo-Pacific crocodiles (Crocodylus porosus), and implications for the taphonomic interpretation of fossil crocodyliform material. Palaeogeography Palaeoclimatology Palaeoecology 412:108-123. 10.1016/j.palaeo.2014.07.013 
1615 Tavares SAS, Ricardi-Branco F, Carvalho IS. 2015. Osteoderms of Montealtosuchus

1616 arrudacamposi (Crocodyliformes, Peirosauridae) from the Turonian-Santonian (Upper

1617 Cretaceous) of Bauru Basin, Brazil. Cretaceous Research 56:651-661.

$1618 \quad$ 10.1016/j.cretres.2015.07.002

1619 Tennant J, Mannion P. 2014. Revision of the Late Jurassic crocodyliform Alligatorellus, and 1620 evidence for allopatric speciation driving high diversity in western European atoposaurids. $1621 \quad$ Peerj 2. 10.7717/peerj.599

1622 Turner AH. 2006. Osteology and phylogeny of a new species of Araripesuchus

1623 (Crocodyliformes: Mesoeucrocodylia) from the Late Cretaceous of Madagascar. Historical

1624

1625

1626

1627

1628

1629

1630

1631

1632

1633

1634

1635

1636

1637

1638

Biology 18:255-369. 10.1080/08912960500516112

Vasconcellos FM. 2006. Descrição do pós-crânio de Uberabasuchus terrificus Carvalho, Ribeiro e Avilla 2004 (Crocodyliformes, Peirosauridae) do Cretáceo Superior da bacia Bauru: inferências morfofuncionais e paleoautoecológicas. MSc Thesis, Universidade Federal do Rio de Janeiro.

Vasconcellos FM, Carvalho IS. 2010. Paleoichnological assemblage associated with Baurusuchus salgadoensis remains, a Baurusuchidae Mesoeucrocodylia from the Bauru Basin, Brazil (Late Cretaceous). Bulletin of the New Mexico Museum of Natural History and Science 51:227-237.

Vickaryous M, Hall B. 2008. Development of the dermal skeleton in Alligator mississippiensis (Archosauria, Crocodylia) with comments on the homology of osteoderms. Journal of Morphology 269:398-422. 10.1002/jmor.10575

Whetstone KN, Whybrow PJ. 1983. A "cursorial" crocodilian from the Triassic of Lesotho (Basutoland), southern Africa. Occasional Papers of the Museum of Natural History, University of Kansas 106:1-37. 
1639 Wilson JA, Malkani MS, Gingerich PD. 2001. New crocodyliform (Reptilia,

1640 Mesoeucrocodylia) from the Upper Cretaceous Pab Formation of Vitakri, Balochistan

1641 (Pakistan). Contributions from the Museum of Paleontology, The University of Michigan

$1642 \quad 30: 321-336$.

1643 Woodward AS. 1896. On Two Mesozoic Crocodilians from the Red Sandstone of the Territory 1644 of Neuquen (Argentine Republic): Notosuchus (genus novum) and Cynodontosuchus (genus 1645 novum) from the Red Sandstone of the Territory of Neuquen (Argentine Republic). Anales 1646 del Museuo de la Plata, Paleontología Argentina 6: 1-20.

1647 Wu X-C, Chatterjee S. 1993. Dibothrosuchus elaphros, a crocodylomorph from the Lower 1648 Jurassic of China and the phylogeny of the Sphenosuchia. Journal of Vertebrate 1649 1650 1651 Paleontology 13:58-89. 10.1080/02724634.1993.10011488

Wu XC, Sues HD. 1996. Anatomy and phylogenetic relationships of Chimaerasuchus paradoxus, an unusual Crocodyliform Reptile from the Lower Cretaceous of Hubei, China. Journal of Vertebrate Paleontology 16:688-702.

Wu XC, Sues HD, Brinkman DB. 1996. An atoposaurid neosuchian (Archosauria: Crocodyliformes) from the Lower Cretaceous of Inner Mongolia (People’s Republic of China). Canadian Journal of Earth Sciences 33:599-605. 10.1139/e96-044

Wu XC, Sues HD, Dong ZM. 1997. Sichuanosuchus shuhanensis, a new protosuchian (Arhcosauria: Crocodyliformes) from Sichuan (China), and the monophyly of the Protosuchia. Journal of Vertebrate Paleontology 17:89-103.

Wu XC, Sues HD, Sun A. 1995. A plant-eating crocodyliform reptile from the Cretaceous of China. Nature 376:678-680. 10.1038/376678a0 Paleontology and Paleoanthropology, 11: 37-44. 
1663 Young MT, Andrade MB, Etches S, Beatty BL. 2013. A new metriorhynchid crocodylomorph 1664 from the Lower Kimmeridge Clay Formation (Late Jurassic) of England, with implications 1665 for the evolution of dermatocranium ornamentation in Geosaurini. Zoological Journal of the 1666 Linnean Society 169:820-848. 10.1111/zoj.12082

1667 Young MT. Bell MA, Andrade MB, Brusatte SL 2011. Body size estimation and evolution in 1668 metriorhynchid crocodylomorphs: implications for species diversification and niche 1669 partitioning. Zoological Journal of the Linnean Society, 163: 1199-1216. 0.1111/j.10961670 3642.2011.00734.x

1671 Young MT, Brusatte SL, Ruta M, Andrade MB. 2010. The evolution of Metriorhynchoidea 1672 (Mesoeucrocodylia, Thalattosuchia): an integrated approach using geometric morphometrics, 1673 analysis of disparity, and biomechanics. Zoological Journal of the Linnean Society 158:8011674 859. 10.1111/j.1096-3642.2009.00571.x 


\section{Tables and Figure (with captions)}

1676 Table 1. List of taxa used for comparison in the description.

\begin{tabular}{|c|c|}
\hline Taxon & Specimens numbers/references \\
\hline Alligator sp. & Brochu (1992) \\
\hline Aplestosuchus sordidus & LPRP/USP 0229a \\
\hline Araripesuchus gomesii & AMNH 24450; Turner (2006) \\
\hline Araripesuchus tsangatsangana & $\begin{array}{l}\text { FMNH PR 2297; FMNH PR 2298; FMNH PR 2326; FMNH PR 2327; } \\
\text { FMNH PR 2335; FMNH PR 2337; Turner (2006) }\end{array}$ \\
\hline Baurusuchus albertoi & MZSP-PV 140; Nascimento (2008); Nascimento \& Zaher (2010) \\
\hline Baurusuchus salgadoensis & UFRJ DG 285-R; Vasconcellos \& Carvalho (2010) \\
\hline Caiman sp. & LPRP/USP N 0008; MZSP 2137; Brochu (1992); Nascimento (2008) \\
\hline Chimaerasuchus paradoxus & IVPP V8274; Wu \& Sues (1996) \\
\hline Crocodylus sp. & Brochu (1992) \\
\hline Edentosuchus tienshanensis & Pol et al. (2004) \\
\hline Lomasuchus palpebrosus & Leardi et al. (2015)b \\
\hline Mahajangasuchus insignis & FMNH 2721 (research cast of UA8654); Buckley \& Brochu (1999) \\
\hline Mariliasuchus amarali & UFRJ-DG-50-R, UFRJ-DG-105-R; Nobre \& Carvalho (2013) \\
\hline Melanosuchus niger & Brochu (1992); Nascimento (2008) \\
\hline Microsuchus schilleri & Leardi et al. (2015)a \\
\hline Notosuchus terrestris & $\begin{array}{l}\text { MACN-PV RN 1037; MACN-PV RN 1044, MACN-PV N 109; } \\
\text { MUCPv-137; Pol (2005); Fiorelli \& Calvo (2008) }\end{array}$ \\
\hline Orthosuchus stormbergii & SAM-PK 409; Nash (1975) \\
\hline Protosuchus richardsoni & AMNH 3024; UMCP 34634, 36717 \\
\hline Sebecus icaeorhinus & AMNH 3159; Pol et al. (2012) \\
\hline Sichuanosuchus shuhanensis & Wu et al. (2007) \\
\hline Simosuchus clarki & $\begin{array}{l}\text { Research cast of UA 8679; Georgi \& Krause (2010); Sertich \& } \\
\text { Groenke (2010) }\end{array}$ \\
\hline Stratiotosuchus maxhechti & DGM 1477-R; Riff (2007); Riff \& Kellner (2011) \\
\hline Theriosuchus pusillus & NHMUK 48330; Wu et al. (1996) \\
\hline Uberabasuchus terrificus & CPPLIP 0630; Vasconcellos (2006) \\
\hline Uruguaysuchus aznarezi & Pol et al. (2012) \\
\hline Yacarerani boliviensis & Leardi et al. (2015)b \\
\hline
\end{tabular}



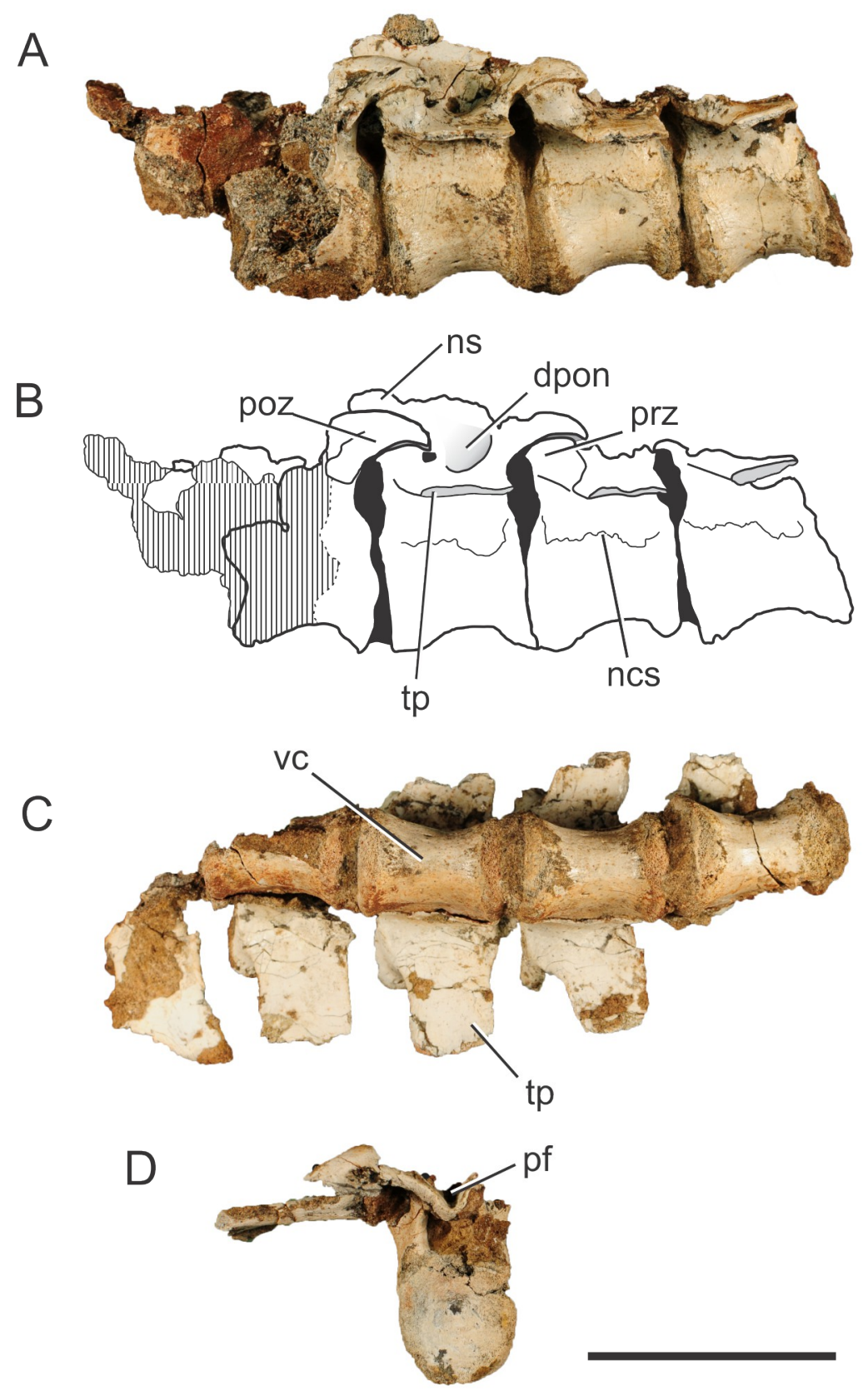

1677 Figure 1. Pissarrachampsa sera (holotype, LPRP/USP 0019), photographs and schematic drawing of 1678 the articulated dorsal vertebrae in left lateral (A and B) and ventral views (C), and isolated dorsal 1679 vertebra in caudal view (D). Cross-hatched areas represent broken surfaces. Black areas represent 1680 sediment-filled areas. Abbreviations: dpon: depression between the postzygapophysis and the neural 1681 spine; ns: neural spine (base); ncs: neurocentral suture; pf: postspinal fossa; poz: postzygapophysis; prz: 1682 prezygapophysis; tp: transverse process; vc: vertebral centrum. Scale bar equals $5 \mathrm{~cm}$. 

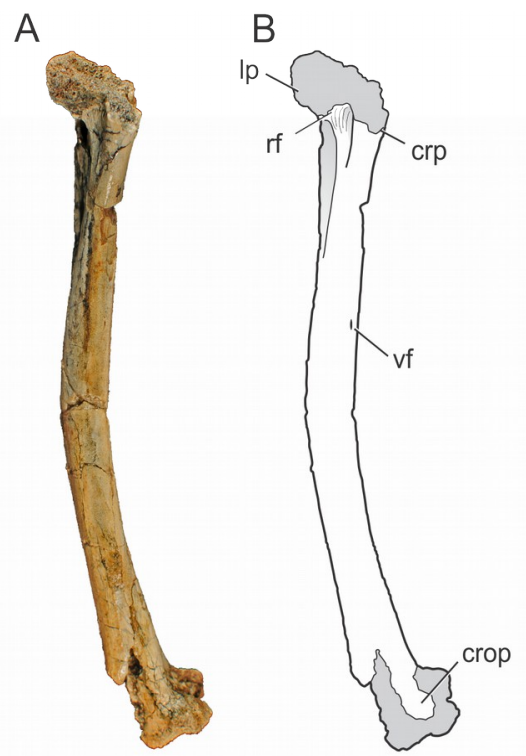

C

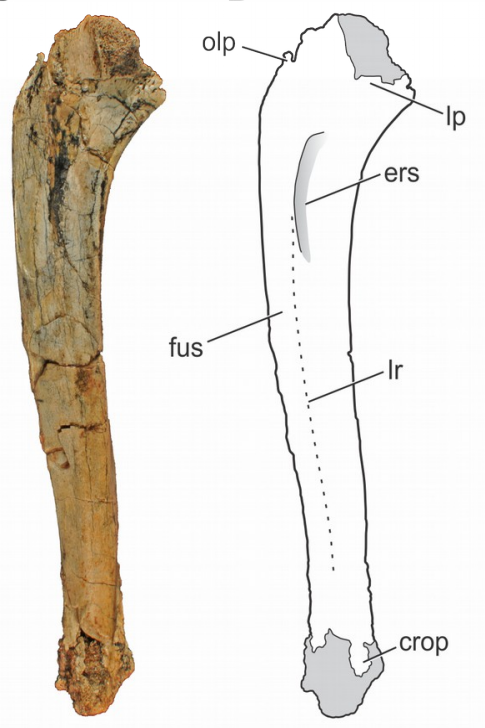

$\mathrm{E}$

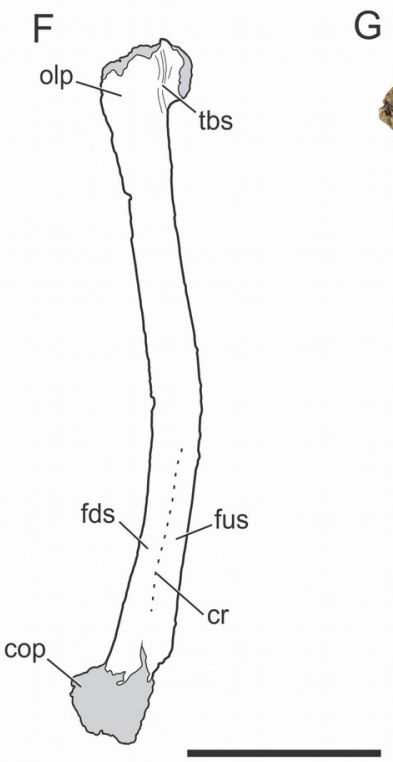

G
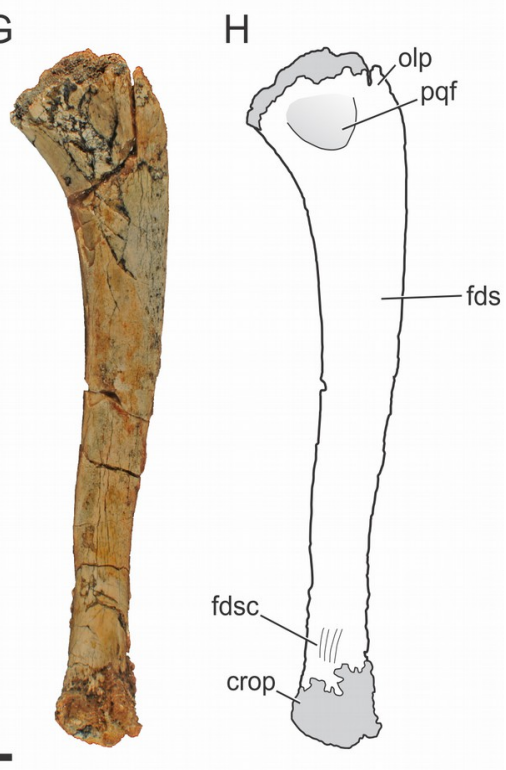

Figure 2. Pissarrachampsa sera (holotype, LPRP/USP 0019), photographs and schematic drawings of the right ulna in cranial (A and B), lateral (C and D), caudal (E and F), and medial views ( $G$ and $H$ ). Light grey represents (broken) articulation areas. Abbreviations: cop, caudal oblique process; cr, caudal ridge; crop, cranial oblique process; crp, ulnar cranial process; ers, M. extensor carpi radialis brevis sulcus; fds, M. flexor digitorum longus insertion surface; fdsc, M. flexor digitorum longus insertion scars; fus, $M$. flexor ulnaris insertion surface; lp, ulnar lateral process; lr, lateral ridge; olp; olecranon process; pqf; M. pronator quadratus origin fossa; rf, radial facet; tbs, M. triceps brachii insertion scars; vf, vascular foramen. Scale bar equals $5 \mathrm{~cm}$. 

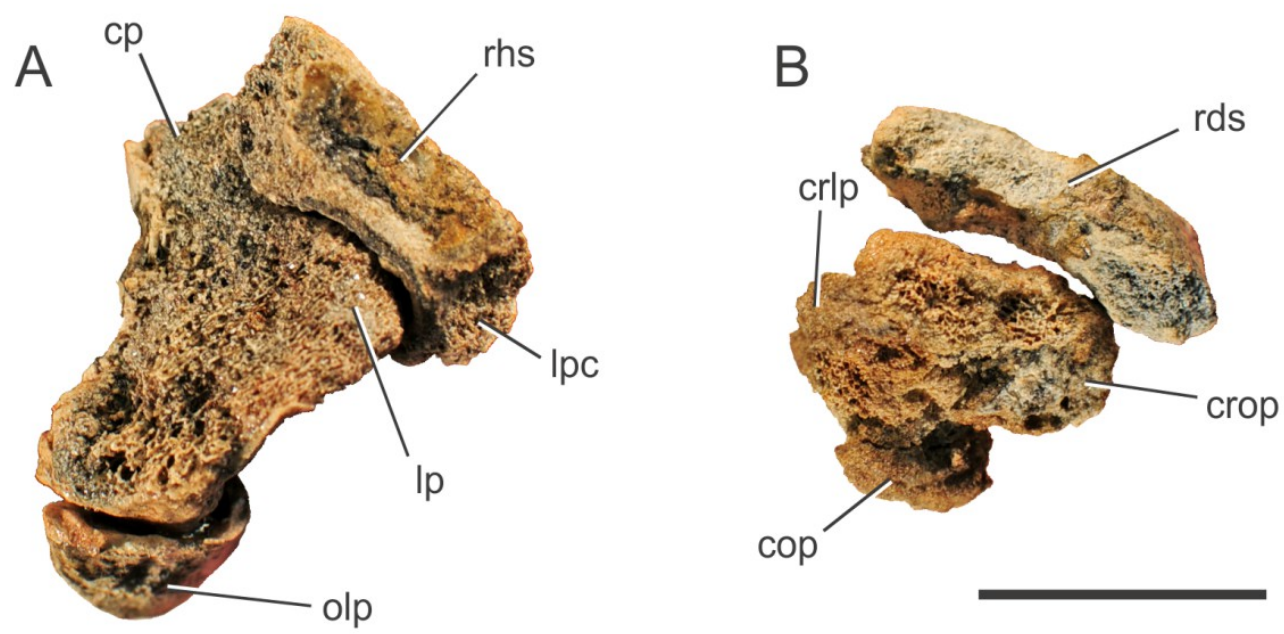

Figure 3. Pissarrachampsa sera (holotype, LPRP/USP 0019), photographs of articulated right ulna

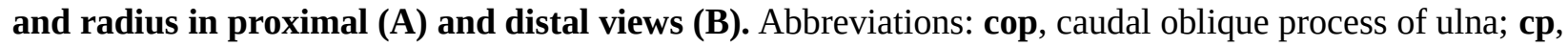
ulnar cranial process; crlp, craniolateral process of ulna; crop, cranial oblique process of ulna; lp, ulnar lateral process; lpc, lateral process of proximal condyle of radius; olp; olecranon process of ulna; rhs, radiohumeral articular surface; rds, radiale articular surface of radius. Scale bar equals $5 \mathrm{~cm}$. 

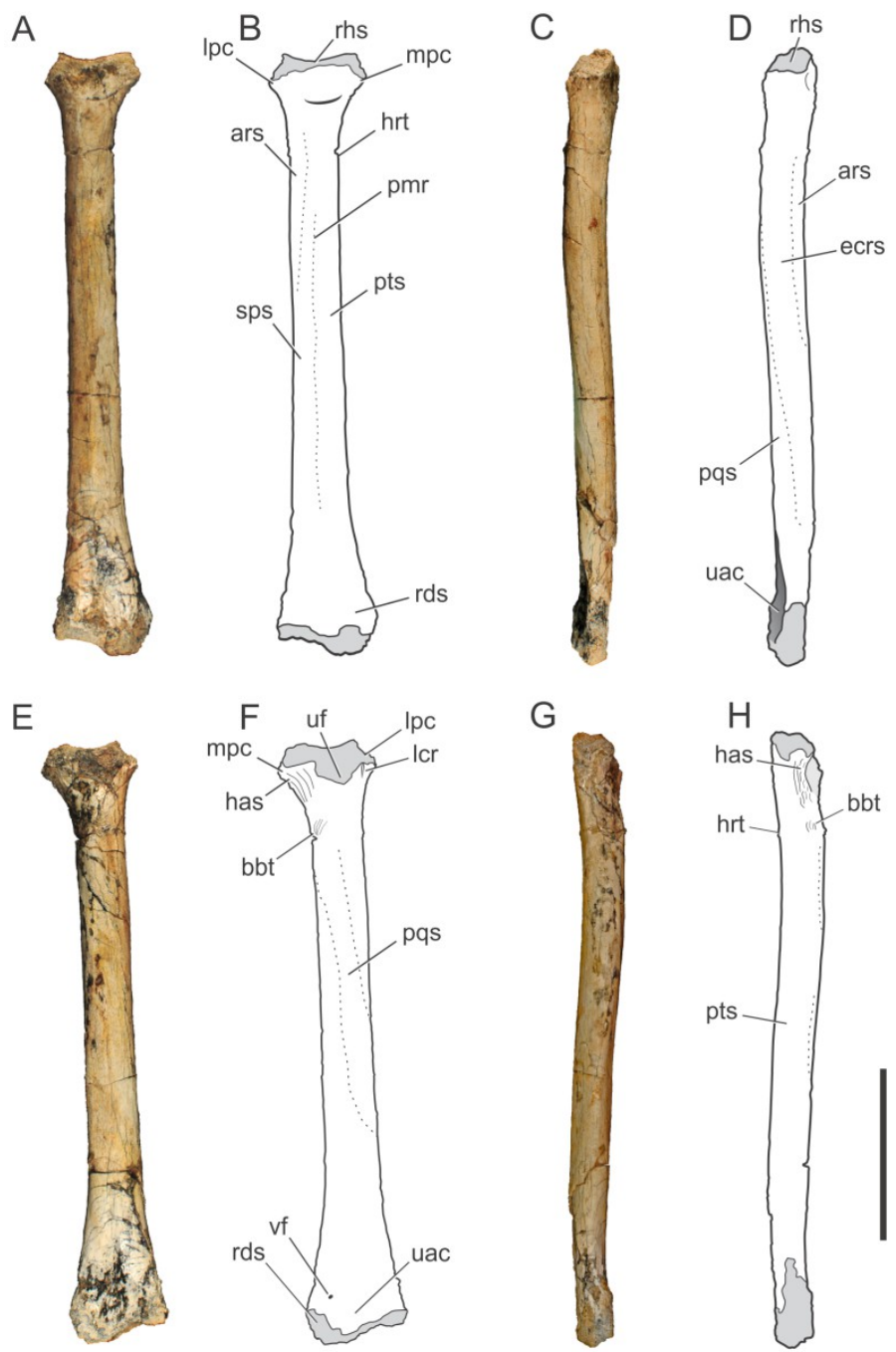
the right radius in cranial ( $A$ and $B$ ), lateral (C and D), caudal ( $E$ and F), and medial views (G and H). Light grey represents articulation areas. Abbreviations: ars, M. abductor radialis insertion surface; bbt, $M$. biceps brachii insertion tubercle; has, $M$. humeroantebrachialis inferior insertion scar; ecrs, $M$. extensor carpi radialis brevis insertion surface; hrt, $M$. humeroradialis insertion tubercle; lcr, thin longitudinal crest; lpc, lateral process of proximal condyle; mpc, medial process of proximal condyle; pmr, proximodistal medial ridge; pqs, M. pronator quadratus insertion surface; pts, M. pronator teres insertion surface; rds, radiale articular surface; rhs, radiohumeral articular surface; sps, M. supinator 1704 insertion surface; uac, ulnar articulation concavity; uf, ulnar facet; vf, vascular foramen. Scale bar equals $17055 \mathrm{~cm}$. 


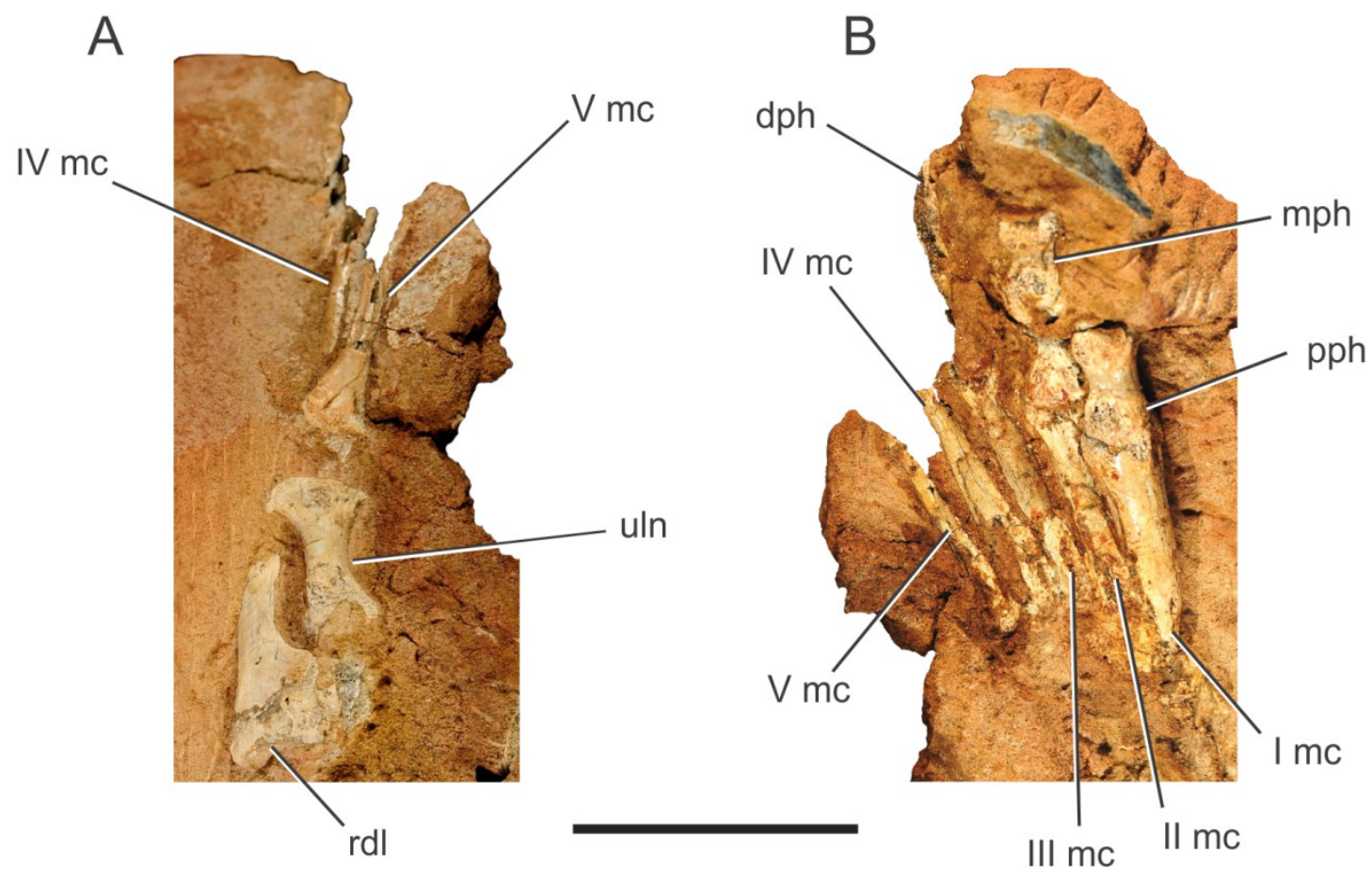

1706 Figure 5. Pissarrachampsa sera (holotype, LPRP/USP 0019), photographs of the right carpus/manus

1707 in dorsal (A) and ventral views (B). Abbreviations: I mc, metacarpal I; II mc, metacarpal II; III mc,

1708 metacarpal III; IV mc, metacarpal IV; V mc, metacarpal V; dph, distal phalanx; mph, medial phalanx;

1709 pph, proximal phalanx; rdl, radiale; uln, ulnare. Scale bar equals $5 \mathrm{~cm}$. 
A

B
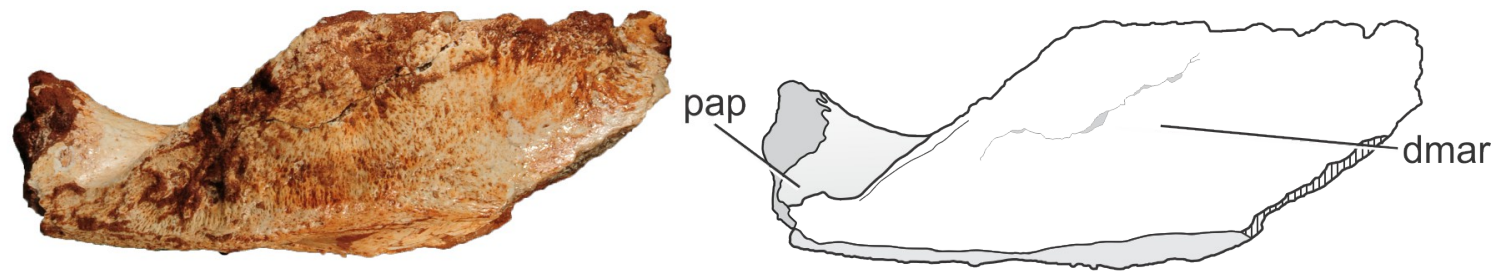

C

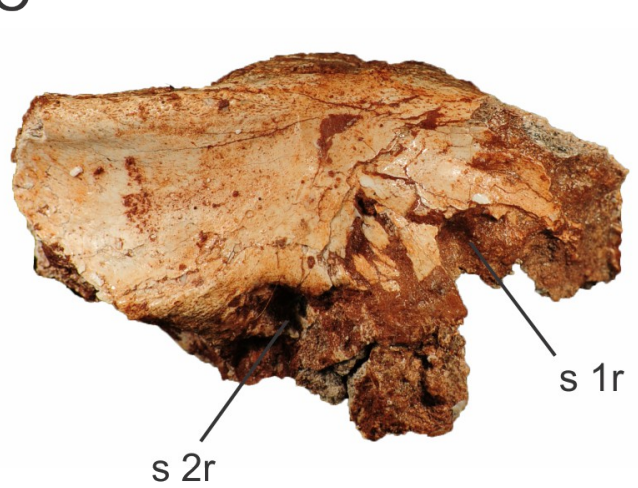

$\mathrm{D}$
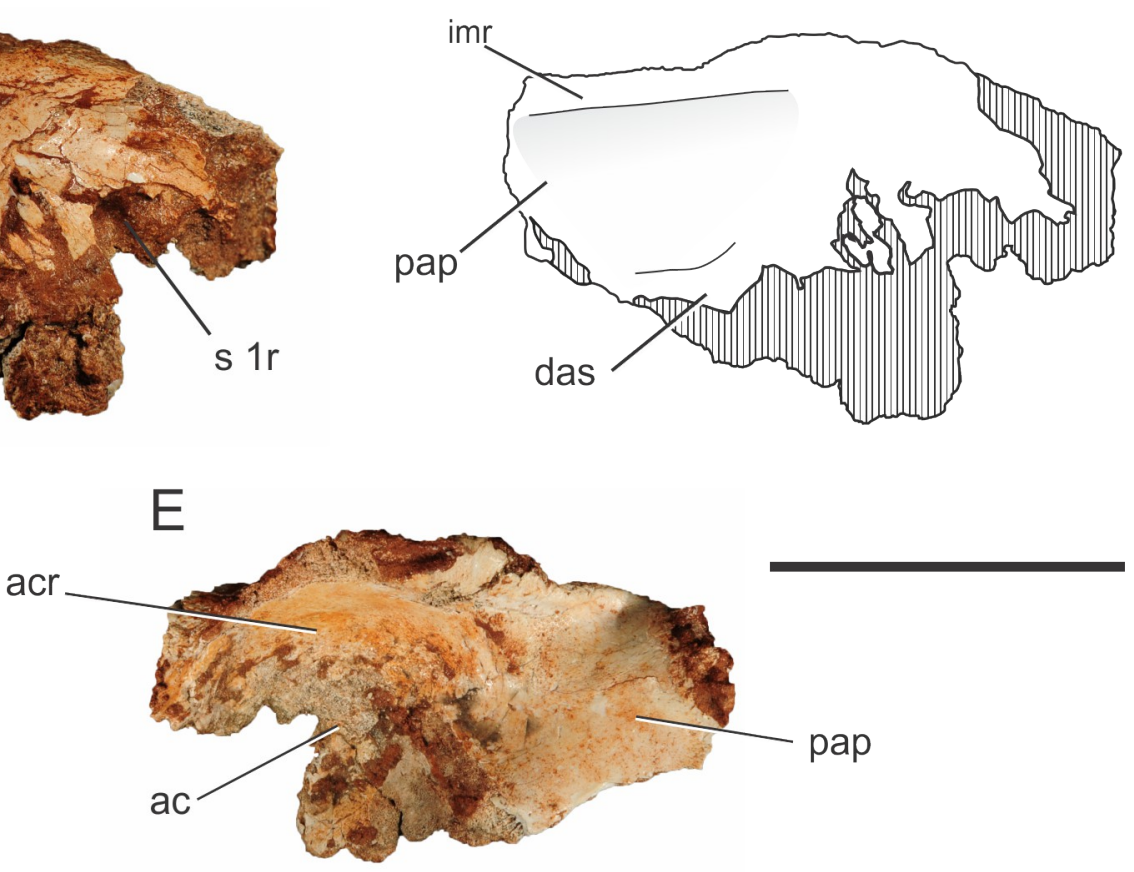

1710 Figure 6. Pissarrachampsa sera (LPRP/USP 0742), photographs and schematic drawing of the left

1711 ilium in dorsal (A and B), medial (C and D), and lateral views (E). Cross-hatched areas represent

1712 broken surfaces. Abbreviations: ac: acetabulum; acr: acetabular roof; das: dorsal portion of the

1713 articular surface for the second sacral rib; dmar: dorsal margin of the acetabular roof; pap:

1714 postacetabular process; imr: ridge on the medial surface of the ilium; s 1r: articular surface for first sacral

1715 rib; s 2r: articular surface for second sacral rib. Scale bar equals $5 \mathrm{~cm}$. 
A

B
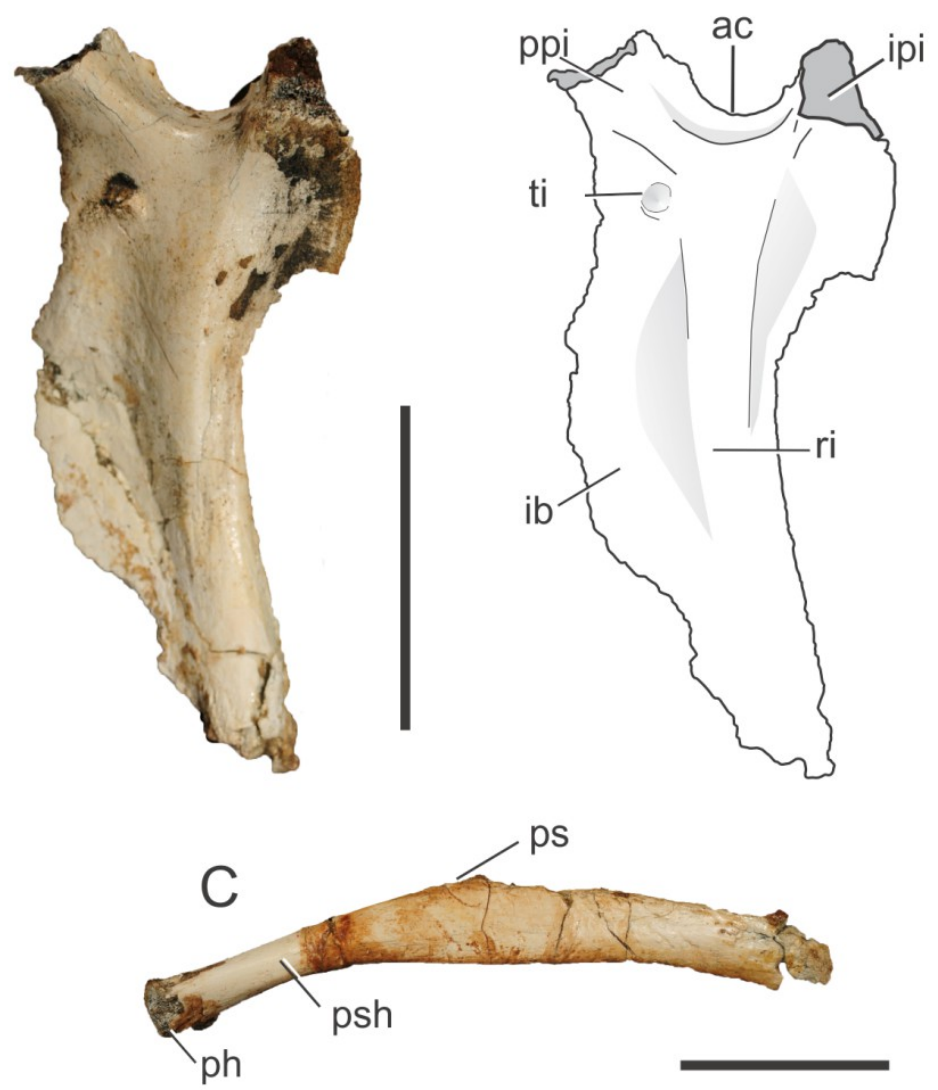

1716 Figure 7. Pissarrachampsa sera (holotype, LPRP/USP 0019), photographs and schematic drawing of

1717 left ischium in lateral view (A and B) and pubis in caudal view (C). Abbreviations: ac: acetabulum; ib:

1718 iliac blade; ipi: iliac peduncle of ischium; ph: pubic head; ps: pubic symphysis; psh: pubic shaft; ppi:

1719 pubic peduncle of ischium; ri: ridge; ti: tubercle of the ischium. Scale bar equals $5 \mathrm{~cm}$. 

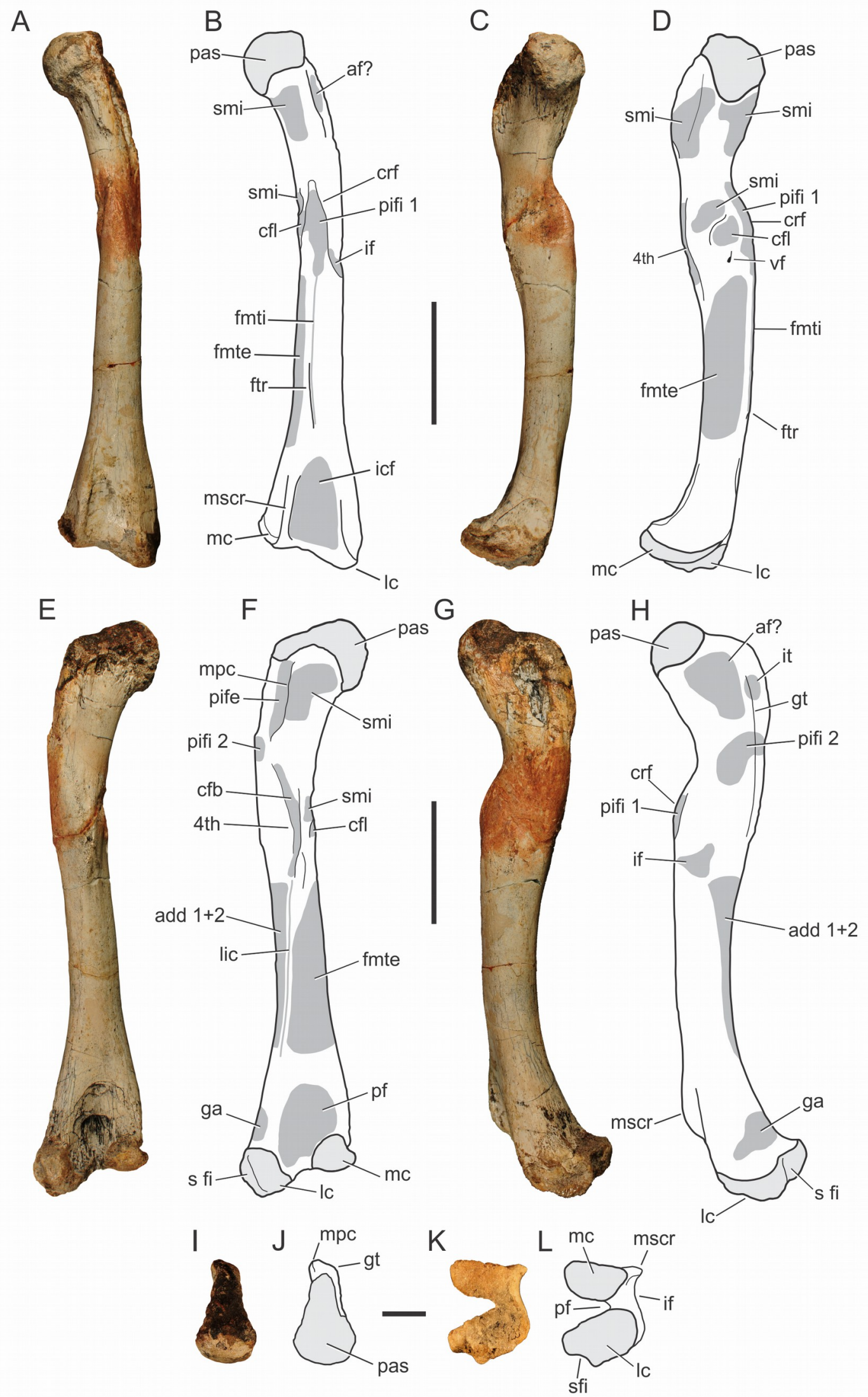
1720 Figure 8. Pissarrachampsa sera (holotype, LPRP/USP 0019), photographs and schematic drawings of 1721 the left femur in cranial (A and B), medial (C and D), caudal ( $E$ and F), lateral ( $G$ and $H)$, proximal 1722 (I and J), and distal views (K and L). Areas of musculature insertion are shadowed in dark gray. Light 1723 grey represents areas of bone articulation. Abbreviations: af?, adductor fossa; add1 + 2, M. adductor 1724 femoris 1 \& 2; $\mathbf{c f b}$, M. caudofemoralis brevis; cfl, $M$. caudofemoralis longus; crf, cranial flange; fmte, $M$. 1725 femorotibialis externus; fmti, M. femorotibialis internus; ftr, femorotibialis ridge ; ga. M. gastrocnemius ; 1726 gt, greater trochanter; if, M. iliofemoralis; icf, intercondylar fossa ; it, $M$. ischiotrochantericus; lc, lateral 1727 condyle ; lic, linea intermuscularis caudalis; mc, medial condyle ; mpc, medial proximal crest ; mscr, 1728 medial supracondylar crest; pas, proximal articulation surface; pf, popliteal fossa ; pife, $M$.

1729 puboischiofemoralis externus; pifi 1, M. puboischiofemoralis internus 1; pifi 2, M. puboischiofemoralis 1730 internus 2; s fi, articular surface for fibula ; smi, surface for muscular insertion; vf, vascular foramen; 4th, 1731 fourth trochanter. Scale bar equal $5 \mathrm{~cm}(\mathrm{~A}-\mathrm{H})$ and $2 \mathrm{~cm}(\mathrm{I}-\mathrm{M})$. 


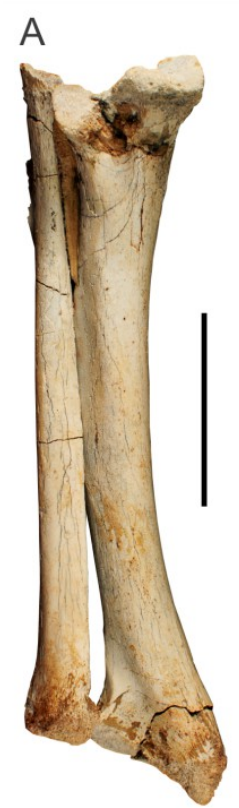

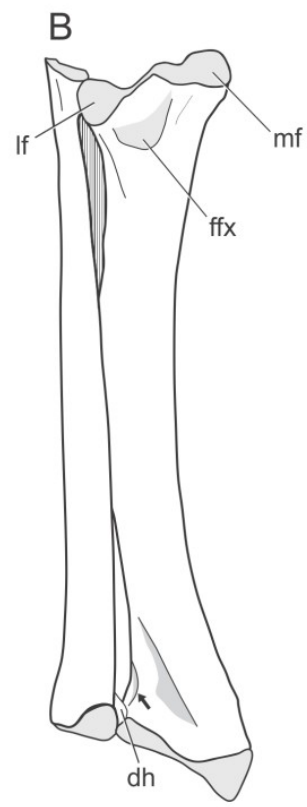

G

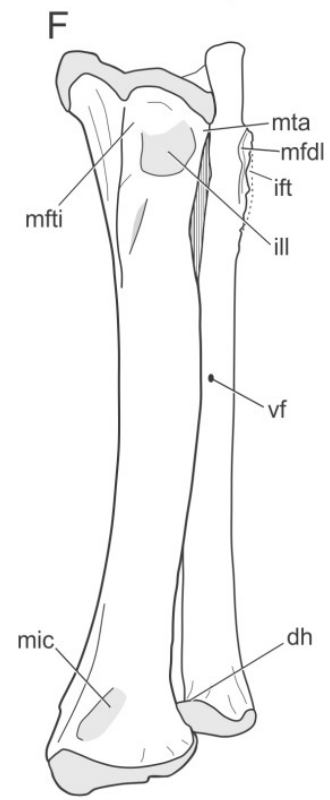

C
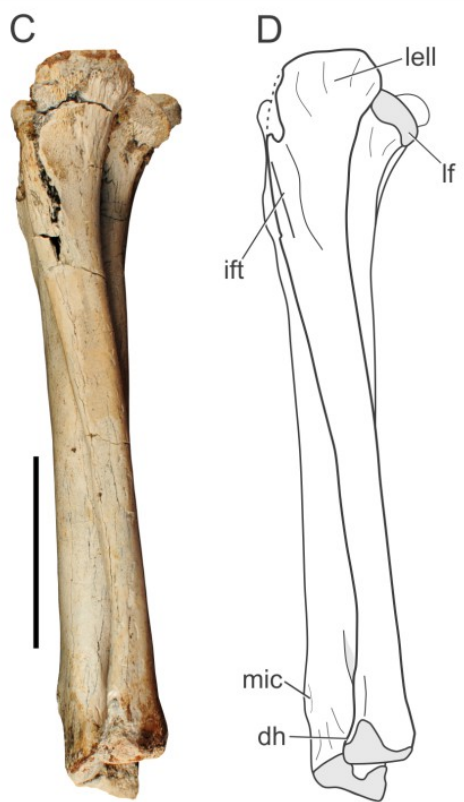

$\mathrm{H}$
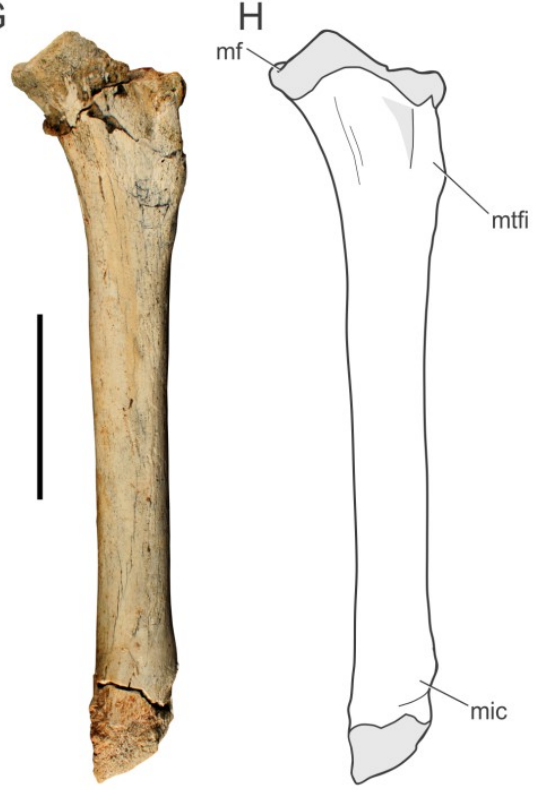

1732

1733

1734

1735

1736

1737

1738

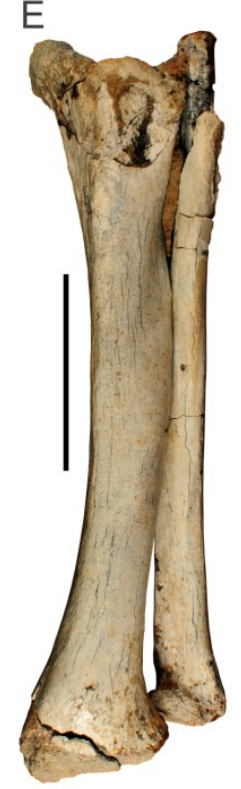

Figure 9. Pissarrachampsa sera (holotype, LPRP/USP 0019), photographs and schematic drawings of the articulated left tibia and fibula in caudal (A and B), lateral (C and D), cranial (E and F), and medial views (G and $\mathbf{H})$. Light grey represents areas of bone articulation. Arrow indicates a "sharp crest". Abbreviations: dh, distal hook; ffx, fossa flexoria; ift, iliofibularis trochanter; ill, internal lateral ligament; lell, long external lateral ligament; lf, lateral facet; mf, medial facet; mfdl, origin of M. flexor digitorium longus; mfti, M. flexor tibialis internus insertion; mic, $M$. interosseous cruris insertion; mta, M. tibialis anterior insertion; vf, vascular foramen. Scale bar equals $5 \mathrm{~cm}$. 

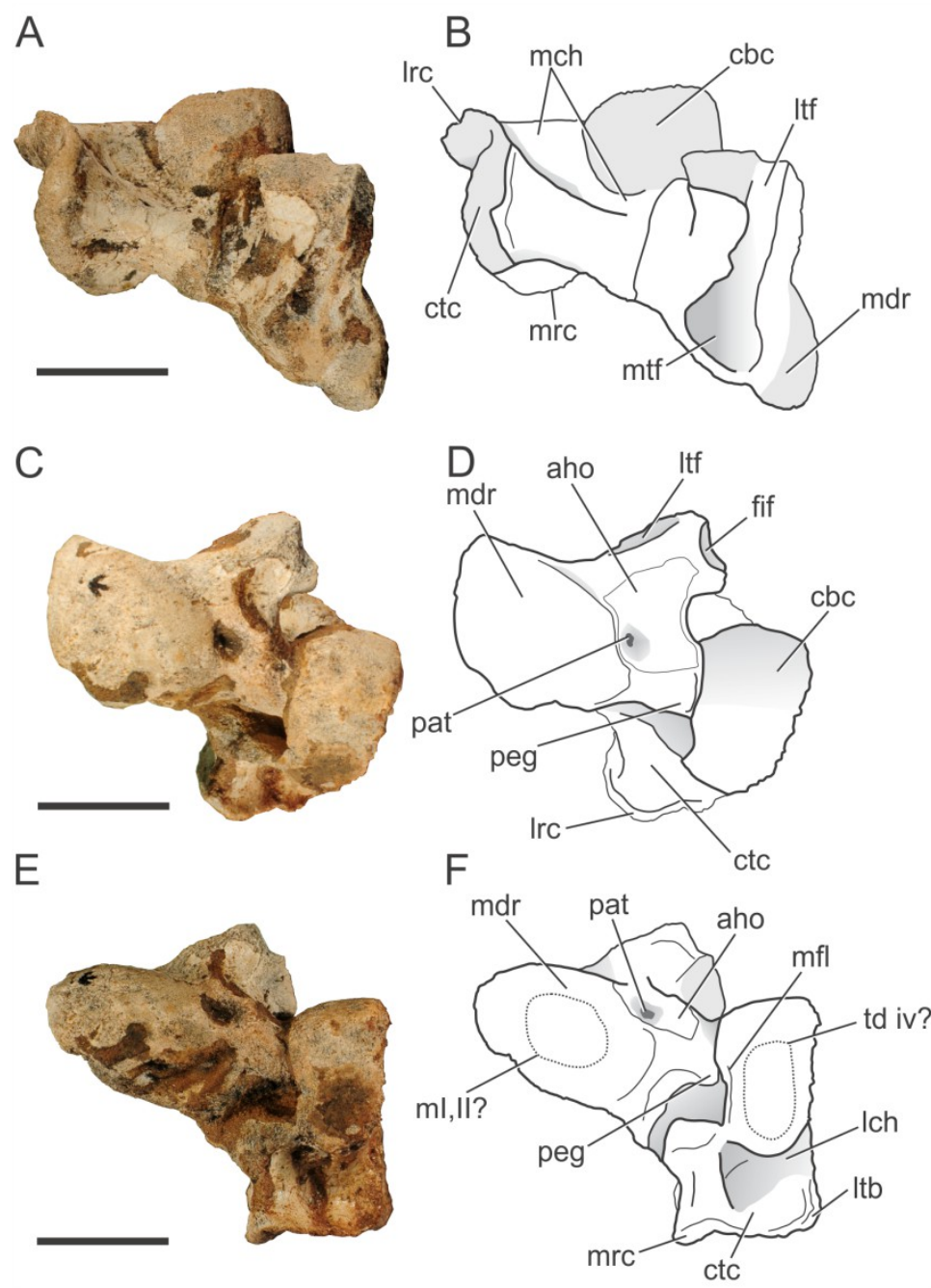

Figure 10. Pissarrachampsa sera (holotype, LPRP/USP 0019), photographs and schematic drawings

1741 and F). Abbreviations: aho, "anterior hollow"; cbc, cranial body of calcaneum; ctc, caudal tuber of

1742 calcaneum; fif, fibular facet; lch, lateral channel; lrc, lateral ridge of calcaneal tuber; ltb, lateral tubercule;

1743 Itf, lateral tibial facet; m i, ii?, area for articulation with metatarsals I and II; mch, medial channel; mdr,

1744 medial distal roller; mfl, medial flange; mrc, medial ridge of calcaneal tuber; mtf, medial tibial facet; pat,

1745 pit for astragalar -tarsal ligament; peg, astragalar peg; td iv?, area for the articulation with tarsal distal IV.

1746 Scale bar equals $2 \mathrm{~cm}$. 

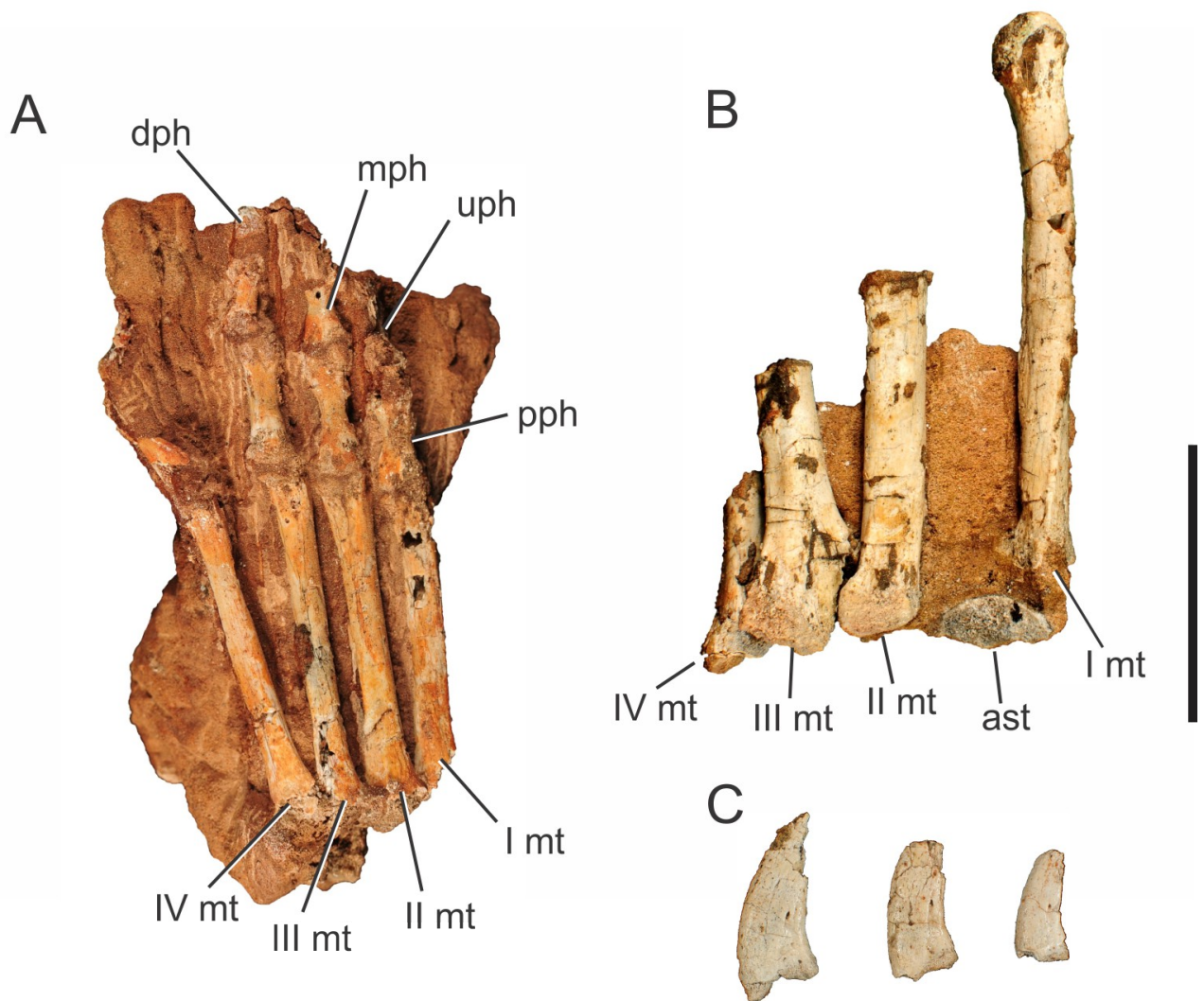

1747 Figure 11. Pissarrachampsa sera, photographs of two pedes and ungual phalanges. A. right pes of

1748 LPRP/USP 0746 in ventral view; B. left pes of LPRP/USP 0019 (holotype) in dorsal view. C. ungual

1749 phalanges of LPRP/USP 0019 (holotype). Abbreviations: I mt, metatarsal I; II mt, metatarsal II; III mt,

1750 metatarsal III; IV mt, metatarsal IV; ast, astragalus; dph, distal phalanx; mph, medial phalanx; pph,

1751 proximal phalanx; uph, ungueal phalanx. Scale bar equals $5 \mathrm{~cm}$.

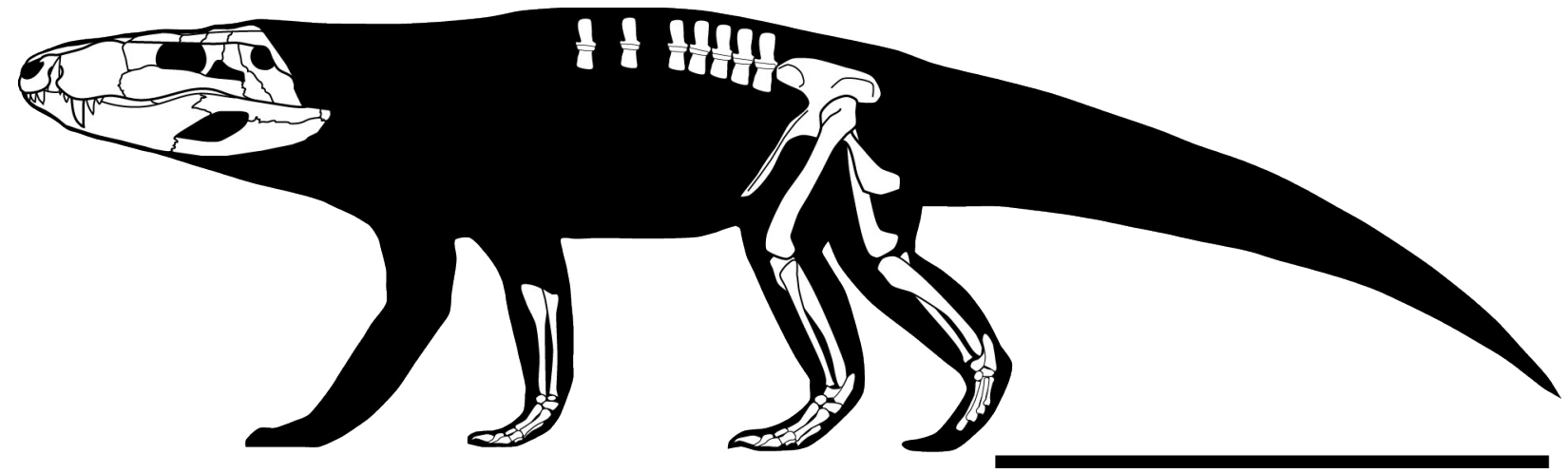


1752 Figure 12. Skeletal reconstruction of Pissarrachampsa sera, including all known cranial and

1753 postcranial material. Scale bar equals $80 \mathrm{~cm}$.

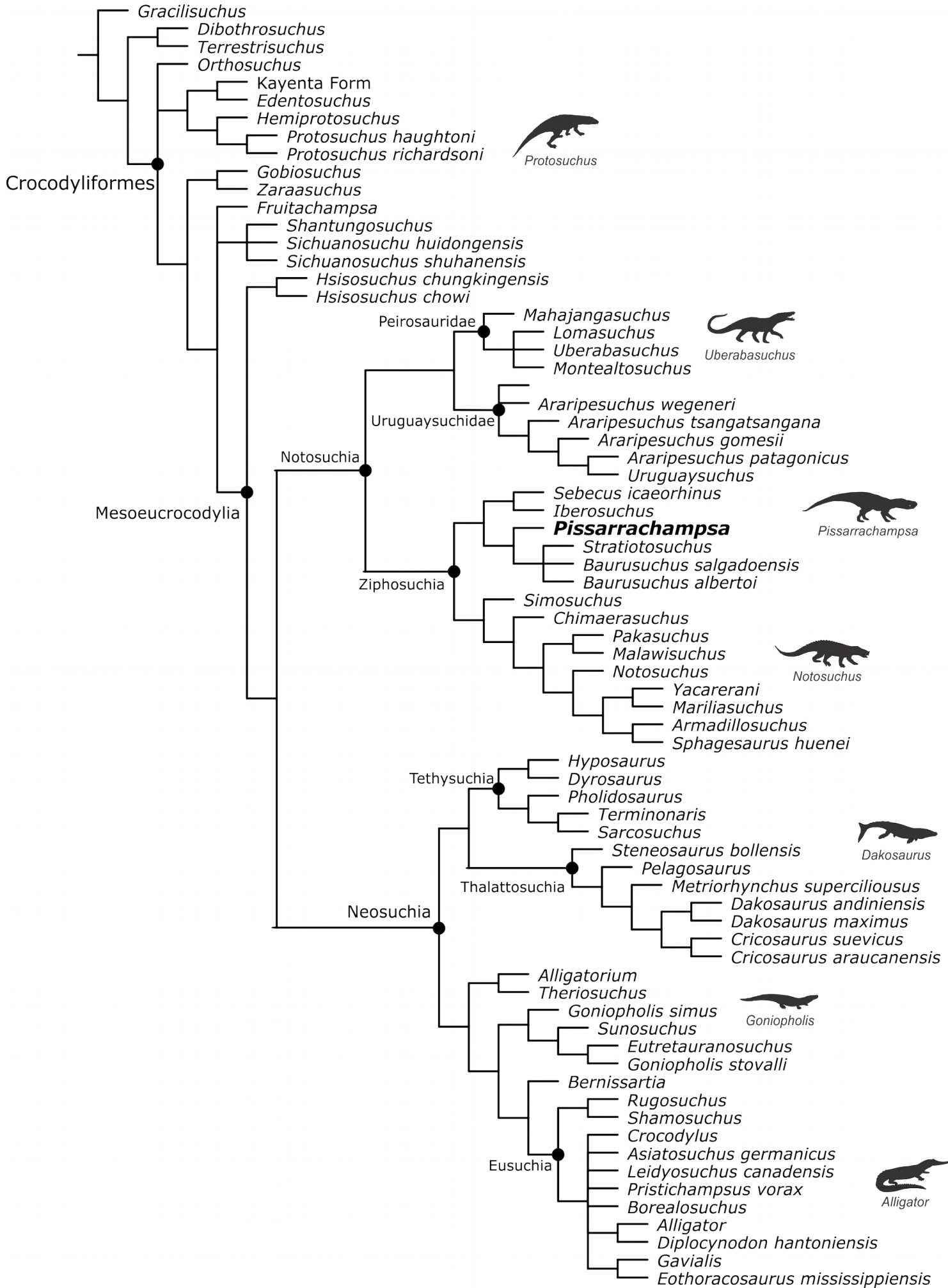


1754 Figure 13. Strict consensus tree of the "control analysis" after excluding taxa with no cranial or

1755 postcranial characters. Silhouettes of representative crocodylomorphs from Bronzati et al., 2012 and

17562015.

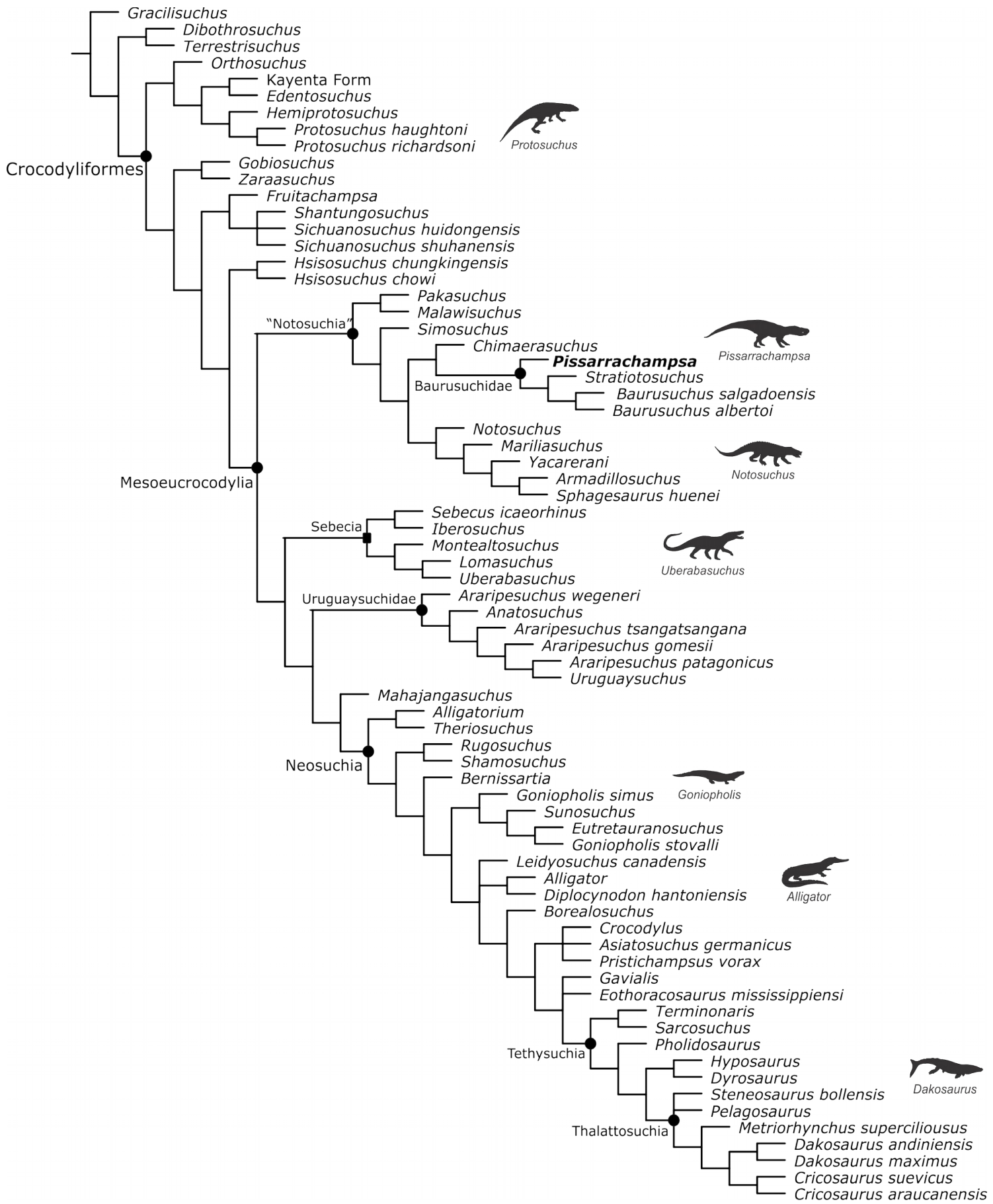

1757 Figure 14. Strict consensus tree of the analysis based only on cranial characters. Name of clades

1758 between quotes indicates that their inclusivity differs from those of the "control analysis". Clade with the 
1759 node marked by a square (Sebecia) represents those not present in the "control analysis". Silhouettes of 1760 representative crocodylomorphs from Bronzati et al., 2012 and 2015.

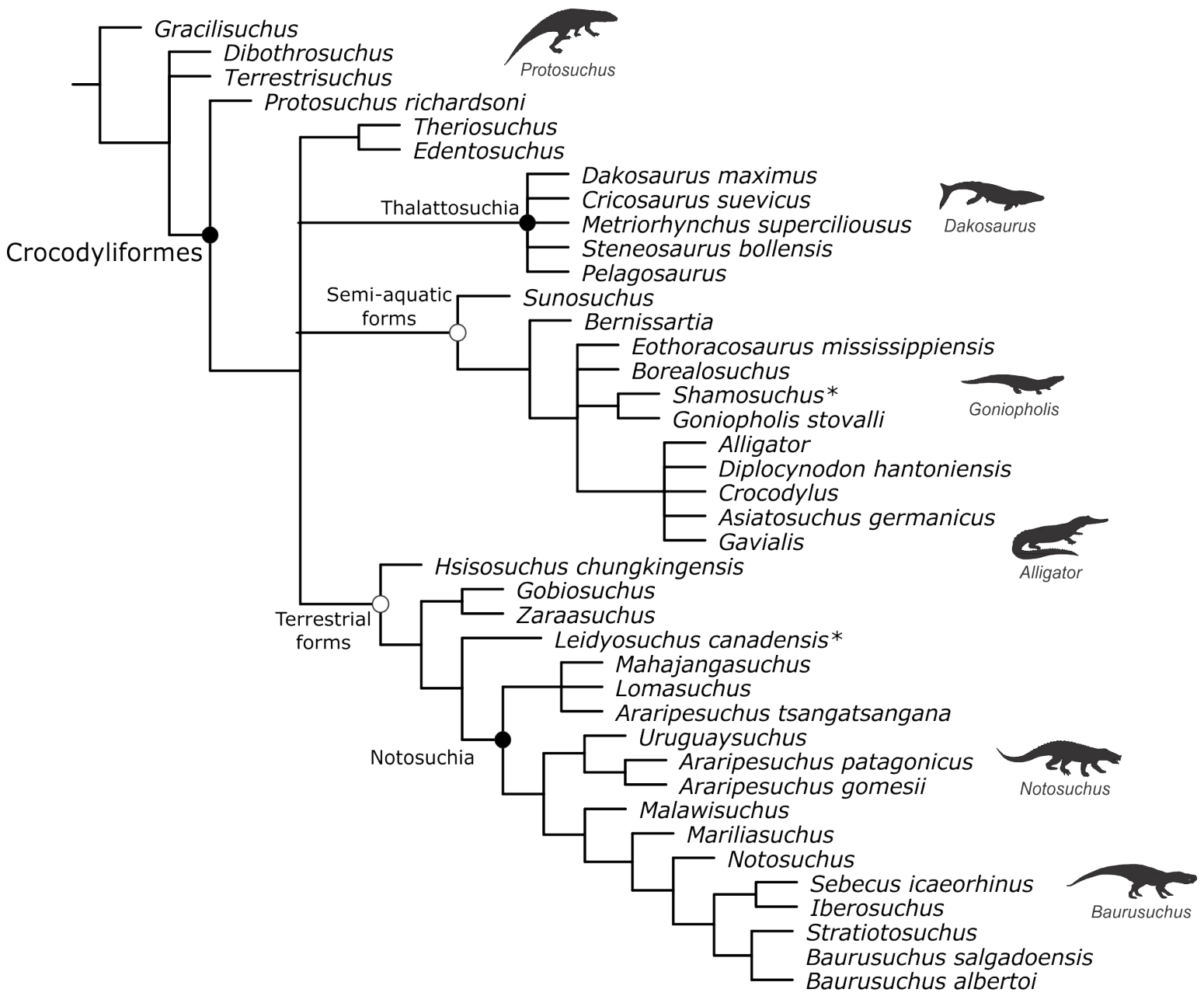

1761 Figure 15. Reduced strict consensus tree of the analysis based only on postcranial characters after

1762 the exclusion of very unstable taxa. Name of clades between quotes indicates that the assemblage of taxa

1763 related to the clade differs from the one of the "control analysis". Clades identified with a white circle

1764 represent informal clades. Taxa marked with * have a seemingly anomalous position within each informal

1765 clade recovered. Silhouettes of representative crocodylomorphs from Bronzati et al., 2012 and 2015. 